\title{
REVIEW OF PIPE-BREAK PROBABILITY ASSESSMENT METHODS AND DATA FOR APPLICABILITY TO THE ADVANCED NEUTRON SOURCE PROJECT FOR OAK RIDGE NATIONAL LABORATORY
}

\author{
R.R. Fullwood
}

Date Completed: August 1988

Date Published: April 1989

Prepared by

ENGINEERING TECHNOLOGY DIVISION DEPARTMENT OF NUCLEAR ENERGY BROOKHAVEN NATIONAL LABORATORY ASSOCIATEO UNIVERSITIES, INC.

UNDER THE USDOE CONTRACT NO. DE-ACO2-76CHOOOI6

\section{Prepared for}

OAK RIDGE NATIONAL LABORATORY

Operated by

MARTIN MARIETTA ENERGY SYSTEMS. INC.

UNDER THE USDOE CONTRACT NO. DE-ACO5-840R21400 
This report provides a summary of methods for assessing pipe break probabilities to determine trends and scaling relationships that might be useful to designing the ANS reactor for maximum safety and availability. A secondary purpose is a review of calculational procedures and codes for use in constructing a PC interactive code for parametric studies.

This work reviews pipe leaks at the BNL High Flux Beam Reactor and accelerated embrittlement that has been observed at the High Flux Isotope Reactor at ORNL. The regulatory background and supporting studies related to pipe and vessel failure are presented along with pipe break statistics based on field incidents. Models for assessing vessel and pipe break are organized into two classes: phenomenological and theoretical. Representing the phenomenological method is the work of Thomas from which the scaling relationships are obtained. Theoretical models are of three types. Two types are represented by the codes OCTAVIA and PRAISE-B. OCTAVIA calculates the probability of a transient event that results in pressure exceeding the strength of the vessel which has a pre-existent flaw distribution. Other codes of this type are OCA-P, VISA and an unnamed code used in NUREG-0778. All of these are designed for pressure vessel weld analysis. PRAISE-B differs from these by beginning with an initial small flaw distribution resulting from manufacture and grows the flaws to a critical size as the result of cyclic and residual stress and other factors. The last theoretical model is the stress-strength distribution overlap method which is exemplified by application to calculating the rupture probability of a steam line passing through a BWR wet-well.

The report defines a figure of merit (FOM) as being the ratio of the flow volume and the break probability. From this it is deduced that the FOM is maximized by large diameter short length piping. A reason for the strong (3.5) power dependence on pipe dlameter is that the wall thickness is taken as proportional to the diameter. While this is true of the minimum wall thickness, the ANS piping could be designed with thicker than necessary walls from strength considerations and achieve high reliability with small pipe (data show that small pipe has a higher per-length failure rate than larger piping). Based on the FOM, the HFIR configuration with a large manifold connecting the reactor vessel with the heat exchangers is good.

The report reviews other data on parametric dependencies as well as the leak-before-break studies and provides suggestions (some rather obvious or well-known) for guiding the ANS design. It also outlines the form of a PC code that uses phenomenological and theoretical methods.

Guidelines fron the reviews regarding the reduction of pipe failures are:

- Mininize the length of piping,

- Maximize the diameter and/or wall thickness,

- If stainless steel piping is chosen, the carbon content should be less than 0.05 wt 8 , 
- Minimize the presence of oxygen in the coolant,

- Residual stresses should be relieved as far as possible,

- Design out any potential for water hammer that could result from valve opening,

Vibratory stress should be reduced as far as practical,

Make the replaceable pipe that encompasses the reactor as long as practical to reduce the fast neutron flux damage to the nonreplaced pipe and flanges,

- Optimize both the inspection reliability and minimum flaw size detectability,

Pre-service and in-service inspections are effective but the frequency of the latter was not determined,

Reliable and sensitive leak detection, when acted upon, is effective in reducing the probability of a pipe break (tritium detection provides a signature that should provide ANS with a more sensitive leak detection capability than is available in nuclear power plants).

Some topics not resolved were leak-before-break (LBB) and alternative pipe materials. Regarding LBB, it appears that the probability of leaks is about 10 times that of breaks. While it appears clear that to go from a noleak situation to a break situation, there must be a transition through leak. No data were found concerning the rapidity of the transition, i.e., whether or not sufficient time is available after leak detection to act upon the information before it becones a break. This does not mean that leak detection should not be used but rather that a 100 \& leak detection capability does not necessarily avoid breaks. It does, however, greatly reduce the probability of breaks.

No pipe failure data or flaw information was found on non-ferritic or austensic materials. Considering the low capture cross section of aluminum, the question of Its usefulness in this application arose but was not resolved. Its comparative weakness would require thicker pipe walls, but the scaling information indicates that this would reduce the break probability.

The interactive PC model is expected to be a combination of phenomenology and fracture mechanics theory with the main emphasis on the former. More specifically, it may be an implementation of the Thomas model in a PC code to provide the normalization for a pipe break estimate with the parametric trends taken from theoretical models exemplified by PRAISE-B and/or the OCTAVIA group. The Thomas model has already been interpreted and applied to estimating the probability of catastrophic pipe break in HFIR. In this PL\&G treated three cases: base metal, circumferential welds and longitudinal welds. It is believed that the latter were, at least, to some extent included in the pipe data. No attempt has been made to estimate the pipe break 
frequency for ANS. However, the conceptual design has elght pipe runs connecting reactor to heat exchangers as compared with two, larger diameter pipes in HFIR. This would increase the ANS probability by a factor of four for the extra length and something more for the smaller diameter except for the fact that the HFIR analysis is dominated by the piping associated with the heat exchangers, so the results may be similar for the two reactors. 


\section{ACKNOWLEDGEMENTS}

The BNL PRA team providing support to ANS consists of: M. A. Azarm, J. L. Boccio, A. N. Fresco, R. R. Fullwood, R. E. Hall and J. C. Higgins. All members provide advice and review of the work and contribute according to expertise and availability. Their contributions are heartily acknowledged.

Particular thanks is extended to John Weeks and John Lehner for their comments and suggestions. Thanks also go to Kathy Nasta and Sue Monteleone for preparing the final report.

Lastly but most appreciatively, the advice, technical consultation and review of ORNL staff, in particular D. Selby, R. Cheverton and M. Harrington, is acknowledged. 
1. INTRODUCTION, BACKGROUND AND OUTLINE . . . . . . . . . . . 1-1

1.1 Introduction . . . . . . . . . . . . . . . . . . . . . . 1-1

1.2 Background . . . . . . . . . . . . . . . . . 1-1

1.2.1 HFBR Experience ............. . . 1.1

1.2 .2 HFIR Experience . . . . . . . . . . . . 1-2

1.3 Objectives . . . . . . . . . . . . . . . . . . 1-3

1.4 Report Organization.............. . 1-3

2. PROBABILISTIC PIPE AND BREAK ASSESSMENTS METHODS . . . . . . . 2-1

2.1 Introduction . . . . . . . . . . . . . . . . . . . . . 2-1

2.2 Phenomenological Modeling of Pipe Break Frequencies . . 2-2

2.3 Probabilistic Fracture Mechanics Mode1.... . . . . 2-2

3. SCAIING FACTORS FOR PIPE BREAKS . . . . . . . . . . . 3-1

3.1 Relationship between Plpe Break Probability,

3.2 Figure of Merit . . . . . . . . . . . . . . . . . 3-1

3.3 Relationship between Diameter and Minimum Wall Thickness 3-2

3.4 A Relationship for Flow Volume . . . . . . . . . . . 3-2

3.5 Evaluating the Figure of Merit . . . . . . . . . . 3-3

4. SENSITIVITY STUDIES ................. . 4-1

4.1 Background and Base Case .. . . . . . . . . . . . 4-1

4.2 Effectiveness of Inspection . . . . . . . . . . . . . . 4-1

4.3 Vibratory Stress Effects . . . . . . . . . . . 4-5

4.4 Residual stress . . . . . . . . . . . . . $4-5$

5. CONCLUSIONS AND RECOMMENDATIONS ... . . . . . . . . . 5-1

5.1 Conclusions .. . . . . . . . . . . . . . . . . . . 5-1

5.2 Recommendations................ . 5-2

6. REFERENCES .................... 6-1

APPENDIX A - FRACTURE TOUGHNESS AND STRESS CORROSION CRACKING . . . A-I

APPENDIX B - ASSESSMENTS OF PIPE AND VESSEL BREAK PROBABILITIES . . B-1

APPENDIX C - SUMMARY OF THE PRAISE CODE . . . . . . . . . . . . . C C 1

APPENDIX D - REVIEW OF THE OCTAVIA AND NUREG-0778 CODES . . . . . D-1

APPENDIX E - REVIEW OF OCA-P, THE ORNL CODE FOR PRESSURE VESSELS - E-1

APPENDIX $F$ - REVIEW OF VISA, THE PNL CODE FOR PRESSURE VESSELS . . $F-1$

APPENDIX G - REVIEW OF THE PHENOMENOLOGICAL METHOD OF THOMAS . . . G-1

APPENDIX H - METHOD OF OVERLAPPING STRESS-STRENGTH DISTRIBUTION . . H-1 


\section{LIST OF FIGURES}

No.

Iitle

Page

2-1 Comparison of probabilistic and deterministic techniques

for evaluating fallure .. . . . . . . . . . . . . . . . . . 2-4

2-2 Probabilistic fracture mechanics procedures.......... 2.6

4-1 Conditional leak probability for the 2lon-1 base case... . 4-2

4-2 Sensitivity to the 50\% crack non-detection probability for

the base case and at 40 years... . . . . . . . . . . . . . 4-3

4-3 Effects of non-detection uncertainty . . . . . . . . . . . . . . 4-4

4-4 Effects of vibratory stress on the conditional leak

probability with and without pre-service inspection . . . . . 4-6

4-5 Sensitivity of leak probability to the 508 crack non-detection

probability for three vibratory stress levels . . . . . . . . 4-7 


\section{INTRODUCTION, BACKGROUND AND OUTLINE}

\subsection{Introduction}

The Advanced Neutron Source (ANS) (Difilippo, 1986; Gamble, 1986; West, 1986; Selby, 1987) will be the world's best facility for low energy neutron research. This performance requires the highest flux density of all nonpulsed reactors with concomitant low thermal inertial and fast response to upset conditions. One of the primary concerns is that a flow cessation of the order of a second may result in fuel damage. Such a flow stoppage could be the result of break in the primary piping. This report is a review of methods for assessing pipe break probabilities based on historical operating experience in power reactors, scaling methods, fracture mechanics and fracture growth models. The goal of this work is to develop parametric guidance for the ANS design to make the event highly unlikely. It is also to review and select methods that may be used in an interactive IBM-PC model providing fast and reasonably accurate models to aid the ANS designers in achieving the safety requirements.

\subsection{Background}

\subsubsection{HFBR Experience}

Six : 2 rs after the High Flux Beam Reactor (HFBR) went into operation in 1965, stress corrosion cracking was experienced in one 18-in. diam. weld-neck flange in the HFBR primary piping circult (Powel1, 1973).

HFBR is a heavy water cooled and moderated $40 \mathrm{MW}$ (upgraded to $60 \mathrm{MW}$ ) research reactor at the Brookhaven National Laboratory. The reactor vessel is fabricated of 6061-T6 aluminum as are the fuel element side plates and the fuel plate cladding material. The transition from 20-inch aluminum reactor inlet and outlet piping to 304 stainless steel is made at the flange joints. The 20-inch stainless piping then branches into two (A and B) 18-inch diameter primary cooling loops each consisting of an inlet and outlet valve, primary pump, check valve and a horizontal "U-type" heat exchanger.

In March 1972, during the last three weeks of an operating cycle, a continuous slow increase in tritium to 188 of background in the exhaust from the shielded primary heat exchanger rooms was detected. During shutdown, inspection revealed $\mathrm{D}_{2} \mathrm{O}$ leakage from a pump flange (corrected by gasket replacement) and five longitudinal cracks in the body of the 18-inch weld-neck flange. These cracks were about 0.5 inch long and located at the transition from the cylirdrical neck to the tapered body on the flange bottom quadrant. The parallel cracks, in the direction of the piping, were revealed by dye penetrant testing of the inside of the pipe. Metallographic examination of specimens removed from the cracked area showed:

a) The cracks were intergranular.

b) They originated from the inside surface of the flange. 
c) They originated in an area several millimeters away from the weld, possibly in a heat-affected-zone (HAZ) or at the point of maximum stress.

d) The cracks did not extend into the weld metal.

e) The areas containing the cracking were not highly sensitized but there was sone sensitization due to the welding.

Fron these observations, it was concluded that the leak was due to stress-corrosion cracking of an intergranular type which requires low $\mathrm{pH}$, dissolved oxygen, high temperature, high stresses and sensitization.

The hoop stresses in the piping produced by the normal fluid pressure in the region of the cracking were about $8000 \mathrm{psi}$. The flanges had a history of difficulty in achieving leak tightness, and in fact the flanges had been leaking when accepted fron the plant construction contractor which were subsequently corrected using a tapered spacer to correct misalignment.

Following the discovery of cracks, extensive calculations of stresses were nade. It was calculated that the initial pressure testing could have resulted in stresses as high as 39,700 psi. However, continual stresses during normal operation were calculated to be less than 16,800 psi.

The coolant operates at a rather low temperature ( $134^{\circ} \mathrm{F}$ ) with the heavy water chenistry based on compromises which minimize dissolved oxygen to the extent that its absence does not interfere with $\mathrm{pD}$ control.

The solution to the pipe leak problen was to eliminate the weld-neck type of flange which showed hoop stresses when bolted by van Stone lap joints. The Flexitalilc gaskets, which are radiation resistant, require high bolt loading. These were replaced by Parker-0-Rings inasmuch as the radiation effects were less than originally anticipated.

Fortunately, the failure occurred in one of two parallel cooling loops which permitted continued operation of the reactor at 75 power for 80 days during the extensive tine required for procurement of materials and the repair. The total downtine attributed to the difficulty was 40 days.

\subsubsection{HFIR Experience}

The High Flux Isotope Reactor (HFIR), a $100 \mathrm{MW}$ light water cooled, beryllium moderated research reactor is located at Oak Ridge National Laboratory. The reactor vessel is stainless steel clad carbon steel and the primary coolant piping is stainless steel. The Code of Federal Regulations Title 10 Part 50, Appendix G, requires that the fracture toughness of reactor vessels and piping be such that $\mathrm{RT}_{\mathrm{NDT}}+60^{\circ} \mathrm{F}$ is less than test and operating temperatures. To assure that this is being done, Charpy V-notch specimens representing the vessel shell and nozzle materials were installed prior to operation at locations of naximun fast-neutron flux (Cheverton, 1987). In addition, samples of bean tube material were included in the beryllium reflector. 
HFIR began full power operation in 1966 and periodic surveillance of the specimens was performed. By 1983, it was found that the $\mathrm{RT}_{\mathrm{NDT}}+60^{\circ} \mathrm{F}$ for a portion of the shell and one nozzle exceeded the $70^{\circ} \mathrm{F}$, minimum temperature for pressurization, by 45 and $15^{\circ} \mathrm{F}$, respectively. The reactor was shutdown in November 1986, and the 1986 survelllance data (17.5 effective full-power years-EFPY) showed that $\mathrm{RT}_{\mathrm{NDI}}+60^{\circ} \mathrm{F}$ was exceeded by $15^{\circ} \mathrm{F}$ at the normal operating temperature of $120^{\circ} \mathrm{F}$.

Radiation embrittlement of the HFIR reactor vessel was recognized as a problem in achleving 20 EFPY lifetine. The solution was to surround the core and beryllium reflector with sufficient water to effectively shield the materials from the fast neutron flux, hence the large size of the HFIR reactor vessel. The unexpectedly higher rate of radiation embrittlement was the result of extrapolating the lower fluence level data that was available at the time of design.

The response to the problen is thoroughly described in Cheverton, 1987. Basically this reference suggests that conservatism and operational changes justify extension of the operation of HFIR until ANS is operational. Appendix $F$ of Cheverton, 1987 presents the results of calculations with computer code OCA-P (Appendix E). These indicated that the probability of vessel failure in 10 additional EFPY's is $<2 \times 10^{-8}$.

It may be noted that the ANS design concept places the pressure boundary near the reactor core, inside of the reflector and in high neutron fluence. That is, the pressure boundary material is not shielded to protect it from radiation embrittlement. Instead, it is designed to accommodate periodic vessel tube replacement. The rate of this replacement can be adjusted according to measurements of embrittlement and not according to theoretical predictions of lifetime. In this sense, the lifetime of ANS is indefinite except for effects on components not being replaced.

\section{3 objectives}

The purposes of this work are:

- Review methods for estimating the probability of vessel and piping failure for applicability to ANS.

- Identify parameters governing vessel and pipe failure.

- Identify algorithms useful for preparing an interactive computer code which may be used by the ANS designers to select design options.

\subsection{Report Organization}

The design of the report is to place the detailed supporting material in the appendices and results of direct applicability to ANS in the body. 
Section 1 (this section) contains background information from relevant reactors showing that potential problems exist. Section 2 summarizes the methods used in estinating pipe and vessel failure probabilities, and Section 3 provides scaling relations fcr pipe leak or break probabilities to guide in the ANS design configuration. Section 4 presents sensitivity studies based on fracture mechanics to exhibit how some parameters can affect the failure probabilities. Section 5 provides conclusions and recomendations, and references are presented in Section 6. Appendix A briefly summarizes codes, regulations and supporting studies that are applicable to the design.

Appendix B sumarizes operating experlence data, and Appendices C, D, E and F summarize respectively, the PRAISE, OCTAVIA, OCA-P and VISA codes used for break calculations. Appendix $G$ summarizes the method of Thomas which uses experience data to determine scaling relationships. This method is exemplified by its application to HFIR. Appendix $\mathrm{H}$ presents the method of overlapping distribution functions, which is conceptually appealing, but the difficulty lies in determining the paraneters of the distributions - a problem that is not unique to this method. 


\section{METHODS OF PIPE BREAK FREQUENCY DETERMINATION}

\subsection{Introduction}

The earliest ways for estimating the probability of pipe failure was to compile pipe failure incidents. However compiling incidents at various plants or for various pipe transmission lines is not enough because it is reasonable to expect a greater number of incidents if more piping is involved than if less is involved. The earliest method to adjust the data for this effect was to divide the number of incidents in a time period (usually a year) by the length of piping. Because many of the incidents occurred at welds, separate failure rates may be based on the number of welds that are involved. It was also observed that there is a strong variation with diameter of pipe. To allow for this fact, WASH-1400 compiled statistics according to failures per length in large and suall pipe groups. The number of welds was not explicitly addressed but was partially contained in the definition of a pipe "section". Basin, 1977, carried the analysis further in EPRI-sponsored work by analyzing the data according to PIRs and BWRs, pipe sizes and pipe elements. These data were simply presented without interpretation ${ }^{2}$. Thomas, 1980, used the data and determined statistical correlations among the variables but without providing physical explanations for the dependencies. Nevertheless, this was a major contribution and is valuable for design studies as well as estimating pipe break probabilities as exemplified in Appendix G.9 for HFIR. However it is fairly restricted to configuration modeling and does not help in the study of other parameters affecting the failure rate.

In the sane time period following WASH-1400, Harris and Fullwood (Harris, 1976) demonstrated the application of fracture mechanics to estimating the frequency. The original concept was to restrict the method to obtaining the relative fallure rates among the various pipe segments in a plant and to normalize the results to field data such as prepared as part of WASH-1400. But this procedure that used laboratory flaw distribution data with the flaws being grown by a crack growth model gave results comparable with field experience so the original relative probability model gave way to an absolute nodel (the PRAISE-B code). About this time, Vesely, 1978, presented a different approach for assessing pressure vessel failure probability as the result of a pressure transient (the OCTAVIA code). This method begins at a later tine in the growth stage when there is a probability of sizeable flaws in the pressure vessel and does not grow the flaws but calculates the critical pressure at which failure of the vessel would occur. The probability of this critical pressure occurring or being exceeded is determined fron statistics on pressure transients, thus providing the probability of vessel failure. While PRAISE-B deals with material details, OCTAVIA uses Regulatory Guide 1.99 and code correlations ${ }^{2}$ for determining the shift in the

${ }^{3}$ Appendix B provides a review of field data from which failure rates have been calculated which may be used for estimating pipe failure frequencies.

${ }^{2}$ Appendix A provides a review of fracture toughness and stress corrosion cracking based on Regulatory Guides, codes and NRC studies. 
nil ductility reference naterial as a function of fast neutron flux, copper and phosphorous content in the netal. The nethodology of OCTAVIA was improved by the work reported in NUREG-0778 by better data and the use of Monte Ca=10 saupling. Further improvenents were made in OCA-P and VISA which were applied to the analysis of over-cooling transients associated with the pressurized thermal shock investigation. Another approach, closely related to the others is the stress strength distribution overlap method presented in Appendix $H$. This method is quasi-theoretical in that the basic problem lies in determining the distributions of stress and strength by a combination of theoretical calculations and field data.

\subsection{Phenomenolorical Modeling of Pipe Break Frequencies}

This approach uses the body of experience with pipe break and pressure vessel failure to nake predictions about the probability of fallure in a systen under investigation. Thomas, 1980, provides a unification of data such as that presented in Appendix B through formulae as discussed in Appendix $G$. Because this is a fairly simple process and the essential equations are presented in the next section, it will not be discussed further.

\subsection{Probabilistic Fracture Mechanics Models}

Over the past several years, probabilistic analysis methods have gained increased acceptance for evaluating the safety of nuclear power plants. One form is probabilistic risk analysis (PRA) in its usual sense as exemplified by WASH-1400 in which the probabilities and the consequences of radiological releases to the public are calculated. A different use of probabilistic methods evaluates the adequacy of individual systems, structures and components for resisting failures due to the stresses expected from normal operation and anticipated incidents. This process evaluates the strength of the material to withstand stresses which may be applied to it. Should stress exceed the strength, fallure is presumed to occur.

The traditional method for addressing this problem considers the strength and the stress as being numbers known with high precision (point values) whereas in fact both the strength and stress are characterized by probability distributions. The stress is distributed because it is the result of various combinations of paraneters that depend on the exact circumstances of the occurrence, each of which can only be specified with a certain probability. Simllarly, the strength is a distributed variable that depends on the imperfections that were formed at the time of creation, the environmental effects (e.g. stress corrosion cracking) and stresses to which it may have been exposed. 
Figure 2-1 (from PBTG, 1984) 11lustrates deterministic point estimates of stress and strength. These are nominal values established according to conservative estimates of the load and material strength. It is known that such point values do not represent practical reality, but the intention is that the estimated values are conservative and actually provide an upper bound on the stress and a lower bound on the strength. The statistical confidence for these limits is not known (e.g., the 958 confidence bound) but it is hoped and presumably demonstrated by prior experience that the ASME Code prescriptions are sufficiently conservative that material breakage will not occur. Nor will the effects of radiation, chemicals, stress cycles and aging reduce the strength to the point that failure occurs.

The probabilistic approach accepts the fact that the stress and strength are distributed variables and attempts to characterize the distributions so that statistical confidence in the safe operation may be characterized. The probability of failure is the probability that stress will exceed strength and as shown in box $c$ in Figure 2-1. (The method of the stress-strength overlap is discussed further in Appendix H.) A probabilistic evaluation estimates the failure probability of the design, and if the probability is sufficiently low, it is considered safe or reliable. What is acceptably low is a matter for judgment, although with regard to nuclear power plant risks, safety goals have been set (51FR30028, August 21, 1986).

This is a point of departure between the PRAISE-B type of code and the class represented by OCTAVIA which has only been applied to pressure vessel failure for welds at the beltline. The latter class use the linear elastic failure model (LEFM), and the criterion that strength be greater than stress. This criterion can be expressed as:

$$
\mathbf{K}_{\mathrm{I}} \geq \mathbf{K}_{\mathrm{Ic}}
$$

where

$$
\begin{aligned}
& \mathrm{K}_{\mathrm{I}}=\sigma \sqrt{\pi a} f(\sigma) \\
& \mathrm{K}_{\mathrm{Ic}}=\mathrm{F}\left(\mathrm{T}_{\mathrm{a}}, \mathrm{NF}, \mathrm{CU}, P\right)
\end{aligned}
$$

and :

$$
\begin{aligned}
& \text { a - flaw depth, } \\
& \sigma=\text { stress on structure due to pressure, thermal, or } \\
& \text { residual loadings, } \\
& \mathrm{T}_{\mathrm{w}}-\text { metal temperature at crack tip, } \\
& \mathrm{NF}=\text { neutron fluence, } \\
& \mathrm{Cu}-\text { percent of copper in welds, } \\
& \mathrm{P}-\text { percent of phosphorus in welds. }
\end{aligned}
$$


Probabilistic Approsech

(a)

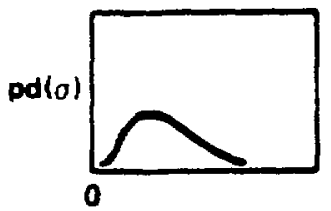

Stress (u). (b)

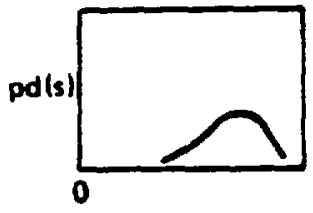

Strength (S) (c)

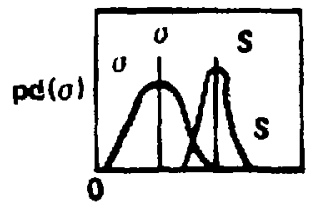

(d)

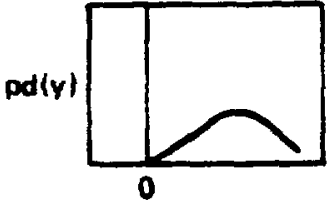

Deterministic Approsch

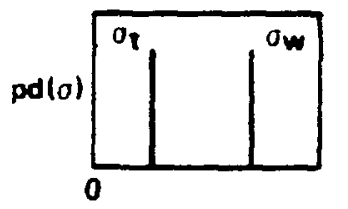

Applied Stress

Measure, 0 pd(s)

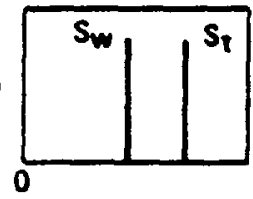

Strength

Maesure, S

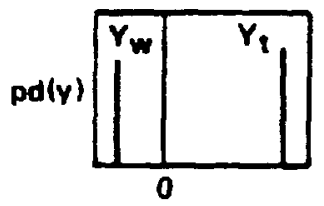

Safety Margin. $Y=\mathbf{S}-\boldsymbol{O}$

"Typical" (t) Analysis Indicatos Adequate Safoty Mergin.

"Worst-Can" (w) Andysis Indicates Negetive Sefety Mergin or Failure.

Figure 2-1

Comparison of probabilistic and deterministic techniques for evaluating failure

(Stress is represented by "sigma" and strength by "S")

In the process of making this determination, sone of the more difficult steps are in determining the breaking pressure of a vessel in the presence of radiation embrittlement and the presence of flaws. Sone of these procedures are discussed in Appendix D. Both the OCTAVIA and PRAISE-B types of calculations must address questions of crack arrest and structural instability. These calculations are complex and the parameters have different distributions, so recourse is made to Monte Carlo calculations. 
The other, PRAISE-B type of calculation for the evaluation of the guillotine pipe break probability (Appendix $C$ ) is illustrated by Figure 2-2 from PBTG, 1984. The probability of pipe breaking at the welded joints is presumed to be the result of crack growth due to continuous and cyclic stress. The left column in the figure represents the analytical procedure and the right colum indicates the input information and analytical models used in each step of the simulation.

Because of the many probabilistically distributed parameters, Monte Carlo methods are necessary. Each replication is the result of the weighted random selection of individual parameter values to be used in the formulae for the dependent variable deternination. The process begins with the selection of a preexisting flaw length and depth. Fatigue growth of the assumed crack is calculated by the Paris growth model through the application of normal, anticipated and seismic stresses. Precursor information such as provided by nondestructive examination and leak detection is included through the use of appropriate statistical distribution functions that characterize their efficacy. Leak occurs when the crack grows sufficiently to reach through the wall of the pipe; break occurs when failure criteria based on net section collapse or tearing instability are exceeded.

The ensemble of these Monte Carlo replications of each of the microfractures in the weld provides the fallure probability distribution as a function of time for that particular weld. By combining results for all welds in a particular piping system, the probability of a leak or guillotine break is obtained.

It should be noted that this process is not what is usually considered to be PEA to which allusion was made previously. A PRf. is a plant analysis that determines systen failure probabilities on the basis of component failure probabilities. The procedure just described is a method for determining the failuxe probability of a component (pipe or pipe section), the results of which may be used in a PRA. The alternative and complement to this process is to estimate pipe failure rates on the basis of historical experience with similar pipe in a similar environment. 


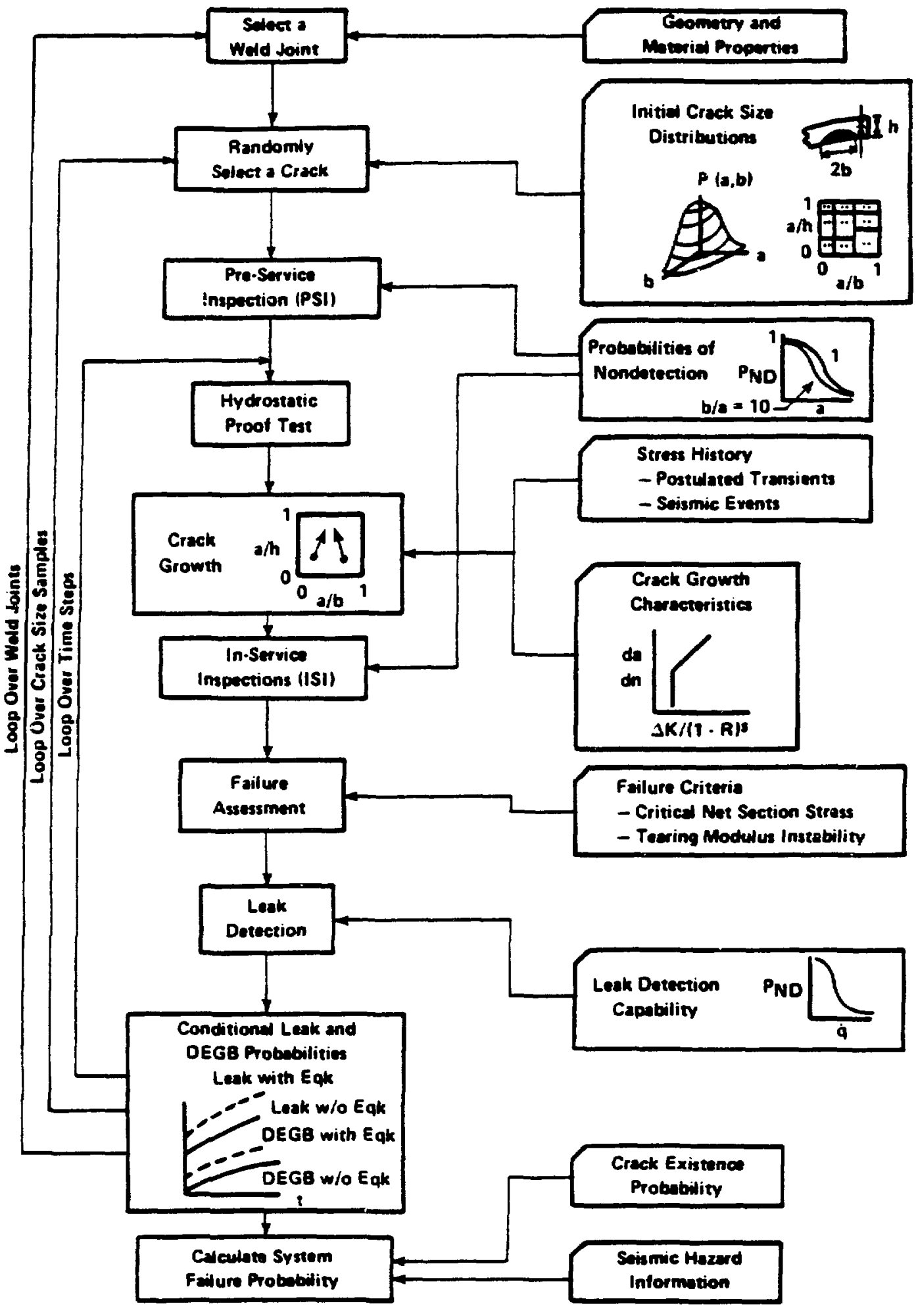

Figure 2-2

Probabilistic fracture mechanics procedures 


\section{SCALING FACTORS FOR PIPE BREAKS}

A primary purpose of this work is to provide configuration guidance assistance to the ANS designers in achleving an ANS design that meets the performance requirements while minimizing the probability of pipe failures.

\subsection{Relationship Between Pipe Break Probabllity, Pipe Length, Diameter and Wa11 Thickness}

Thomas, 1980, examines the piping failures in nuclear and fossil power experience and well as gas transmission line experience. By treating the wall thickness as a free parameter and performing computer fitting to the data, a relationship is determined (see Appendix G).

$$
P_{b}-C * L * D / t^{2}
$$

where $P_{b}$ is the probability of a leak or catastrophic break characterized according to the proportionality constant $C$, where $L$ is the length, $D$ is the pipe diameter, and $t$ is the wall thickness. Thomas treats welds as being 1.75 times the wall thickness and 50 times more susceptible to failure, so an equivalent length may be defined

$$
\mathrm{L}_{\bullet \mathrm{q}}=\mathrm{L}+\mathrm{N} * 8 \mathrm{~T} .5 * \mathrm{t}
$$

where $\mathrm{N}$ is the number of welds. Equation 3-1 may be rewritten as

$$
P_{b}=C * L_{a q} * D / t^{2}
$$

In the following discussion, the equivalency subscript is dropped as being assumed to be understood.

Equation 3-3 is at interesting equation in that the proportionality to the length times the diameter constitutes scaling according to the surface area of the pipe. If the flaws were on the surface, the number of flaws would be proportional to the surface area. However, flaws are distributed throughout the volume of the pipe wall so a proportionality to $L * D * t$ might be the expected scaling. It will be shown that the wall thickness of piping is approximately proportional to its diameter, suggesting a scaling relationship as: $L * D^{2}$. This is not found in data. For example, WASH-1400 and Basin, 1977, show higher failure rates for smaller than larger pipe diameters. This effect is reflected in equation $3-3$ because Thomas selected a scaling model that reflected the data that were available. Thomas does not provide physical reasons why equation 3-3 should be correct except to suggest that the relationship is complex.

\subsection{Fipure of Merit}

It is instructive to define a figure of merit for piping based on the scaling relationships for the flow volume, $Q$ and the probability of pipe break presented in equation $3-3$. The proposed figure of merit is

FOM - flow volume/pipe break probability 
FOM is maximun when flow volume is maximum and/or the pipe break probability is minimun. Since the latter is given in equation $3-3$, it is necessary to determine the former.

\section{3 Relationshtp Between Dlameter and Mtnimum Wa11 Thickness}

Before the figure of mertt can be calculated, a relationship between the minimun wall thickness of piping and the dianeter is needed. The mechanical engineering handbook (Bauneister, 1967 p 8-207) provides this as

$$
\tau=P * D /(2 * S+y * P)+C
$$

where $t_{\text {g }}$ is the minimun wall thickness, $P$ is the maximum internal pressure including water-hamer or other transient pressure surges, $D$ is the outside diameter, $S$ is the allowable stress for the pipe material at the service temperature. The parameter, $y$, is given in a table in the reference and ranges from 0.4 to 0.7 for ferritic and austensic steels in the respective temperature range $900-1150^{\circ} \mathrm{F}$. C is also given in the reference as a small correction for threads and grooves.

The denoninator in equation $3-4$ is dominated by the $2 * S$ terms and the $C$ tern may be neglected in this case so

$$
\text { t. }-k \star P * D
$$

where $k$ is another constant of proportionality.

\subsection{A Relationship for Flow Volume}

The Darcy-Weisbach equation (op. c1t. p 3-58) provides a relationship for the pressure drop for an incompressible fluid moving in a pipe

$$
d P=f * L * w * V^{2} / 2 * D * g
$$

where $f$ is the friction factor, $V$ is the velocity of the flutd, $w$ is the specific weight of the fluid and $g$ is the acceleration of gravity.

The flow volume, assuming a uniform velocity across the pipe, is the area times the velocity

$$
Q=p 1 * D^{2} * V / 4
$$

giving

$$
Q=p i * D^{2} / 2 *(d P * D * g / 2 * L * f * w)^{1 / 2}
$$

or

$$
Q=k^{\prime} * D^{5 / 2} / L^{1 / 2}
$$

where $k^{\prime}$ is a proportionality constant if dP is constant. 


\subsection{Evaluating the Fipure of Merit}

If It is assumed that the thickness is the minimum thickness according to equation 3-4, the figure of merit can be determined to be

$$
\text { FOM }-\left(k^{\prime} * D^{5 / 2} / L^{3 / 2}\right) /(C * L / D)-k^{n} * D^{7 / 2} / L^{3 / 2}
$$

where $k^{n}$ is another constant of proportionality.

The figure of merit is most strongly improved by increasing the pipe diameter but nearly as strongly improved by reducing the pipe length. The reason for the improvement with diameter is the wall thickness is assumed to be proportional to diameter, so if smaller piping were desired for other reasons, increasing the wall thickness would achieve the same effect. The reason for the improvement with length reduction is that the shorter the pipe, the less there is to fall, but the reason it goes as the $3 / 2$ power is that less length also reduces the pipe impedance and so helps in the flow part of the figure of merit. 


\section{SENSITIVITY STUDIES}

\section{I Background and Base Case}

In a sense, Section 3 presented a form of sensitivity study by determining parameters of the configurational sensitivity. This section addresses the sensitivity of the probability of pipe leak or break to other parameters. The work discussed in this section is based on Hong, 1984, using the PRAISE code (an early form of PRAISE-B). The plant studied was Zion 1 constructed principally with 316 austensic stainless steel. Definitions used in the base case calculations are: 40-year plant lifetime, hydrostatic proof test to 3125 psi, exponential crack depth distribution with a mean of 0.246 in., an aspect ratio lognormally distributed with a mean of 2.55, variance of 2.178 and a normalization of 1.419. Pre-service inspection is performed with a sensitivity such that a crack depth of $1.25 \mathrm{in}$. has a 50 \% probability of detection with a detection uncertainty of 1.6 in a lognormal model. The crack growtin model is a power law with an exponent of 4 , threshold of $4.6 \mathrm{ksi} \mathrm{in}^{1 / 2}$, lognormally distributed with a median of $9 \mathrm{E}-12$ and 90 percentile of $3.5 \mathrm{E}-11$. The normal operating pressure is $2250 \mathrm{psi}$, the cold shutdown stress is $2 \mathrm{ksi}$ and the normal stress is $8.75 \mathrm{ks} i$ with the heatup-cooldown cycle occurring 5 times per year. The base case assumes no vibratory, residual or seismic stresses.

\subsection{Effectiveness of Inspection}

The results of the base case calculation are shown in Figure 4-1 along with the influence of pre-service inspection, in-service inspection and proof testing. The leak probability per plant lifetime given the crack being present in the hot leg is about 1.E-6. Thus, the numbers in the figures should be reduced by the probability of the crack's presence, which is about a factor of 10 .

Pre-service inspection decreases the conditional failure probability by an order of magnitude. The pre-service fallures are caused by large cracks for which the probability of detection is -0.1 , hence producing the results as shown. The reason that the omission of the proof test has no effect on the leak probabilities is that it will not weed out the intermediate cracks that can grow to produce a leak.

By regulation, the primary piping is required to be inspected during the ife of the plant. Figure 4-1 shows the cumulative effects of inspection at $3,10,23$ and 40 years fron which it is seen that the effects are most significant for the first inspection and diminish thereafter. This may be understood by the fact that the ratio is the product of the repeated application of the non-detection probabilities at each inspection. Since the non-detection probability is low, the repeated application is lower.

The overall failure probabilities are directly proportional to the crack non-detection probability. These are functions of $a^{\star}$, the crack for which the detection probability is $50 \%$ and $\nu$, the uncertainty in the detection probability. The sensitivity to $a^{*}$ is shown in Figure 4-2 and to the uncertainty in detection probability in Figure 4-3. The improvement of a* to 0.25 inches 


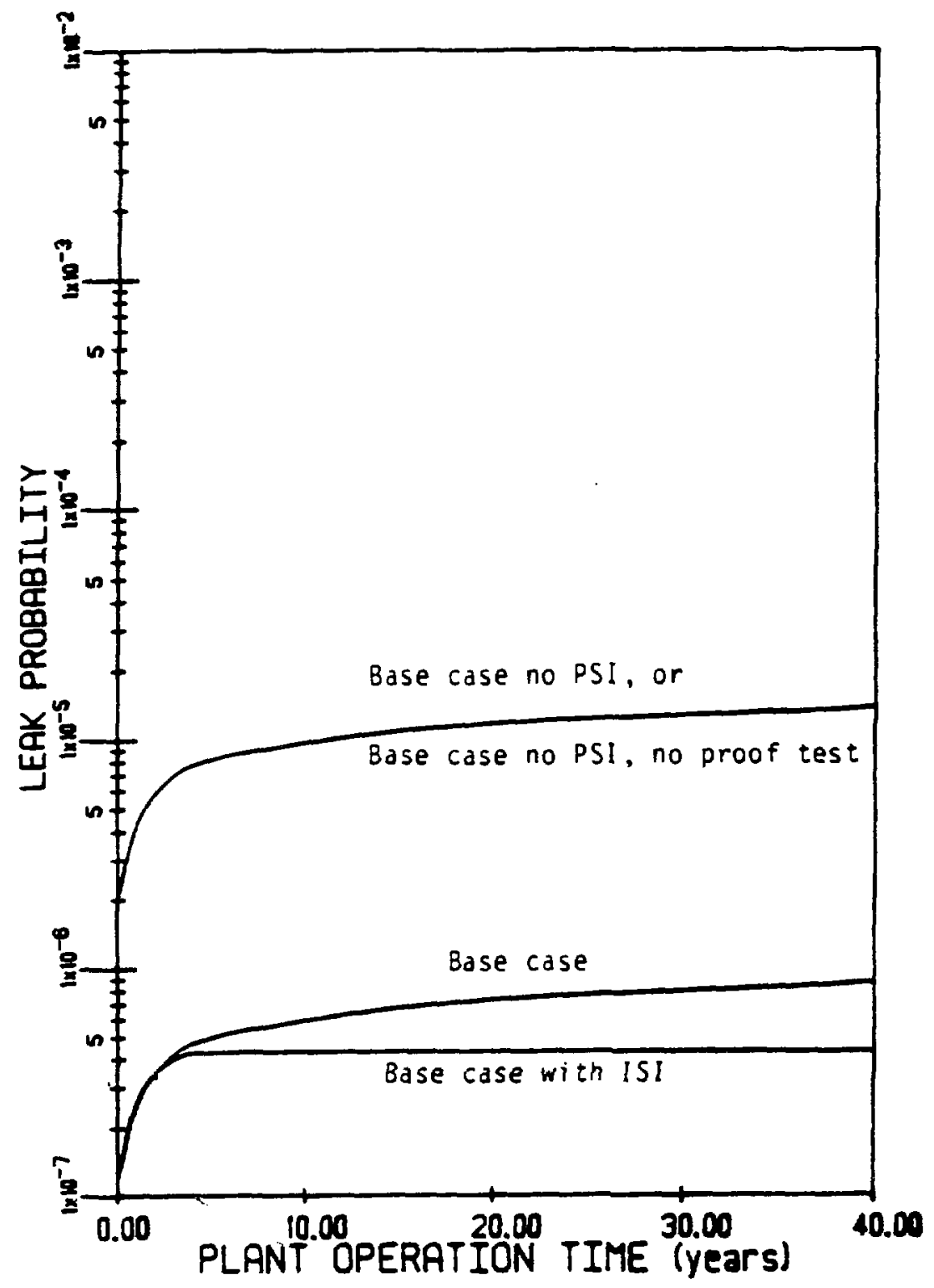

Figure 4-1

Conditional leak probability for the Zion- 1 base case also showing the influence of In-Service Inspection (ISI), Pre-Service Inspection (PSI) and proof testing. This probability is conditioned on the probability of the crack so the ordinate should be reduced by about a factor of 10 to give the probability per plant lifetime ( 40 years). 


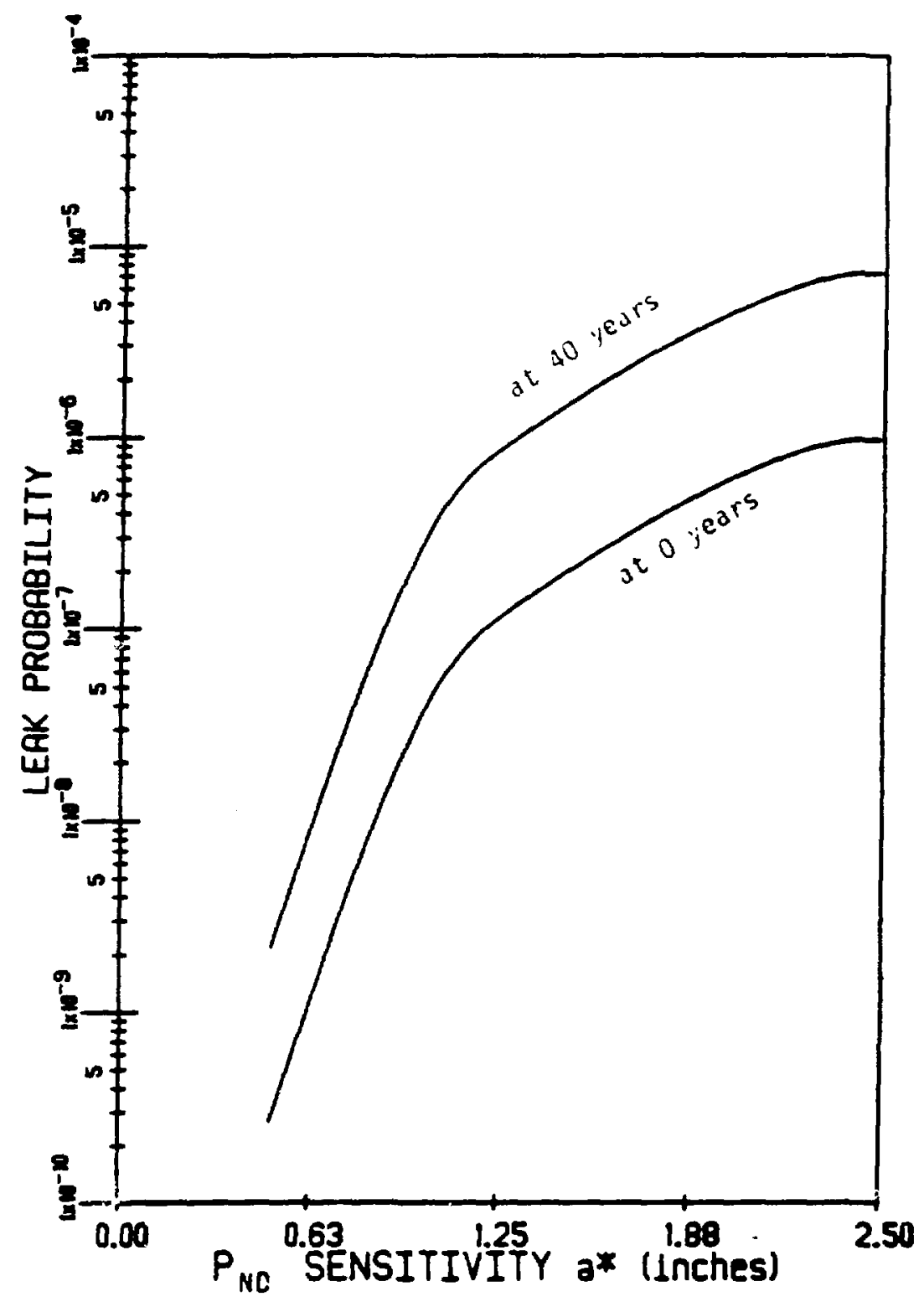

Figure 4-2

Sensitivity to the 508 crack non-detection probability for the base case and at 40 years 


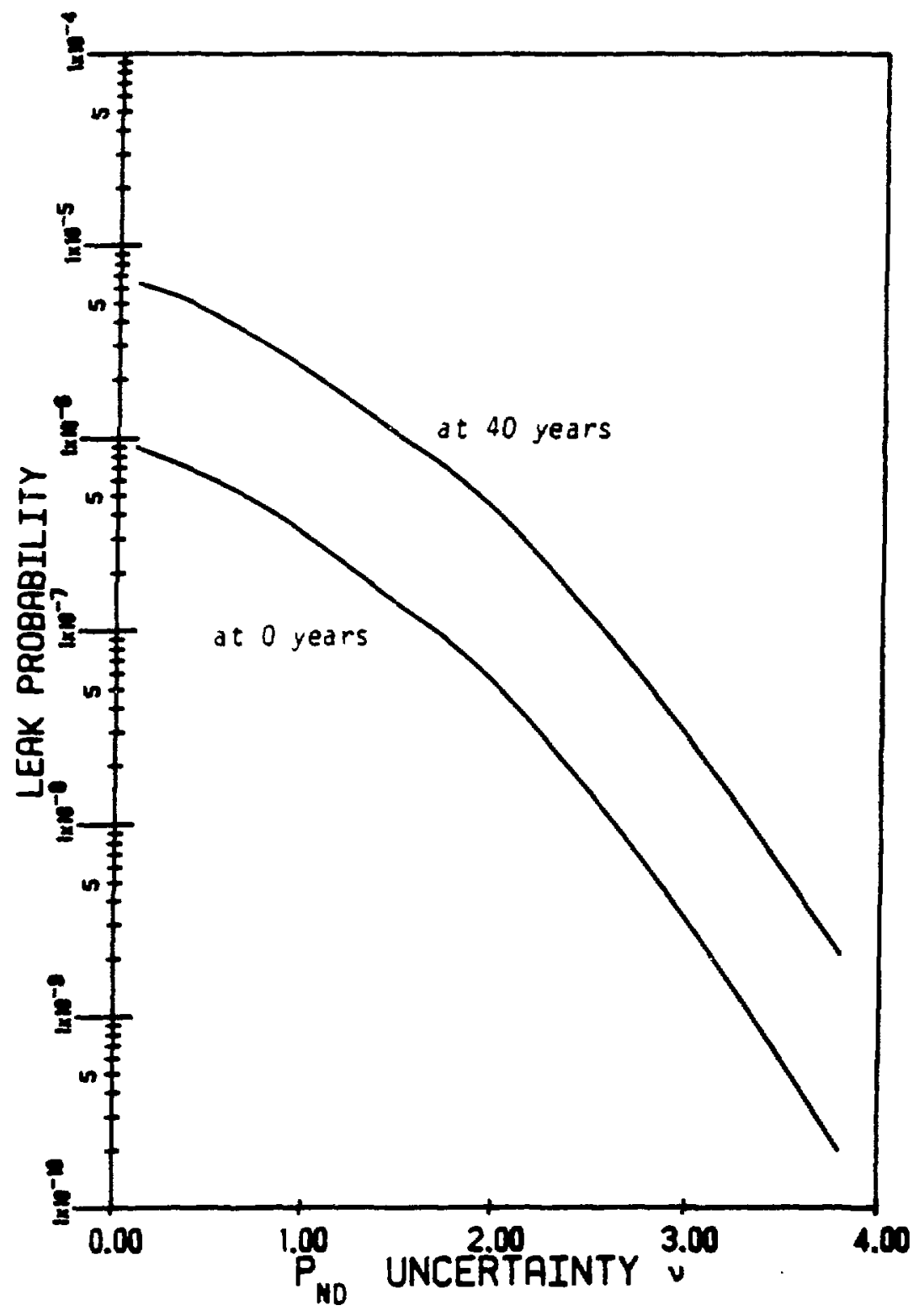

FIgure 4-3

Effects of non-detection uncertainty 
could reduce the pipe failure probability by a factor of 10,000 over the forty year lifetime. Reducing the uncertainty of detection could also yield order of magriltude improvements.

\subsection{Vibratory Stress Effects}

Hong, 1984 also evaluates vibratory effects on the piping. The stress vibrations are not well known but one reference (Chan, 1981) indicates that the amplitude of the stress oscillations is of the order of 500 psi. For these sensitivity studies, $16.7 \mathrm{~Hz}$ is assumed, corresponding to the rotational speed of the main cooling pump. The effects of vibratory stress are shown in Figure 4-4. Figure 4-5 shows that the increase in the leak probability due to vibratory stress is greatly affected by the sensitivity of leak detection (a").

\subsection{Residual Stress}

Residual stress may be the result of welding; it was due to flange misalignment at HFBR and was identified as a major cause of the piping problems discussed in Section 1. Hong, 1984, finds that in the absence of vibratory stress, it has a slight beneficial influence on fatigue crack growth but when it combines with vibratory stress, its reduction in the leak probability is shown to be marked. ${ }^{1}$

1 The explanation given by Hong, 1984, is in terms of the mathematics of the model. The authors of this report have little confidence in the reality of the result from an overall perspective, because in the limit, residual stress is capable of causing failure by simply making the stress exceed the strength. Residual stress is also a factor in stress corrosion cracking which was not included in PRAISE (although it is in PRAISE-B). 


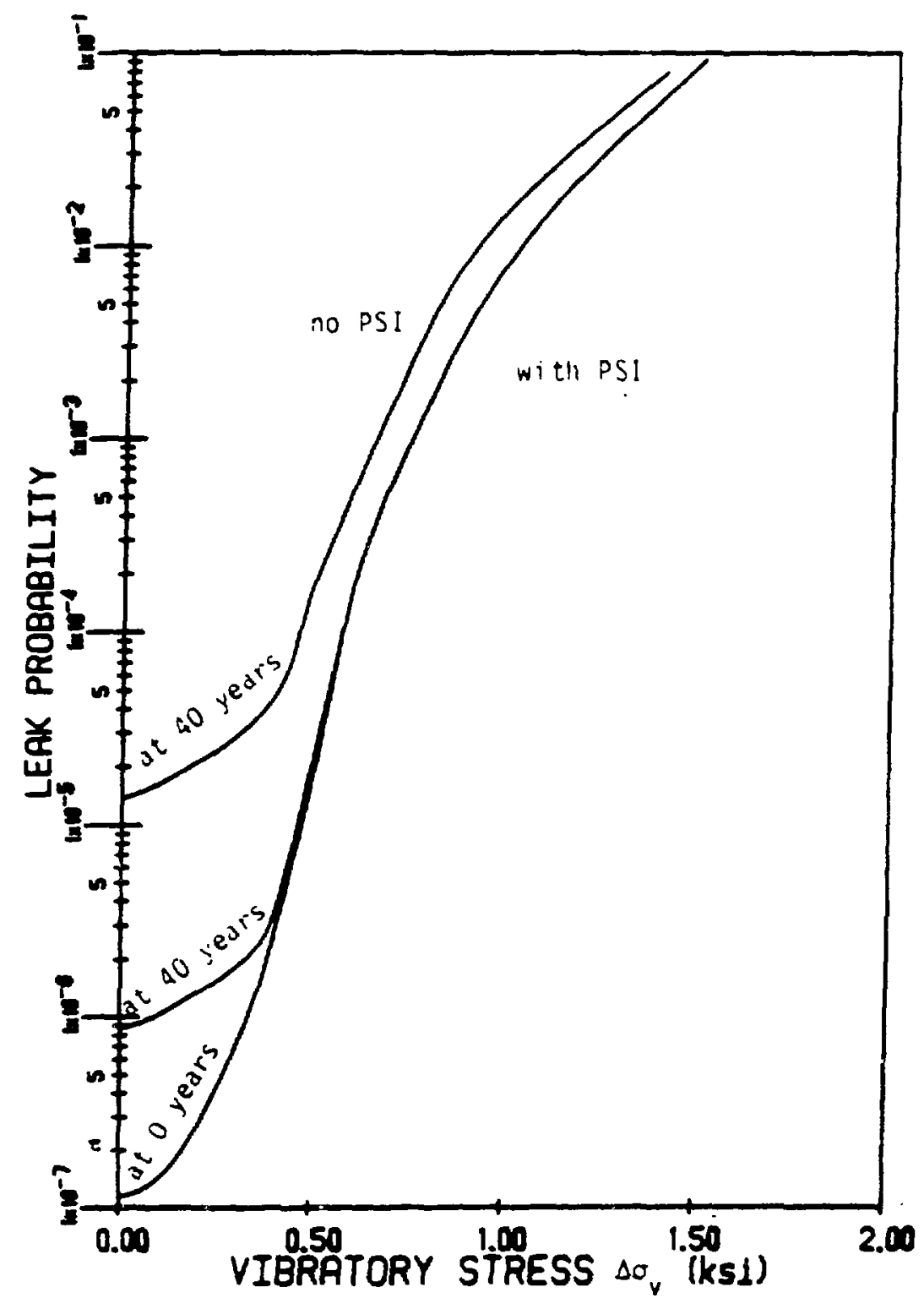

Figure 4-4

Effects of vibratory stress on the conditional leak probability with and without pre-service inspection 


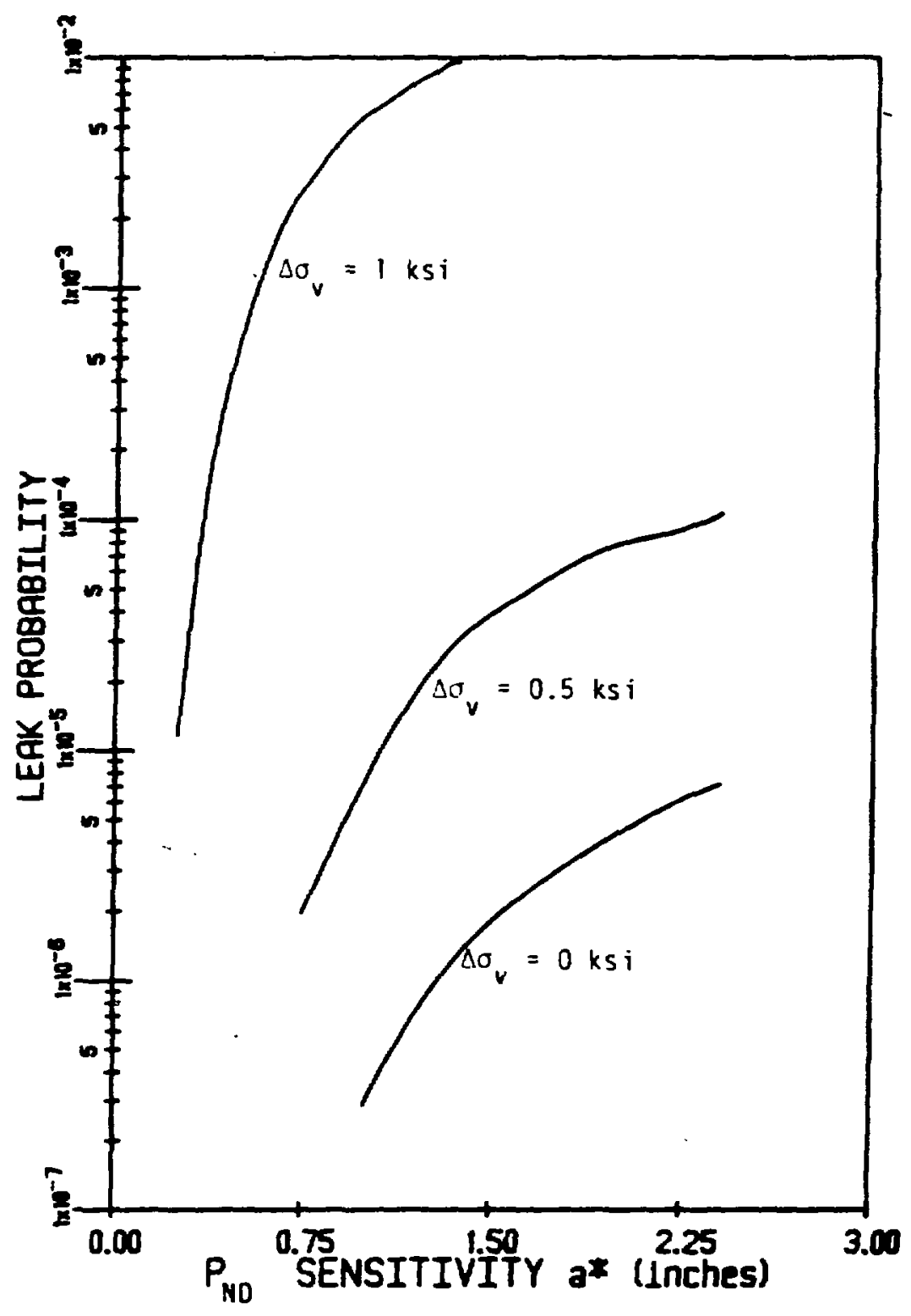

Figure 4-5

Sensitivity of leak probability to the 50 crack non-detection probability for three vibratory stress levels 


\section{CONCLUSIONS AND RECOMMENDATIONS}

\subsection{Conclusions}

Field experience in pipe failures indicates failure rates of the order of 2.E-4 for small ( $<6$ in.) and $2 . E-5 / m-y r$ for larger sizes, although this size distinction is not shown in CANDU data. Thomas, 1980, correlates the failure rate with surface area and wall thickness, and finds that the probability of pipe failure is proportional to the product of the length and diameter divided by the inverse square of the thickness. Welds have about 50 times the failure probability per length as compared with base metal pipe. The Thomas method has been applied to HFIR by PLAG with the resulting predicted frequency of a large loss of coolant accident being $1 . \mathrm{E}-5 / \mathrm{yr}$. The frequency of pipe connected with the pump/heat exchanger failing is about five times larger than the probability of the rest of the pipe failing. The PL\&G analysis computes failure probabilities for base metal, circumferential and longitudinal welds. We were not able to determine the fractions of seamless, shop weld and field welds but believe that the data on which the Thomas method is based may be including longitudinal welds with the base metal data.

Leaks are Delieved to be precursors of breaks in some cases while in other cases the crack growth may arrest with the leak. Leak-before-break (LBB) was investigated by LLNL using the PRAISE-B code and best estimate probabilities of leaks less than $3 \mathrm{gpm}$ in the range of $5 . \mathrm{E}-9$ to $5 . E-7 / \mathrm{yr}$ were obtained as compared with 1 .E-12 to 6.E-12/yr for the probability of doubleended guillotine breaks or nearly four orders of magnitude separation. (Thomas assesses one order of magnitude between leak and break - neither of which being very specifically defined.) Nevertheless, the Pipe Break Task Group (PBTG, 1984) recommended to the NRC that DEGB be retained for design purposes and LBB only be used in the absence of excessive loads and cracking mechanisms that could adversely affect flaw evaluation.

Thomas, 1980, expresses doubts about the ability of probabilistic fracture mechanics models to accurately predict fallure rates and indicates that flaw growth (such as modeled in PRAISE-B) only constitutes about 18 of the pipe fallures that have been reported. (These modeis tend to underpredict field experience by about this factor.) Nevertheless, even if the absolute predictions of these models are in doubt, they are very useful in embodying physical processes for the determination of parametric sensitivities such as reported by Hong, 1984, showing strong effects on pipe failure frequency from inspection and vibratory stress. Hong, 1984, also reported a strong beneficial effect from residual stress which is hard to reconcile with its effect in stress corrosion cracking. More investigation is reeded to assure that these results do reflect reality and not just model deficiencies. The probabilistic fracture mechanics codes only analyzed fallures at welds. This seems inadequate because the PLSG analysis of HFIR finds a higher contribution to the probability coming from base metal. 


\subsection{Recommendations}

a) Based on the scaling of Thonas, the ANS pipe break probability would be reduced by nininizing the length and maximizing the diameter or wall thickness of the piping. A configuration similar to HFIR is suggested in which the flow between pump/heat exchangers and the reactor vessel is by large inlet and outlet headers that may be considered as being part of the reactor vessel that has been deformed to place the pump/heat exchangers in a benign radiation environnent. Considering the headers as part of the vessel suggests that they be sinilarly submerged because isolation of either by valves near the reactor vessel would not be practical or desirable.

b) ANS uses the concept of a replaceable reactor vessel in the form of a plpe ("Core Pressure Boundary Tuba"). This pipe should be as long as practical in order to separate and consequently minimize the radiation embrittlenent of the non-replaced parts from the high fast-fluence region.

c) If ANS piping uses stainless steel, the low carbon types should be used such as 304L, 316NG or types using nioblum or titanium in preference to chroniun, more or less in this order of preference.

d) Residual stresses should be relieved.

e) Radiolytic oxygen should be controlled by hydrogen addition.

f) Extra low sulfur content $(<0.01$ wt $\$$, reference Torronen, 1984) strongly reduces the fatigue crack growth rate.

g) Vibratory stress should be mininized.

h) Very significant reduction in pipe leak or break probabilities may be achleved by methods capable of detecting with a 50 s probability cracks as suall as 0.25 inches with corresponding reductions in the uncertainty of detection.

i) Pre-service inspection is very important in reducing the leak probability.

j) An interacilve PC conputer nodel should be constructed to aid in the making of design trade-offs. This model should be basically an implementation of the Thomas method for determining the absolute probability with the parametric trending by fracture mechanics nodels. 


\section{REFERENCES}

Adamonis, D.C. and V. Salemann, 1979, "Ultrasonic Evaluation and Sectioning of PVRC Plate Weld and Specimen 201," Welding Res. Counc1l Bul. No. 252, NY, Septenber.

Anderson, 0., 1979, "Fallure Characteristics of 011 and Gas Plpelines," Second National Conference on Reliability, Birminghan.

Ba11, D.G., et al., 1984, "OCA-II, A Code for Calculating the Behavior of 2-D and 3-D Surface Flaws in a Pressure Vessel Subjected to Temperature and Pressure Transients," NUREG/CR-3491, February.

Dircks, J.W., 1982, "Enclosure A: NRC Staff Evaluation of Pressurized Thermal Shock, " SECY-82-465, November.

Bamford, W.H., 1979, "Fatigue Crack Growth of Stainless Steel Piping in a Pressurized Water Reactor Environment," J. Pressure Vesse1 Tech. 101, 1, pp 73-79, Feb.

Basin, S.L. and E.T. Burns, 1977, "Characteristics of Pipe Systen Failures in Light Water Reactors," EPRI NP-438, August.

Becker, P.E. and B. Hansen, no date, "Statistical Evaluation of Defects in Welds and Design Implications," Danish Welding Institute, RISO.

Binford, F.T. and E.N. Cramer, editors, 1964, "The High Flux Isotope Reactor: A Functional Description," ORNL-3572, Volumes A and B, May.

Bloom, J.M., 1984, "Probabilistic Fracture Mechanics - A State of the Art Review," in Advances in Probabilistic Fracture Mechanics ASME PVP Volume 92 p $1-19$.

Bryan, R.H. et al., 1975, "Test of Six-Inch-Thick Pressure Vessels, Series 2: Intermediate Test Vessels $V-3, V-4$, and V-6," ORNL-5059, November.

Bryan, R.H. et al., 1975a, "Test of Six-Inch-Thick Pressure Vessels, Series 2: Intermediate Test Vessels V-3, V-4, and V-6, Series 1," ORNL-5059, February.

Bush, S.H., 1976, "Rellability of Piping in Light-Water Reactors," Nuclear Safety 17, 5, pp 568-579, September-October.

Bush, S.H., 1984, "Probabilistic Assessment of Leak Before Break", NUREG/CP-0051, August.

Chan, A.L., et al., 1981, "Probability of Pipe Fracture in the Primary Coolant Loop of a PWR Plant," NUREG/CR-2189 Volume 3 .

Cheverton, R. D. and D.G. Bal1, 1984, "OCA-P, A Deterministic and Probabilistic Fracture-Mechanics Code for Application to Pressure Vessels," NUREG/CR-3618. 
Cheverton, R.D., et al., 1987, Evaluation of HFIR Pressure-Vessel Integrity Considering Radiation Embrittlenent," ORNL/TM-10444.

Cole, T.E., 1960, "High Flux Isotope Reactor: A General Description," Oak Ridge National Laboratory Central Files Number 60-3-33, March.

Crammond, R., 1974, "A Probabilistic Analysis of Structural Reliability against Fatique and Fallure," PhD Thesis, University of Illinois at Urbana.

Derby, R.W. et al., 1975," Test of 6-Inch-Thick Pressure Vessels, Series 1, Intermediate Test Vessels V-1 and V-2," ORNL-4895, February.

Dircks, J.W., 1982, "Enclosure A: NRC Staff Evaluation of Pressurized Thermal Shock," SECY-82-465, November.

Difilippo, F.C., et al., 1986, "A Prelininary Reactor Design for the Center for Neutron Research," Nuc. Instr. and Meth. In Physics Research A249 pp 58-65.

FCFMS, 1979, "Influence of Various Paraneters on the Determination of the Fatigue Crack Arrest Threshold," Fatigue Comission of the French Metallurgical Society, ASTM th. Pittsburg, PA, October.

Ford, P, Second Semi-Annual Progress Report on EPRI project RP-1332.

Frost, N.E. and K. Denton, 1967, "The Fatigue Strength of Butt Welded Joints in Low Alloy Structural Steel," British Welding Journal, 14, 4, pp 156161, April.

Gamble, R.M. and J. Strosnider, Jr., 1981, "An Assessment of the Failure Rate for the Beltline Region of Pwr Pressure Vessels During Normal Operation and Certain Transient Conditions," NUREG-0778, June.

Gambill, W.R., 1986, "Thermal-Hydraulic Constraints on Water-Cooled Research Reactor Performance," Nuc. Instr. and Meth. In Physics Research A249 p 53-57.

Gibbons, W.S. and B.D. Hackney, 1964, "Survey of Piping Fallures for the Reactor Prinary Coolant Pipe Rupture Study," GEAP-4574, May.

Hale, D.A. et al., 1978, "Fatigue Crack Growth in Piping and RPV Steels in Simulated BWR Water Environment," GEAP-24098, January.

Harris, D.O. et al., 1981a, "Fracture Mechanics Models Developed for Piping Reliability Assessment in Light Water Reactors," NUREG/CR-2301, September.

Harris, D.0., et al., 1981b, "Probability of Pipe Fracture in the Primary Coolant Loop of a PWR Plant, Volume 5: Probabilistic Fracture Mechanics Analysis Load Combination Program Project I Final Report," NUREG/CR2189, August. 
Harris, D.0. and R. Fullwood, 1976, "An Analysis of the Relative Probability of Pipe Rupture at Various Locations in the Primary Cooling Loop of a Pressurized Water Reactor Including the Effects of Periodic Inspection," Science Applications Inc. report SAI-001-PA, June.

Haugen, E.B., 1980, Probabilistic Mechanical Desian, Wiley, NY.

Heliot, J., et al., 1978, "Semi-Elliptical Cracks in the Mendional Plane of a Cylinder Subjected to Stress Gradients, Calculation of Stress Intensity Factors by the Boundary Integral Method," XIth National Symposium on Fracture Mechanics, Blacksburg VA.

Hong, S.Y. and M.L. Yeater, 1984, "Probabilistic Fracture Mechanics - A State of the $\ldots t$ Review," in Advances in Probabilistic Fracture Mechanics ASME PVP - vol 92 p 133-176.

HSST, 1975, "HSST Quarterly Progress Report," ORNL-TM-4914, March.

Johnson, D.H. et al., 1987, "The High Flux Isotope Reactor Probabilistic Risk Assessment: Interim Report (I)," PLG-0573, August.

Johnston, G.0. et al., 1978, "What are the Chances of Fallure? Part 2, NDT, Pressure Vessel Applications and Fatigue," Welding Inst. Res. Bul. 19, pp 78.82, March.

Klepfer, H.H., et al., 1975, "Investigation of Cause of Cracking in Austensic Stainless Steel Piping," NEDO-21000 Volumes 1 and 2, July.

Kumar, V. et al., 1981, "An Engineering Approach for Elastic-Plastic Fracture Analysis," EPRI NP-1931, July.

Labbens, R.A., et al., 1976, "Practical Method for Calculating Stress-Intensity FActors through Weight Functions," Mechanics of Crack Growth, ASTM STP -590 .

Lehner, J.R. et al., 1986, "Estimated Safety Significance of Generic Safety Issue 61," NUREG/CR-4594, June.

Libentrau, A.M. and F.A. Simonan, 1984, "Effect of Input Distributions on the Probabilistic Fracture Mechanics Analysis of Reactor Pressure Vessels," PNL-SA-12038, June.

Lidiard, A.B., 1979, "Probabilistic Fracture Mechanics", in Conference on Fracture Mechanics: current status, future prospects, Pergamon Press, Oxford, p 149-178.

Lidiard, A.B., 1980, "Applications of Probabilistic Fracture Mechanics to Light Water Reactor Pressure Vessels and Piping," Nuc. Eng. and Design 60 p $49-56$. 
Lymn, E.K., 1977, "The OCTAVIA Code for Predicting Vessel Performance and Failure Probabilitles," Fifth Water Reactor Safety Meeting, Gaithersburg MD. , November.

Martin Marietta Energy Systens, 1984, "Feasibility Study for the High Flux Isotope Reactor II (New Facility), "X-OE-265 (internal Report).

Marshal1, W., 1976, "An Assessnent of the Integrity of PWR Pressure Vessels," H. M. Stationary Office, London, October and March 1982.

Mehta, H.S., 1985, "Assessment of the Probability of Double-Ended Guillotine Break in BWR Recirculation Piping," International Conference on Nuclear Power Plant Aging." ASM Met:?'s Park OH, PP 467-472.

Merkle, J.G., et al., 1975, "An Evaluation of the HSST Progran Internediate Pressure Vessel Tests in Terns of LWR Pressure Vessel Safety," ORNL-TM5090 , November.

Merkle, J.G., 1974, "Stress Intensity Factor Estinates for Part-Through Surface Cracks in Plates under Combined Tension and Bending," ORNL-TM4729, Vol II, pp 3-32.

Nichols, R.W., 1975, "The Uses of Welded Materlals In Nuclear Power Engineering," Welding J. 54, 12, pp 417s-432s, Decenber.

Nilsson, F., 1977, "A Model for Fracture Mechanical Estination of the Fallure Probability of Reactor Pressure Vessels," Third International conference on Pressure Vessel Technology. Part II Materials and Fabricatilon, pP 593-601, ASME, NY.

Paris and Tada, 1983, "The Application of Fracture Proof Design Methods Using Tearing Instability Theory to Nuclear Piping Postulated Circumferential through Wall Cracks," NUREG/CR-3464.

Pipe Crack Task Group, 1984, Report of the US Nuclear Regulatory Commission Piping Review Committee: Investigation and Evaluation of Stress Corrosion Cracking in Plping of Bofling Water Reactor Plants," NUREG-1061 Volumes 1, August.

Pipe Break Task Group, 1984, Report of the US Nuclear Regulatory Commission Piping Review Committee: Evaluation of Potential for Pipe Breaks," NUREG-1061 Volumes 3, August.

Pipe Crack Study Group, 1980, Investigation and Evaluation of Cracking in Piping in Pressurlzed Water Reactors," NUREg-0691.

Pipe Crack Study Group, 1975, Investigation and Evaluation of Stress-Corrosion Cracking in Piping of Light Water Reactor Plants," NUREG-0531.

Pipe Crack Study Group, 1975, Investigation and Evaluation of Cracking in Austensic Stainless-Steel Piping of Boiling Water Reactor Plants," NUREG - 75/067. 
PISC, 1979, "Evaluation of PISC Trails Results," Preprint of Report No. 5, Plate Inspection Steering Comittee, May.

Rubinstein, R.Y., 1981, Simulation and the Monte Carlo Method, Wiley, NY.

Rummel, W.D. et al., 1977. "The Detection of Fatigue Cracks by Non-Destructive Test Methods," Materials Evaluation 32, 10, PP 205-212, October.

Powe11, R.W. et al., 1973, "Experience with Stress Corrosion Cracking and Materials Compatibility at the High Flux Bean Reactor," Symposium on Marerials Performance in Operatine Nuclear Systems, CONF-730801, August.

SAI, 1984, "Evaluation of ATR Component Fallure Rates," SAI-84/1543, March.

Selby, D.L., et al., 1987, "ORNL Contributions to the Advanced Neutron Source (ANS) Project for October 1986 - March 1987, ORNL/TM-10579, November.

Shaninian, P. 1979, "Creep-Fatigue Crack Propagation in Austenitic Stainless Stee 1," J. Pressure Vessel Tech. ASME Ppaper 75-WA/PVP-1.

Shabbits, et al., 1969, "Heavy Section Fracture Toughness Properties of A533 Grade B Class 1 Steel Plate and Submerged Arc Weldment," WCAP-7414, December.

Stevens, D.L. et al., 1983, "VISA: A Computer Code for Predicting the Probability of Reactor Pressure Vessel Fallure," NUREG/CR-3384, September.

Tada, H, et al., 1979, "Stability Analysis of Circumferential Cracks in Reactor Piping Systems," NUREG/CR-0838, June.

Tang, W.H., 1973, "Probabilistic Updating of Flaw Information," J. Testing and Eval. 1, 6, PP 459-467, November.

Thomas, H.M., 1981, "Pipe and Vessel Failure Probability," Reliability Engineering 2, pp 83-124.

Thomas, H.M., 1979, "In-service Inspection is Over-Rated," Inst. Nucl. Eng. J. pp 43-46; 51-56, April/May.

Torronen, K., et al., 1984, "Evaluation of the Effect of Metallurgical Variables on Maters Behavior and Reference Curves," Int. J. Pres. Ves. \& Piping 15 p 251-269.

USNRC, 1977, "Effects of Residual Elements on Predicted Radiation Damage to Reactor Vessel Materials," Reg. Guide 1.99, Apri1, Rev. 1.

USNRC, 1984, "Report of the U.S. Nuclear Regulatory commission Piping Review Committee," NUREg-1061 Volumes 1 and 2, August.

UKAEA, 1976, "An Assessment of the Integrity of PWR Pressure Vessels," (no report number) October 1. 
Vesely, W.E., et al., 1978, "The Octavia Conputer Code: PWR Reactor Pressure Vessel Fallure Probabilities due to Operationally Caused Pressure Transients," NUREG-0258, March.

WASH-1400, 1975, "Reactor Safety Study: An Assessment of Accident Risks in U.S. Commercial Nuclear Power Plants," Appendix IV, October.

West, C.D. et al., 1986, "Center for Neutron Research Project Status Report," ORNL/TM-10065, Sept.

Wilson, S.A., 1974, "Estimating the Relative Probabilicy of Pipe Severance by Fault Cause," GEAP-20615, September.

Woo, H.H., 1984, "Probab1listic Study of Leak before Break," NUREG/CP-0051, August. 


\section{APPENDIX A}

\section{FRACTURE TOUGHNESS AND STRESS CORROSION CRACKING}

The purpose of the following discussion is to present reference material for use in the calculation of vessel and pipe break probabilities. It is a selective and not a comprehensive review of the referenced documents which should be consulted for additional information.

\section{A. 1 Code of Federal Regulations}

$10 \mathrm{CFR} 50$ Appendices $\mathrm{G}$ and $\mathrm{H}$ presents requirements for fracture toughness testing and surveillance. The requirements apply to the use of carbon and low-alloy ferritic steel in vessels and piping with minimum yields strengths < $50 \mathrm{ksi}$, welds and $\mathrm{HAZ}$ and bolting and fasteners with minimum yield strengths $<130 \mathrm{ksi}$.

Appendix G endorses ASME Code Section III, subsection 2300 dealing with fracture toughness requirements. It specifies that Charpy $V$-notch tests be performed on the material used in the vessels or piping, over a sufficient temperature to define the fracture toughness properties. From this, the nilductility transition temperature $\mathrm{T}_{\mathrm{NDT}}$ is obtained. If criteria on lateral expansion for a given absorbed energy (ASME III section NB-2331) are met, this is the reference temperature $\mathrm{RT}_{\mathrm{NDT}}$. Whenever the core is critical, the temperature of the reactor vessel shall be high enough to provide adequate margin, with consideration for anticipated operational occurrences, to provide protection against fracture. In no case, when the reactor is critical, shall the temperature be less than the minimum temperature required for hydrostatic testing in the absence of fuel. This temperature for unirradiated material is

$$
T_{\min }=R T_{N D I}+60^{\circ} \mathrm{F}
$$

The consideration for the effects of radiation is to require elevation of $\mathrm{T}_{\min }$ according to a prescription in Reg. Guide 1.99 .

Appendix G also provides requirements for in-service inspection consisting of an essentially complete volumetric examination of the beltine region of the reactor vessel including 100 \% weld inspection.

Appendix $H$ specifies the surveillance program to assure the maintenance of fracture toughness if the neutron fluence $>1 \mathrm{MeV}$ exceeds $10^{17} \mathrm{n} / \mathrm{cm}^{2}$ (for lower fluences no program is required). This program shall comply with ASTM E-185-73 and consist of the use of fracture toughness test specimens located such as to experience the same irradiation history as the inner reactor surface. The capsules shall be withdrawn and inspected according to a schedule in the regulation but basically consists of inspecting in three or four groups the first of which at one-quarter service life or at a time when the predicted shift of the reference temperature is about $50^{\circ} \mathrm{F}$. 


\section{A. 2 Regulatory Guide 1.99}

This guide entitled "Effects of Residual Elements on Predicted Radiation Damage to Reactor Vessel Materials," defines a shift in the reference temperature (A) according to the formula:

$$
A=\mathrm{dRT}_{\mathrm{NDT}}=[40+1000(8 \mathrm{Cu}-0.08)+5000(8 \mathrm{P}-0.008)]\left[\mathrm{f} / 10^{19}\right]^{0.5}
$$

where $E$ is the neutron fluence $\left(\mathrm{n} / \mathrm{cm}^{2}\right)$, the temperature shift is in ${ }^{\circ} \mathrm{F}$, $8 \mathrm{Cu}$ is the weight percent of copper (minimum of 0.08 ) and $8 P$ is the weight percent of phosphorous (minimum of 0.008). Figure A-1 is a plot of this formula.

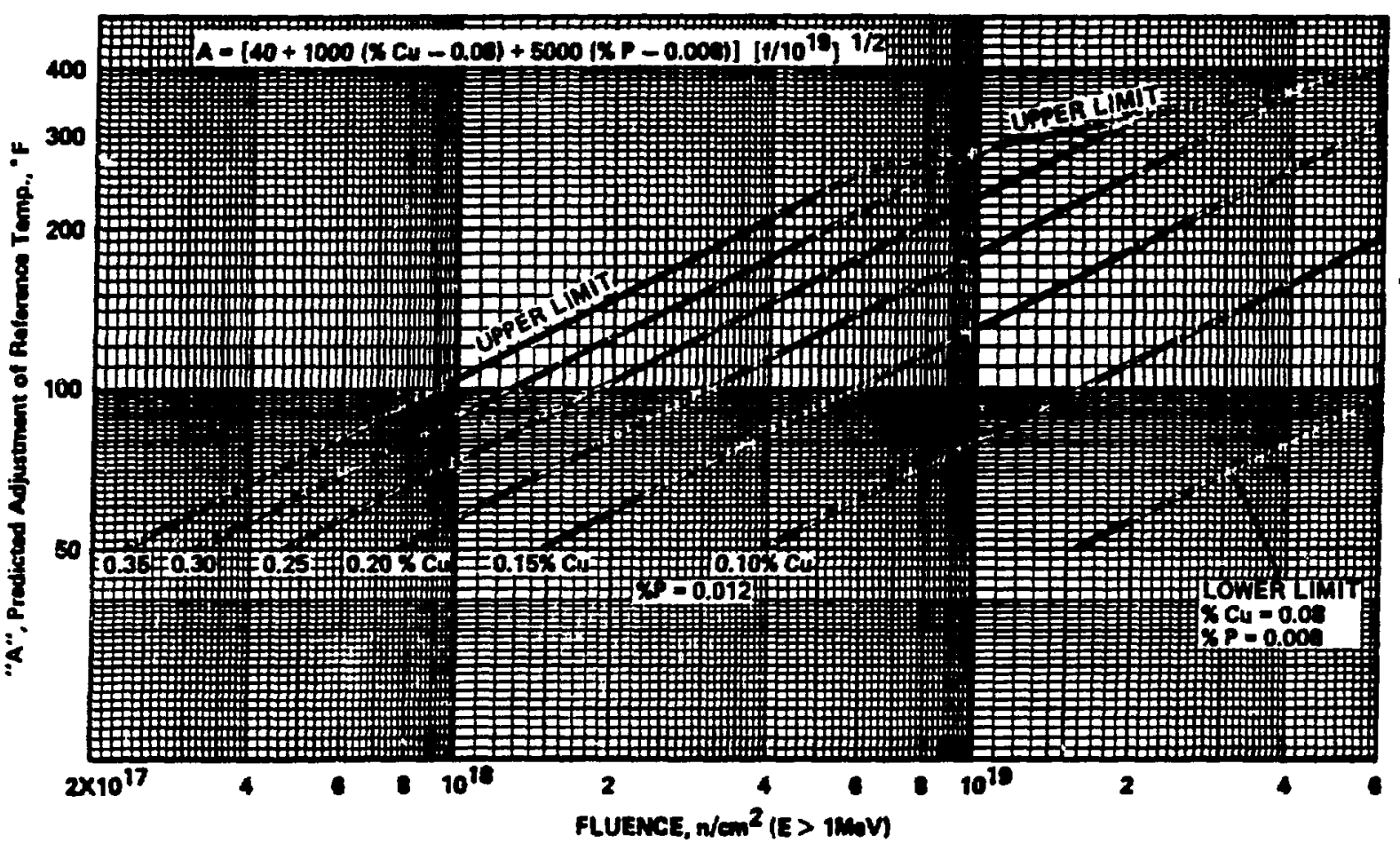

Figure $A-1$

Predicted adjustment of the reference temperature calculated by Formula A-2 for indicated percentages of $\mathrm{Cu}$ and $\mathrm{P}$.

\section{A. 3 Intergranular Stress Corrosion Cracking}

IGSCC in stainless steel arises from the synergistic effects of stress and the environment on a susceptible material. This phenomenon has been exhibited in PWRs and BWRs (Pipe Crack Study Group (PCSG), 1975, 1979, and 1980 ) and is considered to be a problem in BWR recirculation piping (Pipe Crack Task Group (PCTG), 1984). 
The following is a summarization of some material taken from PCTG, 1985 for its relevance to ANS.

Susceptible materials, in which IGSCC has been observed, are 304 and 316 stainless steel in which, in a certain temperature range, grain boundaries networks of chromium ( $\mathrm{Cr}$ ) carbides form thereby depleting adjacent narrow network zones of $\mathrm{Cr}$. These depleted zones are sufficiently reduced in $\mathrm{Cr}$ that electro-chemical cells are setup between the $\mathrm{Cr}$-enriched and the $\mathrm{Cr}$-depleted zones. This zone formation is a function of the steel composition and the temperature - typically requiring 900 to $1500^{\circ} \mathrm{F}$ but some sensitization can occur as low as the operating temperature of a BWR. Sensitization can occur in stainless steel with as low as 0.02 wt. of carbon, it has not been seen in BWRs with steels as low as 0.04 wt. 8 . It rises rapidly above this but remains constant above 0.055 wt. 8. The NRC requires stainless steel to be annealed $>2000^{\circ} \mathrm{F}$ at which temperature $\mathrm{Cr}$ carbides are unstable but preventable by rapid quenching. However the welding of stainless steel produces a band of material in the HAZ that has been sensitized by welding and this is the primary area in which cracks have been observed.

IGSCC is less a problem in steels containing elements that form more stable carbides such as niobium or titanium; however, even with these, there is potential for IGSCC in the HAZ. The compa aiive absence of IGSCC in Swedish and West German BWRs may be due to 0.05 wt. carbon limit in Sweden and the use of low carbon niobium stabilized steel (347NG) in West Germany.

It is believed that the creep of stainless steel under tension results in rupture of the protective oxide films followed by relatively rapid corrosion until the oxide film reheals. In the $\mathrm{Cr}$ depleted zones, the relative Cr loss during rehealing is correspondingly greater. Repeated film rupture, caused by repeated stresses or by residual stresses sich as due to welding, results in preferential cracking along the grain boundaries.

The presence of oxygen from radiolysis of the coolant, places the chemical potential of the stainless steel in a range for initiation of IGSCC in sensitized material. The material responsible for conducting the electrochemical currents may be impurities from heat exchanger leakage or it may be from corrosion of the metal itself thereby producing salts of sulfur, phosphorous, silicon and others.

Recommendations by PCTG, 1984 are:

- Modify one or more of the 3 causative factors: sensitization, environment and stress.

- The preferred action is to use IGSCC resistant material such as 316NG stainless steel; however, care must be exercised in its use to limit hot short cracking by controlling composition and fabrication variables related to hot forming and welding.

- Water chemistry may be controlled to reduce the conductivity such as through hydrogen additions to lower the electrochemical potential to acceptable levels. 
- Residual stresses may be relieved in the HAZ by, for example, induction heating.

- Ultrasonic testing, while cited in PCSG, 1979 as being incapable of detecting and sizing IGSCC, has subsequently developed to the point of acceptability.

\section{A. 4 Leak Before-Break}

The question addressed by PBTG, 1984 was whether or not there is sufficient evidence that leak-before break (LBB) can be used in licensing instead of the double-ended guillotine break (DEGB). By the LBB approach is meant the application of fracture mechanics technology to demonstrate that high-energy fluid piping is very unlikely to experience DEGB or equivalents such as longitudinal or diagonal splits.

The technical bases for LBB were developed for the NRC by LLNL using two approaches: a) determination of the probabilities of DEGB and LBB and b) evaluation of the $\mathrm{J}$-integral method for determining the tearing stability.

a) The determination of these probabilities was performed as an adaptation of the PRAISE code (Appendix $C$ ). For each weld joint of a piping system, the leak or break probability is calculated using Monte Carlo simulation. Each trial begins with the selection of the flaw length and depth from a probability distribution. Fatigue crack growth j.s calculated using a Paris growth model (see Appendix A) subject to the normal stresses and seismic events with consideration for flaw detection and elimination. Leak occurs when a crack grows through the pipe wall and break occurs when failure criteria based on net section collapse or tearing instability are exceeded.

Reference should be made to PBTG, 1984 but briefly, the results are that the "best estimate" DEGB probability ranges from 1.E-12 to 6.E-12 events per plant-year while the "best estimate" probability of a 3 gpm leak ranges from 5.E-9 to 5.E-7 events per plant-year. In actual fact there have been no leaks in large PWR primary coolant piping and the large separation in probabilities between DEGB and LBB supports the use of LBB.

b) The ability of unflawed pipe to withstand stresses is governed by the material's strength. If the material is flawed but has high fracture toughness, it is not sensitive to the presence of a crack and its ability to withstand stress is still governed by its strength. If the pipe has low fracture toughness, the flaw may propagate. Methods for performing fracture mechanics evaluations under linear elastic loading conditions have been extensively developed, validated and applied to evaluation of LBB. 
If the material has sufficient toughness, the method of limit-load analysis may be applied. Most materials used in nuclear facility piping has adequate toughness for the applicability of this method but some exceptions are stainless steel submerged arc weldments.

If the stresses in the cracked component are low so plastic deformation is nc: expected, linear elastic analysis may be applied. For greater loads or larger crack sizes more elaborate methods are required. In the U.S., the Jintegral method is used as a measure of the crack extension leading to a materials/ structural instability depending on the tearing modulus ( $T$ ). In the absence of plastic strain, these parameters may be calculated by the methods of linear elastic analysis. Where significant plasticity exists, finite element analysis may be used. These parameters may also be determined experimentally from which the critical tearing modulus can be determined. PBTG, 1984 compares the EPRI calculational method (Kumar, 1981) with Paris and Tada, 1983 and NRC-revised Paris and Tada, 1983 with experimental data.

The results indicate that the EPRI method is consistently conservative by about 208 for ferritic and 30 for forinless steel piping. Paris and Tada, 1983 is consistently non-conservative by about 108 for stainless steel and $20 \%$ for ferricic piping. The reason being that this latter method does not account for strain hardening. The NRC staff modified the kink angle equations in Paris and Tada to include strain hardening. The modified procedure is conservative by about 10 for stainless steel and 20 of for ferritic steel.

The recommendations of PBTG, 1984 are:

1) LBB should only be used instead of DEGB in the absence of excessive loads or cracking mechanisms that could adversely affect the accurate evaluation of flaws and loads. Such mechanisms are water hammer, water slugging, other large dynamic loads, intergranular stress corrosion cracking and fatigue.

2) The DEGB or its equivalent should be retained as the design bases for containment, ECCS, component and piping supports.

3) Leak detection systems should be examined on a case by case basis to ensure that suitable detection margins for detection of the largest fracture size used in fracture mechanics is greater than a factor of 10 over unidentified leakage.

4) The elimination of the DEGB at the terminal ends of large PWR primary pipes and the control of the maximum flaw size eliminates the need for the consideration of asymmetric pressure vessel loads, jet impingement loads and reactor cavity over-pressurization.

5) Arbitrary intermediate pipe breaks should be eliminated as a design basis requirement. 
6) Numerous changes to codes and requirements will be neccessary and

7) BWRs in which safety piping has been replaced by material resistant to IGSCC should not have DEGB as a design criterion.

\section{A. 5 Summary for ANS Relevance}

This section indicates some of the regulatory requirements that must be observed by ANS such as temperature requirements for avoiding brittle fracture as a function of the metal composition. The regulatory guide indicates the steel should contain minimum copper and phosphorous for this goal. These requirements need reinterpretation for alloys used in proposed ANS piping steels.

Stress corrosion cracking may be resisted by the use of low carbon stainless steels, by stress relief and by hydrogen addition to the coolant for pH control.

The double-ended guillotine break remains for design purposes but there is great likelihood that a leak will precede a break. Leak detection equipment should have a wide margin for detection of small breaks before they are of critical size.

The pipe material should be selected to have high fracture toughness to resist break propagation and to utilize more established break analysis me thods. 


\section{ARPENDIX B}

\section{PIPE BREAK DATA}

\section{B. 1 Querview}

A IIterature search for pipe fallure rate data yielded little prior to 1980. WASH-1400, because of its comprehensiveness still is often referenced. Basin and Burns, 1977 based on the sources avallable at the time, is valuable not only for an additional assessment of the probability of break per unit length but also for the modes of failure. This appendix assembles data that may be useful in the design of ANS to minimize the probability of pipe break as well as provide a basis for estimating the probability for the design that is selected.

\section{B. 2 WASH -1400}

The Reactor Safety Study, 1975 required two classes of pipe failure rate data: LOCA frequencies for quantifying the LOCA initiator and basic, component-level pipe failure rate data for quantifying the report's fault trees.

The approach to obtaining the frequency of pipe break was also two-fold. A review of pipe failure rate data that was available at the time was performed and studies were made of all of the plants in the U.S. in 1972 . The results of the 1972 survey are presented in Table B-1.

Table B-1

Pipe Failures Experienced by the Nuclear Industry in 1972

\begin{tabular}{|c|c|c|c|c|c|}
\hline Plant & $\begin{array}{l}\text { Number of } \\
\text { Failures }\end{array}$ & Plant/yrs & $\underset{58}{\text { Failure }}$ & $\begin{array}{c}\text { Rate/meter } \\
\text { mean }\end{array}$ & $\begin{array}{l}\text {-years* } \\
958\end{array}$ \\
\hline $\begin{array}{l}\text { PWR } \\
\text { BWR } \\
\text { Total }\end{array}$ & $\begin{array}{r}3 \\
8 \\
11\end{array}$ & $\begin{array}{r}9 \\
8 \\
17\end{array}$ & $\begin{array}{l}1.4 \mathrm{E}-5 \\
5.5 \mathrm{E}-5 \\
3.8 \mathrm{E}-5\end{array}$ & $\begin{array}{l}3.1 E-5 \\
9.3 E-5 \\
6.1 E-5\end{array}$ & $\begin{array}{l}8.1 E-5 \\
1.7 E-4 \\
1.0-4\end{array}$ \\
\hline
\end{tabular}

* 10,700 meters of piping are assumed to be in each plant.

Table B-2 presents the sources of information (mostly non-nuclear) and their assessments of the pipe break frequency. It may be noted that most of the sources either did not distinguish between pipe sizes or only considered large diameter piping. The first item in Table B-2 are the final WASH-1400 pipe break assessments based on both the literature review and the 1972 assessment. This information is presented for comparison with the other information sources. Iten 2 of this table presents the data from the 1972 nuclear plant review also presented for comparison. Table B-3 summarizes the failure rate data used in WASH-1400.

To estimare the frequency of a LOCA, WASH-1400 reviewed the 150 nuclear plant-years of experience up to the time of its preparation. There were no "catastrophic" failures in any of the primary cooling loops. A crack in a 
Table B-2

WASH-1400 Review of Pipe Break Information ${ }^{1}$

\begin{tabular}{|c|c|c|}
\hline Data Source & $\begin{array}{l}\text { Failure Rate } \\
\text { Dia. }<-3 \text { in. }\end{array}$ & $\begin{array}{l}\text { per Meter-Hour } \\
\text { Dia. }>3 \text { in. }\end{array}$ \\
\hline WASH-1400 assessment & $5.2 E-8$ & $5.2 E-7$ \\
\hline 1972 Nuclear Experience & $3.2 E-7$ & $3.6 E-6$ \\
\hline Liquid Metal Eng. Cntr. & $2.6 \mathrm{E}-3$ & $2.6 \mathrm{E}-3$ \\
\hline $\begin{array}{l}\text { Systems Reliability Service } \\
\text { UKAEA, UR and European data }\end{array}$ & $1.1 \mathrm{E}-6$ & $1.1 \mathrm{E}-6$ \\
\hline $\begin{array}{l}\text { Collins and Pomeroy (1971 nuclear } \\
\text { operating experience) }\end{array}$ & - & $5.2 E-8$ \\
\hline $\begin{array}{l}\text { Holmes and Harver HN- } 190 \\
1968 \text { one plant } 4 \text { months }\end{array}$ & $\cdots$ & $5.2 E-4$ \\
\hline Pioneer & $\cdots$ & $3.6 E-5$ \\
\hline Shopsky & $5.2 E-6$ & $5.2 E-6$ \\
\hline $\begin{array}{l}\text { Lindackers et al., German } \\
\text { Institute of Reactor Safety }\end{array}$ & -- & $1.1 \mathrm{E}-7$ \\
\hline Davies & - & 1. $5 E-6$ \\
\hline IEEE & -- & $5.2 E-6$ \\
\hline Otway & & $3.1 E-6$ \\
\hline Nat. Reactor Test Sta. & $5.2 E-6$ & $5.2 E-6$ \\
\hline
\end{tabular}

Table B-3

Final Pipe Break Data Assessments used in WASH-1400*

(Estimated error factor of 30 )

\begin{tabular}{ccc}
\hline Pipe Size & Per Section-hour & per meter-year $*$ \\
\hline$<-3$ in. & $1.0 \mathrm{E}-9$ & $5.3 \mathrm{E}-7$ \\
$>3$ in. & $1.0 \mathrm{E}-10$ & $5.2 \mathrm{E}-8$
\end{tabular}

* Data taken from Table III 2-1 of WASH-1400.

+ A section is defined as being the length of pipe between major discontinuities such as valves or pumps.

** 17 meters of pipe are assumed to form a section.

${ }^{1}$ Adapted from SAI, 1984 quoted from WASH-1400 by dividing by an assumed 17 meters of pipe per section. 
secondary loop was recorded but did not lead to complete severance - it was believed to be due to water-hamer. Therefore, conservatively assuming one failure, and using plant operating experience, the LOCA frequency estimates presented in Table B-4 may be calculated. In addition, Table B-5 presents estimates of LOCA frequencies by various authors. Tables B-4 and B-5 were combined to give the WASH-1400 assessed LOCA frequency presented in Table B-6.

Table B-4

LOCA Estimates from Nuclear Plant Experience

\begin{tabular}{|c|c|c|c|c|c|c|}
\hline Item & $\begin{array}{l}\text { No. of } \\
\text { failures }\end{array}$ & $\begin{array}{l}\text { Plant- } \\
\text { years }\end{array}$ & $\begin{array}{l}\text { Meters/ } \\
\text { plant }\end{array}$ & $\begin{array}{c}\text { Failure } \\
58\end{array}$ & $\begin{array}{c}\text { rate/meter } \\
\text { mean }\end{array}$ & $\begin{array}{r}- \text { year } \\
958\end{array}$ \\
\hline $\begin{array}{l}\text { Large rupt. } \\
\text { Small rupt. } \\
1972 \text { exp. }\end{array}$ & $\begin{array}{l}1 \\
1 \\
4\end{array}$ & $\begin{array}{r}150 \\
150 \\
17\end{array}$ & $\begin{array}{r}5700 \\
5000 \\
10700\end{array}$ & $\begin{array}{l}6 E-8 \\
6.8 E-8 \\
7.5 E-6\end{array}$ & $\begin{array}{l}1.2 E-6 \\
1.3 E-6 \\
2.2 E-5\end{array}$ & $\begin{array}{l}5.5 E-6 \\
6.3 E-6 \\
5.0 E-5\end{array}$ \\
\hline
\end{tabular}

Table B-5

Estimates of LOCA Frequency from Varlous Sources

Source and Description

Occurrence/plant-year

Green and Bourne (1968) Prob. of Large

$2.0 E-3$ to $3 . O E-6$

Rupture of the Primary Cooling

Salvatory (1970) Catastrophic Rupture

1. $\mathrm{OE}-4$

Erdmann (1973) Pipe rupture

Otway Pessimistic Prob. of Catastrophic

1.E-4 to $1 . E-3$

Failure of Primary Piping

GE(1970) Prob. of Severance in Primary

1.7E-7

Piping

Well-Knecht (1965) Failure Rate for

5.E-4 UT testing

Rupture of Primary Coolant System Piping

1.E-3 w.0. UT

1.E-7

Table B-6

WASH-1400 Assessment of LOCA Frequency

\begin{tabular}{ccccccccc}
\hline & & \multicolumn{2}{c}{ LOCA Rate/plant-yr } & \multicolumn{3}{c}{ LOCA Rate/meter-yr } \\
Pipe dia. (in) & 58 & mean & 958 & & 58 & mean & 95 z \\
\hline $0.5-2$ & $1 E-4$ & $1 E-3$ & $1 E-2$ & & $3 E-7$ & $3 E-6$ & $3 E-5$ \\
2 & -6 & $3 E-5$ & $3 E-4$ & $3 E-3$ & & $1 E-7$ & $1 E-6$ & $1 E-5$ \\
& $>6$ & $1 E-5$ & $1 E-4$ & $1 E-3$ & & $3 E-8$ & $3 E-7$ & $3 E-6$
\end{tabular}




\section{B. 3 Some Other Pipe Break Assessments}

Pipe break frequency has been assessed by many other sources since it is critical to nuclear power plant safety. Some of these are reviewed in the following.

\section{B.3.1 General Electric}

For many years, the General Electric company was under contract to the AEC for piping studies. Gibbons and Hackney, 1974, summarized some of this work as presented in Table B-6.

\section{B.3.2 Spencer Bush Compilation}

Bush, 1976, reviewed the pipe break data for 250 reactor years of experience as reported in the Licensee Event Reports (LERs) in the years 1970 to 1975, some results of which are provided in Table B-7. Particularly noteworthy is the high frequency of small diameter piping. From these data, a rupture fallure rate for piping $>4 \mathrm{in}$. was assessed to have a mean value of 5.6E-6 with 58 and 958 values of $3.3 \mathrm{E}-6$ and $1.0 \mathrm{E}-5$ respectively per meter-year of experience.

Table B-7

Relative Frequency of Pipe Failures According to Cause and Size

\begin{tabular}{lccc}
\hline Cause & \multicolumn{3}{c}{$\begin{array}{r}\text { Pipe Size } \\
>1\end{array}$} \\
\hline Fatigue & in. & unknown \\
Construction & 45 & 4 & 10 \\
Erosion & 15 & 6 & 6 \\
Water Hammer & 0 & 7 & 8 \\
Brittle Fracture & 1 & 5 & 0 \\
Design & 1 & 1 & 1 \\
Corrosion & 0 & 5 & 0 \\
Missile & -- & -- & -- \\
& -- & -- & --
\end{tabular}

Klepfer et al., 1975 presents data for obtaining a frequency for intergranular stress corrosion cracking (IGSCC -Table B-8). From these data an assessment of failure rates due to IGSCC in furnace sensitized safe ends in BWRs were assessed to be $6.9 \mathrm{E}-4$ per component-year or 7.3E-3 per component wased on 18 failures in 107 reactor years involving 244 components. 
Table B-8

Pipe Failure Rates due to IGSCC in Heat Affected Zones

\section{BWR 1\&2 (except Dresden 1)}

Pipe No. of rate/weld rate/w-yr

Size welds
BWR 384

No. of rate/weld rate/w-yr
welds

\begin{tabular}{rcccccc}
\hline 2 in. & 328 & .0031 & .00036 &.- &.- &.- \\
4 in. & 198 & .0051 & .00059 & 1033 & .025 & .0063 \\
6 in. & 246 & .0041 & .00048 &.- &.- &.- \\
8 in. & 249 & .0040 & .00047 & 425 & .014 & .0035 \\
10 in. &.- &.- &.- & 642 & .013 & .0031
\end{tabular}

\section{B. 3.3 Basin and Burns}

Basin and Burns, 1977 extracted information from LERs, Nuclear Safety Information Center (NSIC) and NUREG-0020 ("Gray Books") covering 207 plant years of data and 203 reported fallures. The data sources used a number of categories but pipe size was the only category used in the study. The data covered piping throughout the plant, all types of fallures not just pipe ruptures, a variety of pipe materials and stress corrosion cracking. The failures in piping with an unknown diameter (15 PWR and 22 BWR) were proportioned over various size classes; the length normalization was based on WASH1400 and thus the authors say "The small diameter failure rate is 1 ikely to be too large and the large diameter fallure rate is likely to be too small.

These results are summarized in Table B-9. In the percentage distribution of failure causes (Table B-10), it may be noted that BWR piping has been susceptible to stress corrosion cracking.

Table B-9

Basin and Burns Pipe Data

\begin{tabular}{|c|c|c|c|c|c|}
\hline Plant & & $\begin{array}{l}\text { No. of } \\
\text { failures }\end{array}$ & $\begin{array}{l}\text { Plant- } \\
\text { years }\end{array}$ & $\begin{array}{l}\text { Meters/ } \\
\text { plant }\end{array}$ & $\begin{array}{c}\text { Failure Rate/m-yr } \\
\text { (mean) }\end{array}$ \\
\hline PWR & $\begin{array}{l}<6 \text { in. } \\
>6 \text { in. } \\
\text { all sizes }\end{array}$ & $\begin{array}{l}71 \\
11 \\
82\end{array}$ & $\begin{array}{l}97.3 \\
97.3 \\
97.3\end{array}$ & $\begin{array}{r}5000 \\
5700 \\
10700\end{array}$ & $\begin{array}{l}1.5 E-4 \\
2.0 E-5 \\
7.9 E-5\end{array}$ \\
\hline BWR & $\begin{array}{l}<6 \text { in. } \\
>6 \text { in. } \\
\text { all sizes }\end{array}$ & $\begin{array}{r}104 \\
17 \\
121\end{array}$ & $\begin{array}{l}110.1 \\
110.1 \\
110.1\end{array}$ & $\begin{array}{r}5000 \\
5700 \\
10700\end{array}$ & $\begin{array}{l}1.9 E-4 \\
2.7 E-5 \\
1.0 E-4\end{array}$ \\
\hline All & $\begin{array}{l}\text { plants } \\
<6 \text { in. } \\
>6 \text { in. } \\
\text { all sizes }\end{array}$ & $\begin{array}{r}175 \\
28 \\
203\end{array}$ & $\begin{array}{l}207.3 \\
207.3 \\
207.3\end{array}$ & $\begin{array}{r}5000 \\
5700 \\
10700\end{array}$ & $\begin{array}{l}1.7 E-4 \\
2.4 E-5 \\
9.2 E-5\end{array}$ \\
\hline
\end{tabular}


Table B-10

Basin and Burns Cause Data

\begin{tabular}{lcccccc}
\hline Plant Type & \multicolumn{7}{c}{ Cause Identificationt } & d & e & f \\
\hline BWR of Fails & 17 & 9 & 11 & 9 & 17 & 38 \\
PWR of Fails & 53 & 6 & 6 & 0 & 18 & 18 \\
Average & 27 & 8 & 9 & 5 & 17 & 33
\end{tabular}

*Cause identification is: a - vibration, b - thermal and cyclic fatigue, c fabrication, d-corrosion, e - erosion and f-stress corrosion cracking.

\section{B.3.4 SAI Compilation for a Japanese Advanced Test Reactor (ATR)}

SAI, 1984, performed a reassessment of pipe break data for a heavy water moderated, BWR reactor having some similarities to a CANDU. In the course of this investigation, B.R. Collingwood, Senior Reliability Engineer at Ontario Hydro, Toronto, Ontario provided the information that is presented in Table B-11. As a result of the data review SAI, 1984 estinates a leak rate for CANDU reactors as $1 . \mathrm{E}-6 / \mathrm{m}-\mathrm{yr}$ and $2 . \mathrm{E}-5 / \mathrm{m}-\mathrm{yr}$ for U.S. LWR pipe data modified for appropriateness to the ATR. The report then takes the geometric mean to estimate $4 . E-6 / m-y r$.

Table B-11

CANDU Pipe Data

\begin{tabular}{|c|c|c|c|c|c|c|}
\hline Item & $\begin{array}{l}\text { No. of } \\
\text { Fails }\end{array}$ & $m-y r$ & 58 & $\begin{array}{c}\text { dean } \mathrm{Fail} \\
\text { mean }\end{array}$ & $\begin{array}{r}\text { Rate } \\
508\end{array}$ & ${ }_{958}^{(/ \mathrm{m}-\mathrm{yr})_{95}}$ \\
\hline $\begin{array}{l}\text { Inlet pipe } \\
2-4 \text { in. dia. }\end{array}$ & 0 & $8.1 E 5$ & $\cdots$ & $\ldots$ & 8. $5 E-7$ & $3.7 E-6$ \\
\hline $\begin{array}{l}\text { Other Pipe } \\
1-6 \text { in. dia. }\end{array}$ & 1 & $1.0 \mathrm{E} 6$ & $3.6 \mathrm{E}-7$ & $9.6 \mathrm{E}-7$ & $1.6 \mathrm{E}-6$ & $4.6 E-6$ \\
\hline $\begin{array}{c}\text { All pipe > > } \\
6 \text { inches }\end{array}$ & 0 & $4.9 \mathrm{E5}$ & $=$ & - & $1.4 E-6$ & $6.1 E-6$ \\
\hline
\end{tabular}

\section{B.4 Relevance for ANS}

Based on the piping review, it is clear that the less piping a plant has, the lower the probability of a leak or break. Most of the data show a higher failure rate per unit length for small diameter piping than for large diameter piping. While PWR piping has been susceptible to vibration, a tentative estimate of a piping leak rate for ANS based on the concluding rate from SAI, 1984 is $4 . E-6 / m-y r$ (greater than 3 in. dia. pipe). The failure rate for breaks (not guillotine breaks) is generally estimated as being about 0.1 of this or 4.E-7/m-yr. The ratio of leaks-to-breaks is addressed further in Appendix G. 


\section{APPENDIX $C$ \\ SURMARY OF THE PRAISE CODE}

\section{C.1 Qverview}

The PRAISE (Piping Reliability Analysis Including Seismic Events) code (Harris, 1981a; Harris, 1981b) is a fracture growth code that models the growth of piping imperfections by continuous, anticipated, or accidental stresses which might occur in the operation of a nuclear power plant. When these grow to a critical level, leak or break of the piping may occur. An earthquake may provide the stress necessary to cause failure. The original PRAISE code was modified to become PRAISE-B for more general purpose application to the analysis of pipe break probabilities from mechanisms in addition to cyclic fatigue such as stress corrosion cracking, stresses due to assembly, vibration and welding. PRAISE-B treats both circumferential as well as longitudinal welds but only considers welding defects because welds are much more likely to be the location of defects in base material which may grow to critical size. The components of the model are presented in Figure $\mathrm{C}-1$ adapted from Harris, 1981. (This figure is an amplification on Figure 2.2-2).

The starting point for a PRAISE-B calculation is the distribution of micro-flaws in the pipe base metal introduced as a result of fabrication (box A). These are assumed to be two-dimensional, semi-elliptical with a. length of $2 b$ and depth of $a$ and the plane of the ellipse is in the radial plane of the pipe. The pipe wall thickness is $h$. Residual and transient stresses on the pipe will cause these small cracks to grow. But as they grow there is a probability that they will be detected and corrected. The crack non-detection probability is represented by box $B$ in the figure. This non-detection probability distribution is applied to the initial crack size distribution to result in a modified post-inspection distribution that feeds to box $E$ in which the crack size as a function of time is calculated. This calculation is modified by the stress history which grows the cracks by cyclic stress, mean stress, stress cycles, thickness variations, operating transients and seismic events. Solution stress (box C) is also included because it causes crack growth from stress corrosion. Box D provides the algorithm in box $E$ that relates the rate of crack growth (da/dn) to the applied stress. (If the stress is below a certain threshold, there is no crack growth).) As a result of the modeling in box $E$, the rate of crack growth is calculated and when it grows to $a$ depth of $h$, the pipe either leaks or fractures. The significance of the growth is evaluated in box $G$ but this evaluation is affected by initially leaking which may be detected according to a probability distribution dependent on the size of the crack (box F) and the leak rate (box H). The significance is also subject to a failure criterion regarding the significance of the crack based on its size. 
(A)

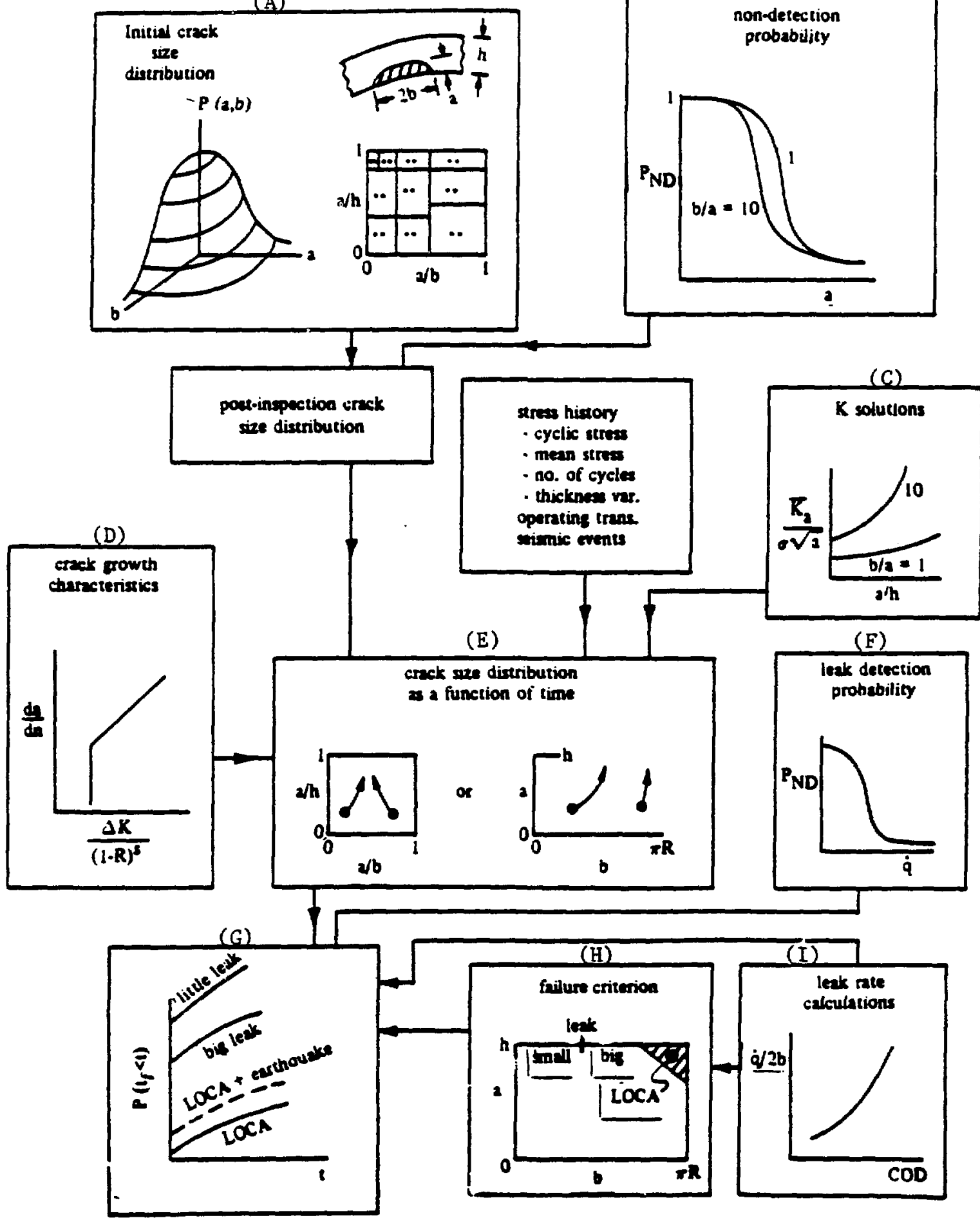

(B)

FIgure C-1

A schematic diagram of PRAISE-B steps for analyzing a given weld. 


\section{2 Major Assumptions in PRAISE-B}

The assumptions made in the PRAISE-B are presented to provide a basis for judging its utility for the ANS design process:

- Piping fallure occurs as the result of the growth of small cracklike defects introduced during fabrication. The distribution of the number and flaw characteristics are not known directly but are inferred from experience with the type of pipe material and its treatment.

- Design, fabrication, and assembly errors are omitted except as they affect the size of the intial defects.

- The defects are confined to weld joints. Furthermore the defects are restricted to being interior circumferential girth butt-welds as possibly leading to LOCA.

- The defects have the same distribution and are independent of each other.

- Cracks shorter than twice the depth are omitted.

- The subcritical crack growth can be predicted from laboratory tests.

- The cyclic stress history controlling crack growth is estimated from expected plant history. Seismic events enter as a stress history.

- Multiple cracks in a weld do not interact.

- The unstable final phase of crack growth to pipe break is calculated by exceeding the critical net section stress or by a tearing instability - whichever result in the smallest crack hence the higher probability.

- Applied stress used in the failure criterion is the stress that is not relieved by crack extension.

- Axlal pipe stress is assumed to be uniform over the pipe section and equal to the maximum at the inside pipe wall.

- The maximum stress is normal to the plane of the crack.

- Cracks grow elliptically until they reach the surface.

A through-wall crack has the same inside and outside dimensions. 
- Leaks greater than 1 gpu are immediately detected with 100 probability.

- The probability of detection with nondestructive evaluation only depends on the current crack size independently of previous tests.

- Cracks found by NDE are repaired and elininated.

- Repair does not introduce defects.

\section{3 Initial Crack Depth Distribution. Aspect Ration and Crack Probability}

For the two-dimensional representation of cracks, the procedure is to determine distribution of the depehs of cracks (a) and then to determine the distribution of the aspect ratio $(a / b)$. The reason for doing this is that the crack depth has a stronger influence on the stress than does the length. Data on the distribution of the depth is presented in Figure C-2.

Wilson, 74, provides data on both depth and length but the figure only shows the depth information. Unfortunately the data are based on judgment. Becker and Hansen, present data on 228 cracks and conclude the distribution seems to be lognormally distributed. Nilson, 77, working with the same data concluded then to be gamma distributed. Marsha11, 76, presented data from cracks found in US and UK nuclear and non-nuclear pressure vessels and concludes that the data are exponentially distributed (the exponential and gama distributions are similar). The exponential distribution is also supported by Lynn, 1977, and Vesely, 78, in the OCTAVIA code. Let $P_{\text {a }}$ be the complementary distribution, then for the exponential distribution function:

$$
P_{a}(>a)=\int_{a}^{\infty} p_{a}(x) d x=e^{-a / \mu}
$$

where $\mu$ is the mean crack depth which Marshall takes to be 0.246 in. to produce the distribution shown in Figure C-2. Also shown in the figure are the data of Becher and Hansen presented as a lognornal distribution, the Wilson distribution and estinates from Lynn, 1977. The reason that the Wilson distribution falls below the others may be due to the exclusion of cracks with initial surface lengths less than 4 in.

Harris, 1981, reports a paucity of data on the crack aspect ratio so the ratio $b / a$ is taken to be either exponential or lognormal and in fact the distribution is taken to be a shifted to omit cracks for which $b / a<1$. Two sources are cited, Frost and Denton, 1967, and Cramond, 1974, from which a value of the parameter $\rho$, the mode of the distribution for $b / a=1$, is $1 . E-2$ in fair agreement with Cramond but not Frost and Denton.

PRAISE-B also requires information on the crack probabllity. 
various Lynn estimates

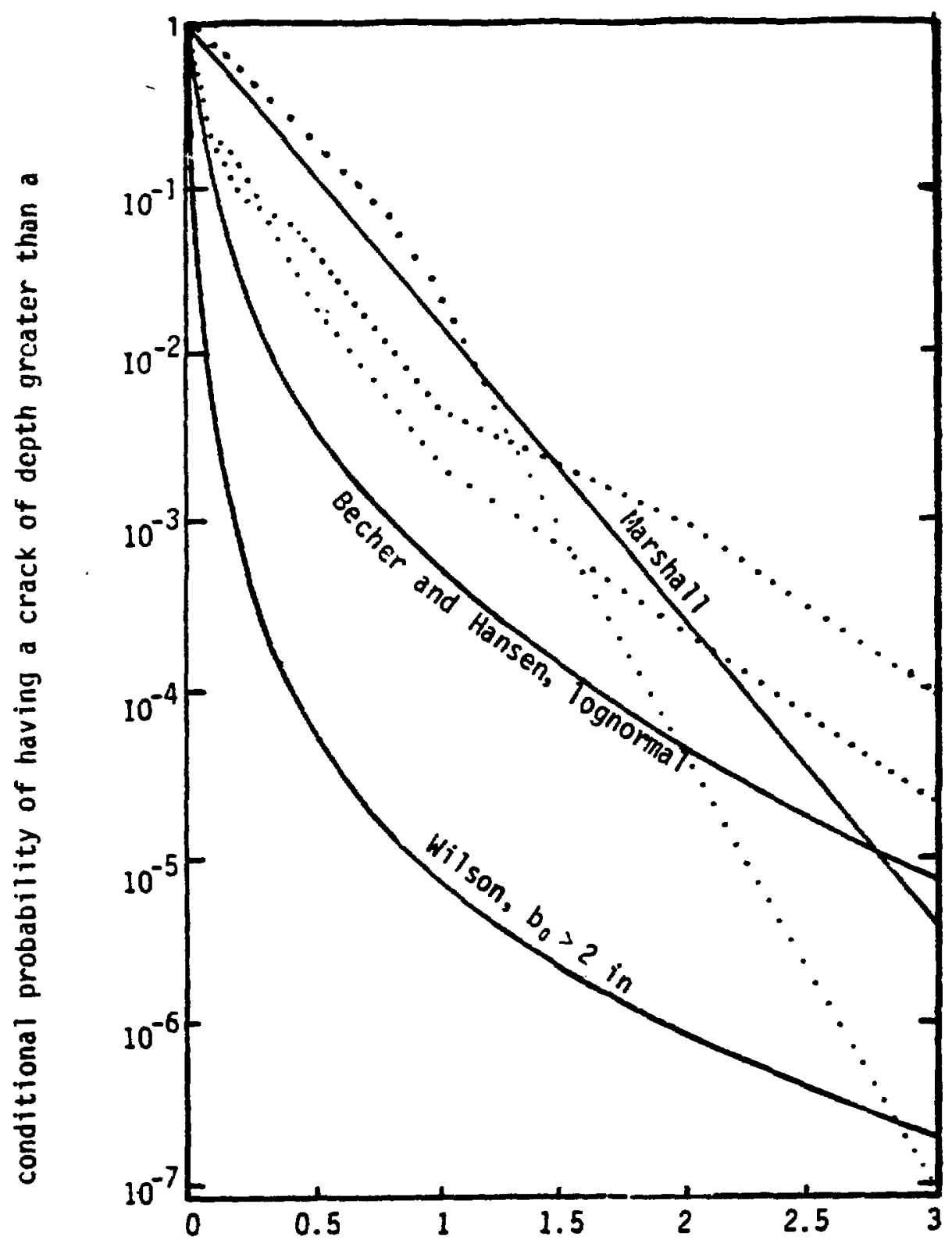

a, crack depth, in.

Figure $\mathrm{C}-2$

Complementary cumulative marginal crack depth distributions as reported by several observers. 
This is taken to be Poisson distributed based on theoretical arguments. From the crack information of Cramond the frequency of cracks varies from 1.E-4 to 9.4E-2/1nch. Marshal1, 67 reports $1.5 \mathrm{E}-3 /$ inch. In 12 out of 44 pressure vessels, cracks were found to have depths between 0.5 and 1 inch. Considering the thickness of the vessels, this may be expressed as $5.4 \mathrm{E}-5 / \mathrm{in}^{3}$. Nichols, 75 also provides information that can be interpreted as $1.7 \mathrm{E}-3 / \mathrm{in}^{3}$

In summary, PRAISE-B uses $1 . E-4 / 1 n^{3}$.

\section{4 Inspection Detection Probab11ities}

The probability of detecting a flaw with ultrasonics or any other nondestructive testing method is a function of the flaw size and location. Harris reviews the data of Harris, 1977b, Rume1, 1974, Tang, 1973, the PISC report, 1979, Johnson, 1979 and Adamonls, 1979 as presented in Figure C-3. These data were based on elther wrought or welded ferritlc steels or aluminum. Ultrasonic inspection is more difficult in the case of cast austensic stainless steel because of the large columar grain formation in the casting process. The concluding representation of non-detection used in PRAISE-B is

$$
P_{\mathrm{ND}}(A)=1 / 2 \operatorname{erfc}(\nu \ln A / A *)
$$

where

$$
\begin{aligned}
& \nu=1.60 \\
& A *=\pi / 4 a * D_{B} \\
& a *=1.25 \mathrm{in} .
\end{aligned}
$$

\section{5 Fatipue Crack Growth}

Harris, 81 reviews the data of Ford, 1980, Banford, 1979, French data (ECFMS, 1979), Shaninian, 1975 and General Electric (Hale, 1978) as shown in Figure $\mathrm{C}-4$. The concluding representation is

where

$$
\mathrm{da} / \mathrm{dn}=\left\{\begin{array}{cc}
0 & \mathrm{~K}^{\prime}<\mathrm{K}_{0}^{\prime} \\
\mathrm{CK} \mathrm{K}^{\prime 4} & \mathrm{~K}^{\prime}>\mathrm{K}_{0}^{\prime}
\end{array}\right.
$$

$$
\begin{aligned}
& \mathrm{K}^{\prime}=\Delta \mathrm{K} /(1-\mathrm{R})^{1 / 2} \\
& \mathrm{~K}_{0}^{\prime}-4.6 \mathrm{ks} 1-\mathrm{in}^{1 / 2} \\
& \mathrm{C} \text { lognormally distributed with } \\
& \quad \begin{array}{ll}
\text { median }-9 / 14 \times 10^{-12} \\
\text { standard deviation }-2.20 \times 10^{-11}
\end{array} \\
& \begin{array}{ll}
\text { da/dn : inches/cycle } & \mathrm{K}: \mathrm{ksi}^{-1 \mathrm{in}^{1 / 2}}
\end{array}
\end{aligned}
$$




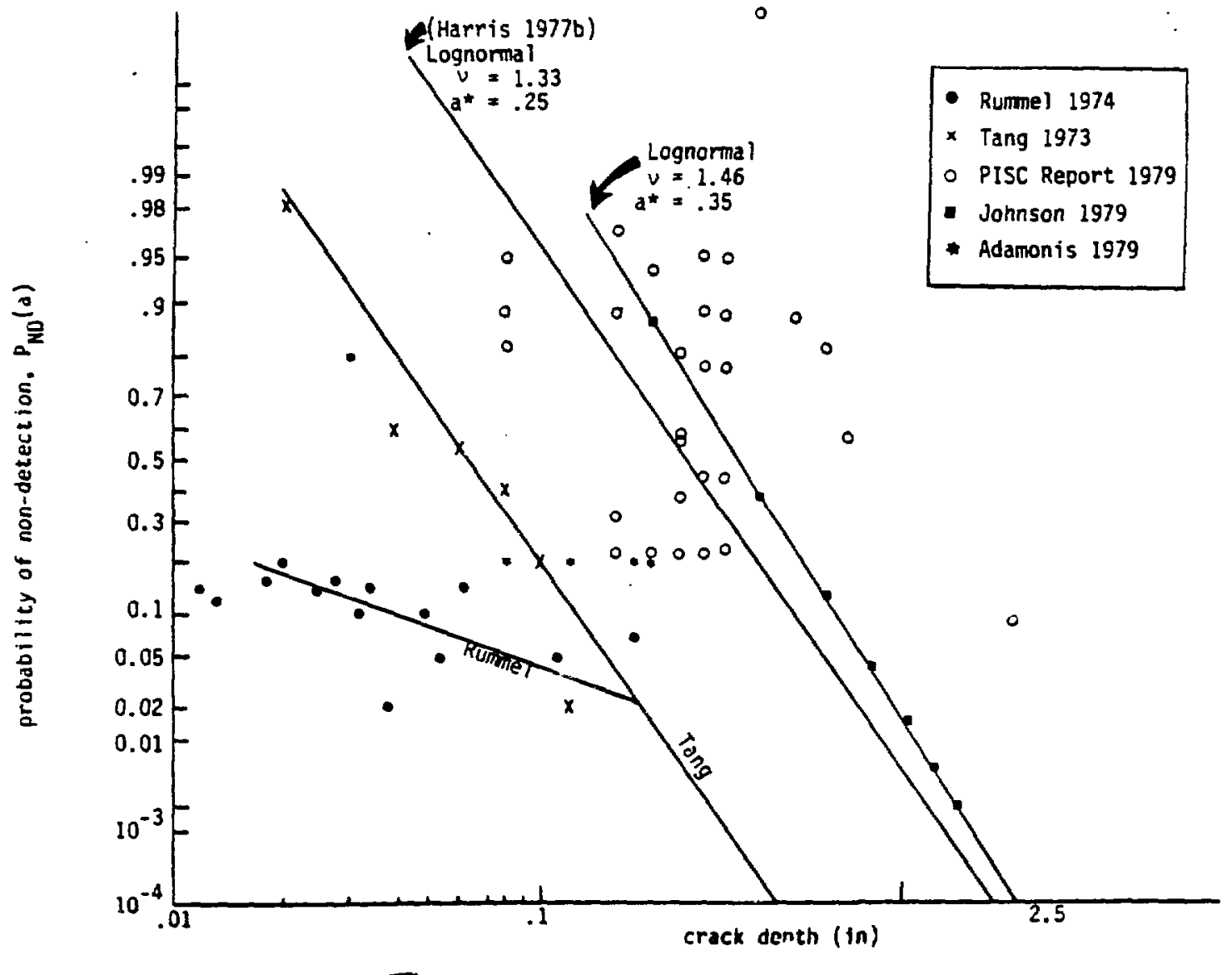

Figure $0-3$

Probability of crack non-detection by ultrasonfc testing as a function of depth as reported by several authors. 


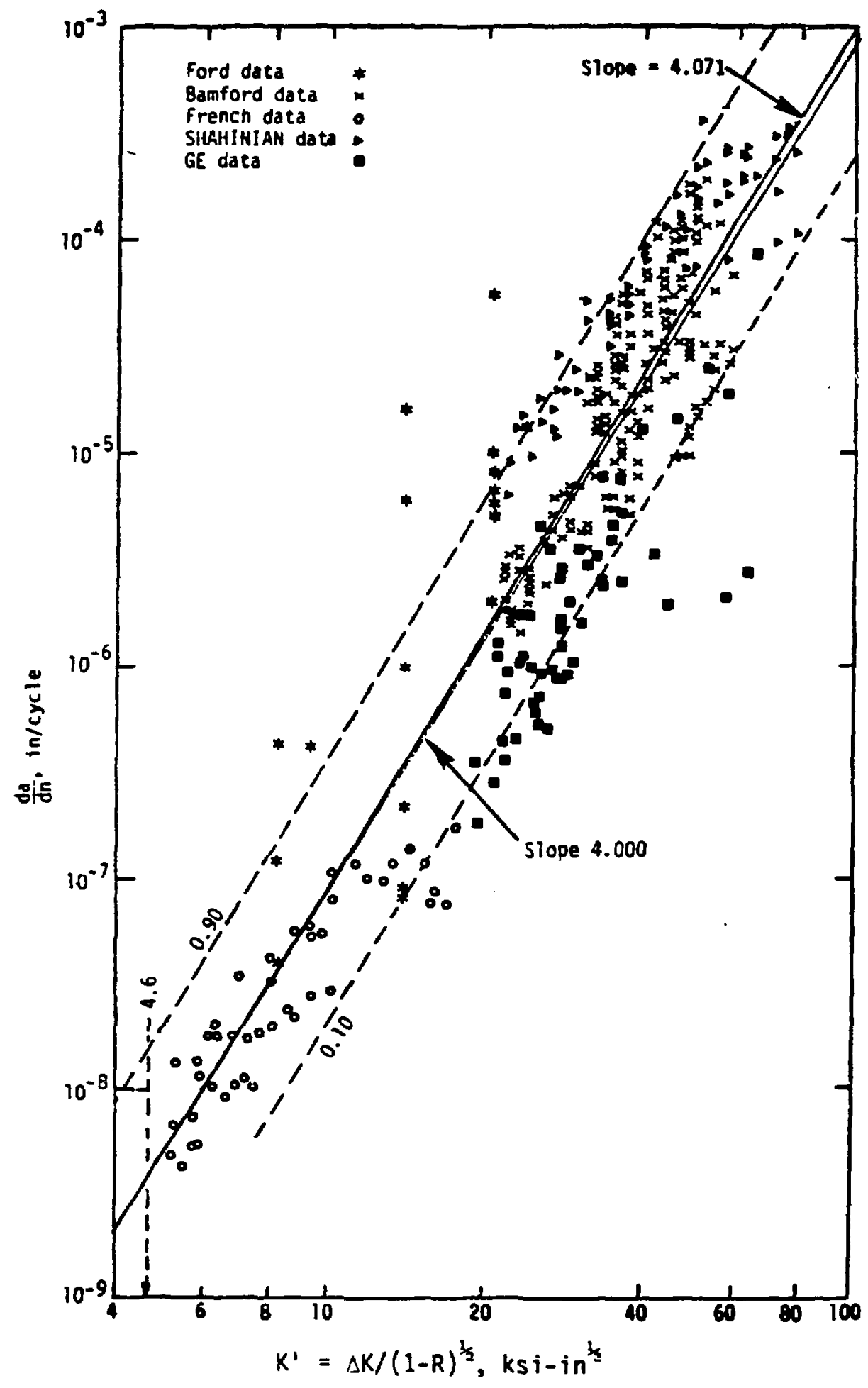

Figure C.4

Fatigue crack growth rate data reported by several authors in terms of depth (a) per cycle $(n)$ as a function of the effective stress intensity. Least square fitted curves are included. 


\section{6 Final Failure}

Final fallure of the pipe may be estimated by either exceedance of Rice's J-integral (Rice, 1968) and the tearing modulus or exceedance of the critical net section stress (see Appendix A.3 of this report and also refer to Harris, 1981). Basically Tada, 1979 show that reactor piping is not subject to tearing instability for length-to-diameter ratios representative of primary reactor piping in Links.

The other failure criterion that could come into play is the critical net section stress criterion for very large cracks that reduce the pipe cross sectional area to the point that the loads are not relaxed by extensive deformation are sufficient to break the remaining area.

\section{7 Numerical Simulation}

Any case (trial) of the PRAISE-B methodology requires the calculation of many uncertain parameters known according to some probability distribution. A practical technique for determining the probability distribution of pipe break or leakage is a Monte Carlo simulation in a value for each of the parameters is selected at random from the distribution of the parameter. After a full set of parameters has been selected, the PRAISE algorithm is exercised and one trial is calculated to determine if the selected set of parameters resulted in a break or leak. The probability of, a break is

$$
P_{\text {broak }}=\lim \frac{\text { Number of Breaks }}{\text { Number of trials }}
$$

This is true in the limit that the number of trials becomes infinite. A direct evaluation of equation $C-4$ in which the parameters are selected according to their modeled frequencies of occurring is computationally inefficlent especially if the probability of a rare event such as pipe break is sought. Furthermore, the simulation of a single occurrence is not sufficient because a number of occurrences is needed for statistical significance.

There are several techniques for increasing the accuracy of Monte Carlo simulations for a given amount of computational time. The method used in PRAISE-B is stratified sampling. The basic scheme is to partition the sample space into a set of mutually exclusive cells. A pre-determined number of samples are then selected from each cell. Within each cell, the individual crack dimensions (or other parameters) are selected according to the estimated crack size distribution. The distribution of the first time to failure is calculated with allowance for the conditional probability of a crack existing in a given cell. 


\section{8 Relationship of PRAISE-B To the ANS Desion}

The PRAISE-B code and the supporting documentation represents extremely detailed application of probabilistic fracture mechanics to the pipe break and pipe leak problems. A caviat is the coment of Thonas, 1980 that fatigue crack growth constitutes a small fraction of the observed pipe failures. PRAISE-B also contains stress corrosion and residual stress calculations which with the seismic analysis, represent the major changes from the original PRAISE code. The details of these treatments are less than the emphas is on fatigue crack growth. It would be difficult to estinate how well PRAISE-B could calculate the observed pipe failures such as those providing the statistics of Appendix B. It would seen to be a fair guess that it would not model all nor would the probabilities calculated by PRAISE-B be in full agreement - considering the difficult of the modeling and the uncertainties in the data used in PRAISE-B.

It also seems that PRAISE-B is a complex code requiring extensive computer time to perform the Monte Carlo simulations hence of limited usefulness for multiple cases to be studied in design. 


\section{APPONDIX D}

REVIEW OF THE OCTAVIA AND NUREG-0778 CODES

\section{1 Qctavia \\ D. 1.1 overview}

OCTAVIA (Operationally Caused Transients and Vessel Integrity Analysis, Vesely et al.,1978) is a code that was developed specifically for analyzing PWR reactor pressure vessel fallure probability under translent loading. The computational method involves two steps; the first one is the calculation of the pressure which will fail a vessel with center-IIne axially orlented flaws. The second step is the calculation of the probability that such a pressure or greater will be experienced. The combination of the two steps gives a probabllity of pressure vessel fallure in the center-1ine region. OCTAVIA is the predecessor of several other codes using the linear elastic fracture mode1: OCA-P (Cheverton, 1984), VISA (Stevens, 1983) and NUREG-0778 (Gamble and Strosnider, 1981 - no code name). Both OCTAVIA and NUREG-0778 codes are reviewed here because of their relationship and their NRC origination.

\section{D.1.2 Critical Pressure Calculation}

In relating reactor pressure vessel (RPV) failure pressure for various flaw sizes, there are 4 distinct reglmes as depicted in Figure D-1. In terms of increasing pressure, these are: 11near-elastic fracture mechanics (LEFM), gross yield plateau, elastic plastic fracture mechanics and the upper shelf plastic instability. The LEFM regime is the governing regime for pressures up to the gross yleld pressure of the vessel and also is the best understood because of significant recent advances in LEFM. The equations describe the imposed stress intensity factor at the deepest point in a semi-elliptical flaw and contain the important parameters which may be used for sensitivity studies. The gross yield plateau manifests a similar phenomenon in the stress strain relationship for the RPV materials. The EPFM regime reflects the additional toughness that is avallable if the material is capable of straining into the strain hardening region as described by Bryan, 1975a.

The calculation of the pressure at vessel fallure in OCTAVIA have been performed by the methods in Merkle, 1975. Unfortunately, the referenced document uses several methods so the actual one(s) used is not clear and methods for 3 regines are presented.

\section{D.1.2.1 Distribution of Flaw Depths}

The determination of the pressure at which fracture of the vessel will occur depends upon the flaws that it contains in the belt line region. Table D-1 fron Vesely, 1978 reports a distribution of flaw depths based on operatlonal information and discussions with metallurgical personnel. The flaw sizes indicated in Table $D-1$ are the center of the range from the midpoint to the next value. For exauple, the size 0.125 represents the range from 0 to 0.183 and 0.25 the range fron the latter value to 0.375 . A difference between OCTAVIA and sinilar codes lies in the assuned flaw distribution. 


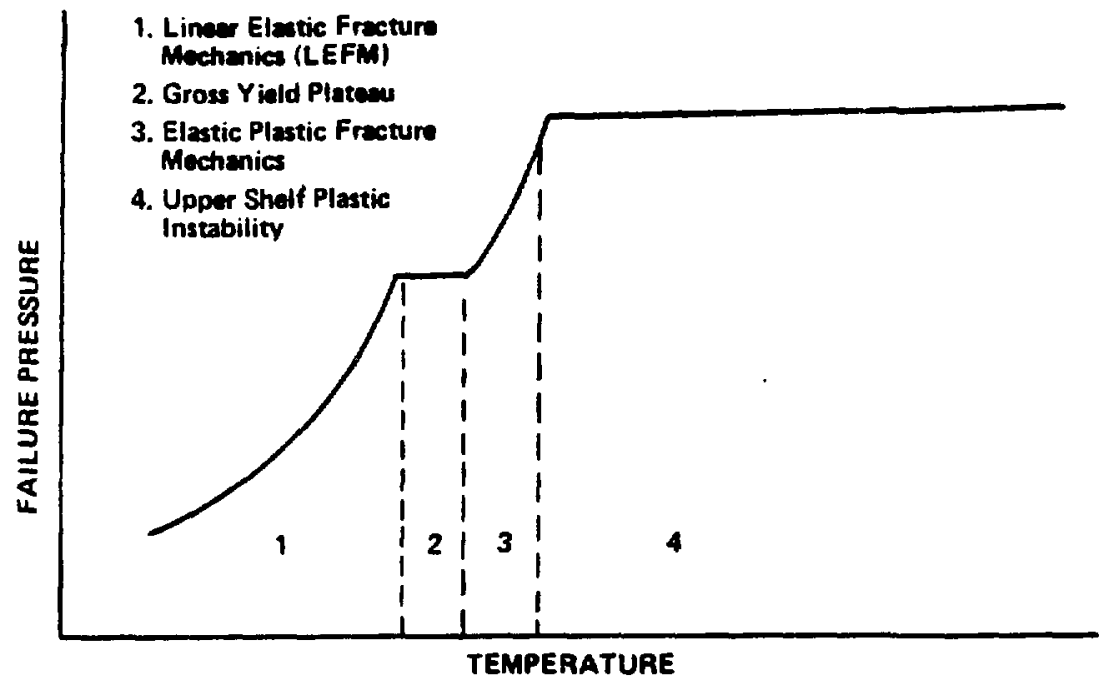

Figure $D-1$

Four regimes of pressure as a function of temperature.

Table D-1

Flaw Distribution Based on Operational Information and Expert Opinion

Flaw Size S (inches) Probability $P_{8}$
0.125
0.25
0.25
0.125
0.5
0.025
1.
0.0025
2.
0.00025
3.
0.000025 


\section{D.1.2.2 Linear Elastic Fracture Mechanics}

Merkle, 1975 refers to Merkle, 1974 to calculate the linear elastic stress intensity factor at the deepest point of the flaw as:

$$
K_{I}=\operatorname{CS}_{3} \sqrt{\pi a} \text {, }
$$

where $S_{\text {. }}$ is the outside surface circumferential stress, a is the flaw depth and $C$ is the nondimensional shape factor

$$
C=M_{1} M_{2} / \phi
$$

where $M_{1}$ is the front-face free surface magnification factor

$$
M_{1}=1.025+0.055(\mathrm{a} / \mathrm{w})
$$

and $M_{2}$ is the back-face free-surface magnification factor

$$
M_{2}=\left(\frac{\tan \pi a / 2 w}{\pi a / 2 w}\right)^{1 / 2}
$$

and $\phi$ is the complete elliptic Integral of the 2 nd kind which may be approximated as

$$
\phi^{2}=1+4.593(a / 2 b) 1.65
$$

By elastic stress analysis, the relationship between the internal pressure and the outside circumferential stress and strain for the model calculated In Merkle, 1975, are:

$$
S_{s}=9.641 p
$$

\section{D.1.2.3 Elastic-Plastic Fracture Mechanics}

Merkle, 1975, performs this analysis using the tangent modulus method of Bryan, 1975a, for which the basic equation is:

$$
\mathrm{d} \varepsilon \sqrt{\rho}=2 C \sqrt{a} \sqrt{\frac{E_{\varepsilon}}{E_{2}}} d \lambda
$$

where $\varepsilon$ and $\rho$ are the notch root strain and root radius, respectively, $C$ is the LEFM shape factor presented in the previous section, a is the crack depth, $E_{B}$ is the tangent modulus corresponding to the gross strain, $E_{3}$ is the strainhardening tangent modulus at the notch tip, and $d \lambda$ is the nominal (gross) strain at the flaw location. The value of dc at fracture is obtained by integrating equation $D-7$ and is directly related to the value of $K_{I_{c}}$. The incremental method is suited to determining increases in fracture toughness into the plastic instability regime. 


\section{D.1.2.4 Upper Shelf Plastic Instability}

An upper limit to the failure pressure of a cylindrical pressure vessel containing an external part-through crack can be estimated as the pressure at which plastic instability occurs in the region surrounding the flaw estimated as (Derby, 1974):

$$
P_{f}=S_{\theta}(Y-1)\left(1-A_{c} / A\right)
$$

where $Y$ is the ratio of the outer to inner radil of the RPV, is the plastic flow instability stress estimated as 1.07 times the average of the yield and ultimate stresses, $A_{c}$ is the crack area and $A$ is the effective load-bearing area containing the flaw as calculated from

$$
A_{c}=\frac{\pi(a+\Delta a)(b+\Delta b)}{2}
$$

and

$$
A=[2(b+\Delta b)+w] w
$$

where $\Delta a$ and $\Delta b$ are estimates of the stable crack growth area that occurs prior to maximum load.

\section{D.1.3 Probability Calculation}

\section{D.1.3.1 Probability of Pressure Translents}

Vesely, 1978, calculates the pressure transient probability distribution using data from operating US nuclear power plants before 1977 which exceeded 800 psi. A plot of these normalized to unity are presented in Figure D-2.

\section{D.1.3.2 Probability of Vessel Failure}

The probability of vessel failure is the joint probability that a transient will occur $\left(P_{I}\right)$ and the probability that it has pressure sufficient to fail the vessel as calculated by the formula

$$
P_{T}-T R \star \exp \left(-\left(p_{t}-800\right) / P\right)
$$

where TR is the rate per year for transients exceeding 800 psi; $p_{1}$ is the failure pressure for $\mathrm{flaw}_{1}$ and $\mathrm{P}-800$ is the average maximum pressure associated with the transient. Formula D-11 is based on statistical analyses of the data. TR $=0.080 / \mathrm{yr}$ and $\mathrm{P}-440 \mathrm{psi}$ are best estimate evaluations. The upper 958 confidence bounds are: $\mathrm{RT}-0.136 / \mathrm{yr}$ and $\mathrm{p}_{\mathbf{1}}-806 \mathrm{psi}$.

Best estimate results from OCTAVIA for the Surry pressure vessel are a failure probability of $1 . E-7$ to $3 . E-5$ at $40^{\circ} \mathrm{F}$ with the fluence varying from 1.E-17 to $6 . \mathrm{E}-19 \mathrm{n} / \mathrm{cm}^{*} \mathrm{~cm}^{*} \mathrm{sec}$. At a vessel temperature of $200^{\circ} \mathrm{F}$ the probability ranges from 2.E-9 to $3 . \mathrm{E}-5 / \mathrm{yr}$. So the effect of temperature is minimal at high fluence. 


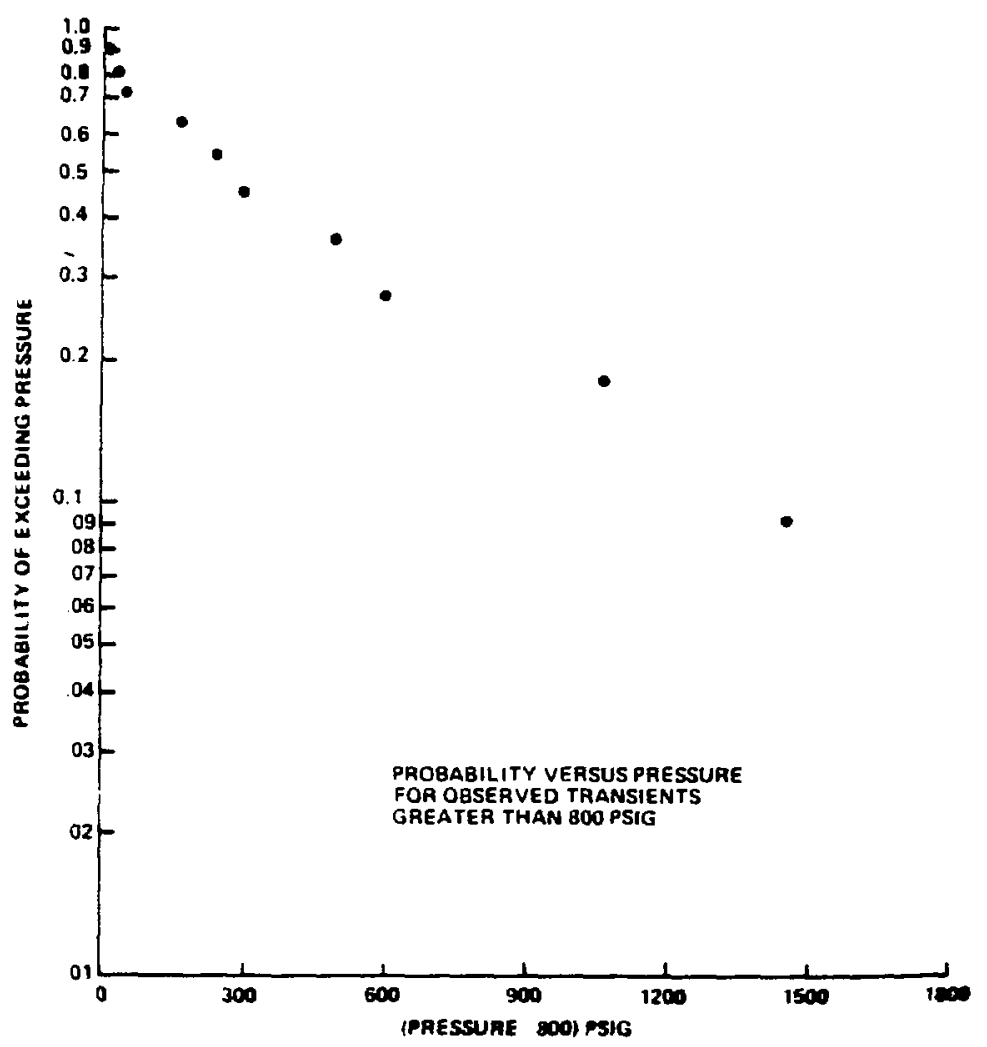

Figure $D-2$

Normallzed probability of pressure transients $>800$ psig.

\section{D.1.4 Differences between OCTAVIA and the HSST Methods}

While OCTAVIA generally follows Merkle, 1975 for the calculation of the rupture pressure, it deviates with regards to the methods for calculating the effects of radiation and fracture toughness as a function of temperature. OCTAVIA uses the algorithm for calculating the effects of radiation degradation presented in Regulatory Guide 1.99 and presented in here in Appendix A. Vesely, 1978 justifies this change on the basis of conservatism, particularly with regards to the residual elements in the steel. Furthermore, only internal flaws are considered because they are more critical in the presence of radiation than external flaws.

OCTAVIA uses the data relating fracture toughness to temperature that was developed in ORNL-TM-4914 as being more representative of the average fracture toughness data developed in the HSST program than that in Merkle, 1975. Vesely, 1978 performed a regression analysis on this data to obtain the following representation:

$$
R I_{c}-a+c e^{b t}
$$

where $\mathrm{RI}_{c}$ is the best estimate of the toughness, $t$ is the temperature ( ${ }^{\circ} \mathrm{F}$ ) and $a=36.94( \pm 1.011), b=0.01794( \pm 0.002179)$, and $c=40.73( \pm 3.655)$. The numbers in the parentheses are standard deviations. 


\section{2 NUREG-0778 Mode1.}

\section{2.1 Overview}

The purposè of this work was to assess the failure rate in the beltline region of a generic PWR pressure vessel. Its objectives were to:

- Better define the effects on neutron radiation, material variation and flaw distributions on the failure rate in the beltilne region,

- Estimate the relative margins against failure for normal and transient operation, and

- Evaluate current limitations in fracture mechanics models for the prediction of failure rates for nuclear pressure vessels.

This code is a direct descendant of the OCTAVIA code and is believed to be an improvement over it by better information on the distribution of flaw sizes, separate analysis for pressure, thermal and residual stress and the convolution of results using Monte Carlo methods.

\section{D.2.2 Methodology}

The computer code that was developed (no name) is based on LEFM to model the variable interactions and to estimate failure by comparison of the potential for flaw-induced fracture $K_{I}$ to exceed the material's resistance $K_{I C}$. Failure is postulated when the former exceeds the latter. The values of $K_{I}$ and $K_{I C}$ are determined by combinations of operational and materlal variables. Generally, $K_{I}$ depends on the flaw size, and stress in the pressure vesse1. The $K_{\text {IC }}$ as shown in Figure A-1 is a function of the neutron fluence, copper and phosphorous (or equivalent) content. For convenience these factors are combinerl to produce an adjusted reference temperature $\mathbf{R T}_{\mathrm{nDr}}$. Because these parameters are random with complex interactions, Monte Carlo methods were used to study the effects of varlous randon combinations - weighted by their probability of occurrence. Figure D-3 shows this process.

The simulation cycle deplcted in Figure D-3 represents a single computer experiment conducred to determine if a single occurrence of a specific operational event will produce failure of the reactor vessel. To determine the failure rate, the cycle is repeated up to 1. E6 times and the failure rate is calculated from the number of fallures to the number of trials. This is the conditional probability of failure given a pressure transient and the probability of failure is the product of this conditional probability and the transient frequency.

The potential for flaw induced fracture $K_{I}$ is separated into components for pressure, thermal and residual stress as:

$$
K_{I}=a \sqrt{\pi a} \sum_{i=1}^{3} \sigma_{1} F_{1}
$$




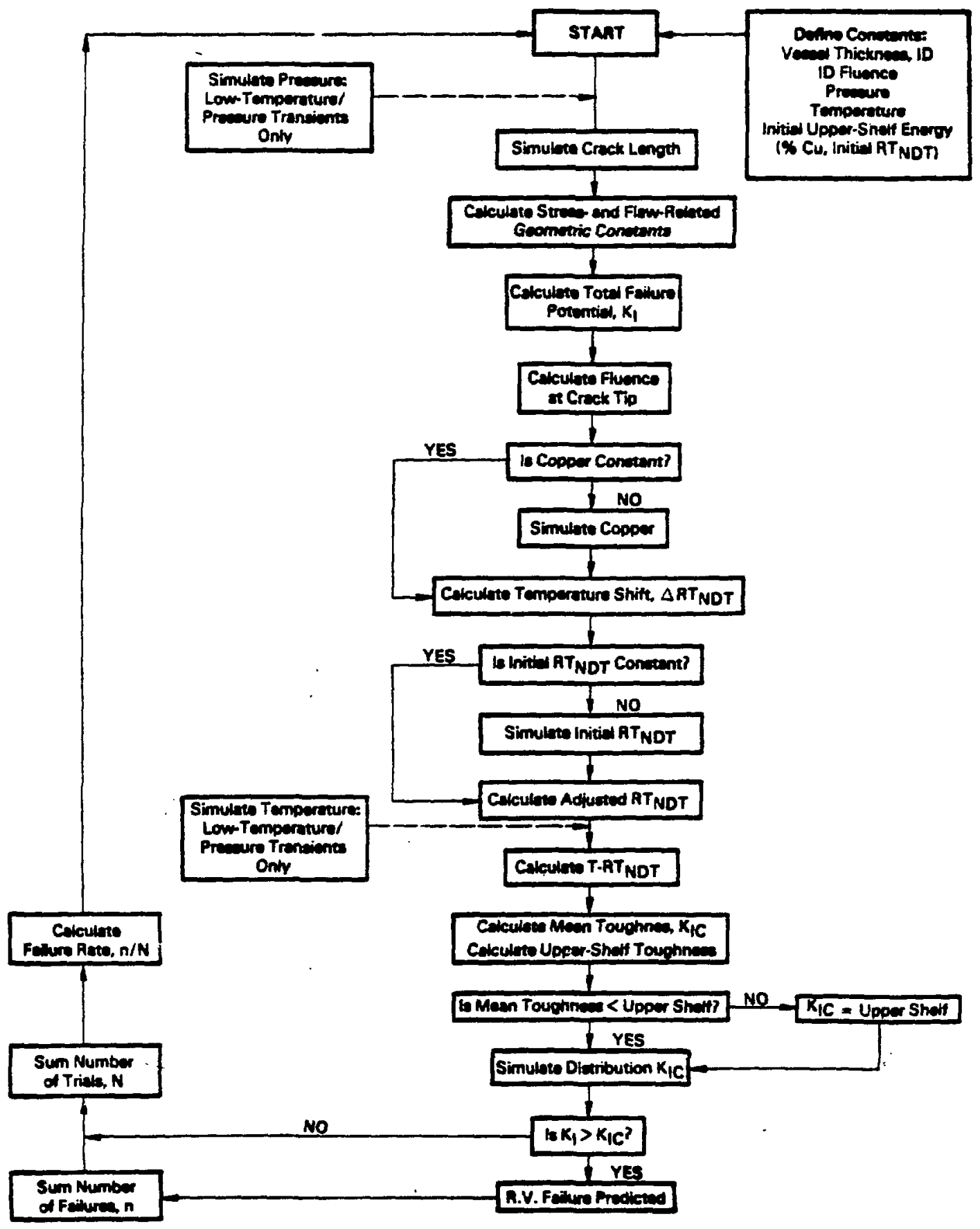

Figure D-3

Procedures in Monte Carlo simulation of vessel failure. 
where a - radial depth of a flaw that extends from the vessel surface part way through the vessel wall, a = flaw shape factor, $\sigma_{1}$ - maximun stress for the $i^{\text {th }}$ stress distribution, and $F_{1}$ - modifying function for the $i^{\text {th }}$ stress distribution.

The $F_{1}$ functions used in NUREG-0778 are presented in Figure D-4 as functions of the ratio of the flaw depth to the wall thickness. The pressure stress is based on membrane theory; the residual stress distribution is estimated to be sinusoidal with a maximun of $8 \mathrm{ksi}$ at the inner and outer surfaces and compression at the midwall. The anount of thermal stress is due to heatup or cooldown at $50^{\circ} \mathrm{F} / \mathrm{hr}$ and at other tines it is taken to be zero. The flaw shape factor, $a$, is taken to be constant at 0.89 corresponding to a semi-elliptical surface flaw having a length to depth ratio of 6 . The independent variables used in each Monte Carlo simulation are pressure and crack depth. For each simulation, the crack depth is sampled from a statistical distribution.

While much of the data needed for NUREG-0778 was obtained from operating experience with PWRs, very little data are avallable on flaw sizes because the information needed is on the flaws that have not been detected. NUREG-0778 made no attempt to collect new information on the flaw distribution but instead used the distributions of Vesely, 1978 and Marshall, 1976 which are shown in Figure D-5. The weld volume in OCTAVIA was defined as the volume in the beltline of a PWR without reference to the total volume while Marshall defined the flaw distribution with respect to the total volume of the reactor vesse1. The normalization used in NUREG-0778 is that the beltine weld volume is 0.01 of the total vessel volume and the circumferential beltine weld volume used in Figure D-5 is 0.02 of the total. The left-most dashed lines in Figure D-5 represent the preservice crack distributions. Even though the crack distributions are shown as continuous curves, Monte Carlo simulation requires discrete values which were chosen to be 9 ranging from 0.25 to 3.5 inches.

NUREG-0778 also uses different fracture toughness values than OCTAVIA and in particular, uses data fron Shabbits, 1969 taken in the HSST program surveillance programs from PWRs and presented as Figure D-6. These data are used in the NUREG-0778 computer code by fitted 2 displaced exponential distributions with a break between the curves at $-16^{\circ} \mathrm{F}$.

In the upper shelf region the fracture toughness is represented as:

$$
K_{I C}=\sigma_{Y}\left(5 C V N / \sigma_{Y}-0.25\right)^{t}
$$

where CVN is the Charpy $V$-notch test upper shelf energy in foot pounds and $\sigma_{y}$ is the material yleld strength in ksi. CVN decreases with neutron irradiation which was taken to correspond to the Regulatory Gulde 1.99 prescription. Some result for vessel fallure probabilities as a function of pressure and temperature are shown in Figure D-7 for 10 EFPY (effective full power years) and end of life. 


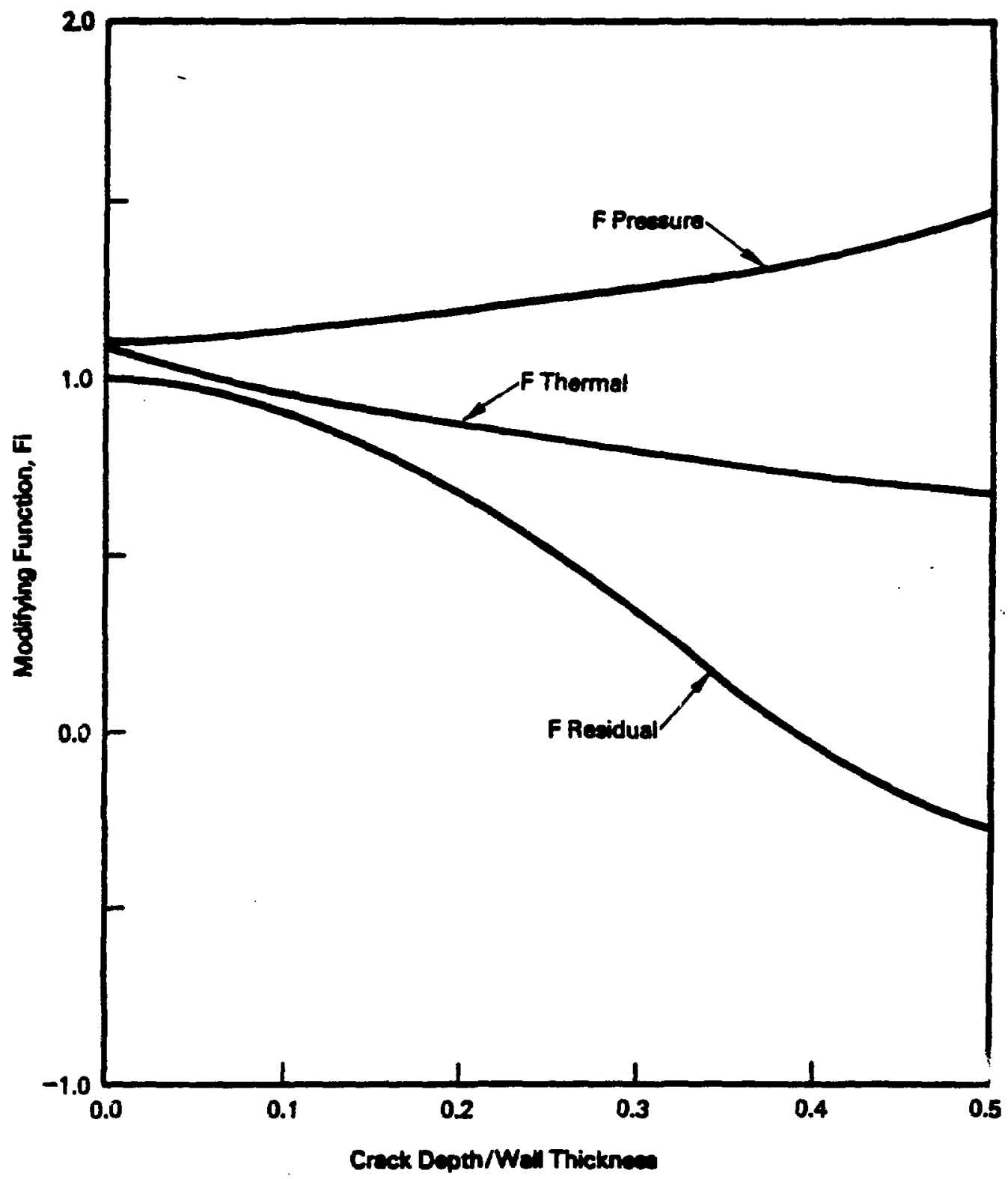

Figure D-4

Stress intensity modifying function relative to the depth to wall thickness. 


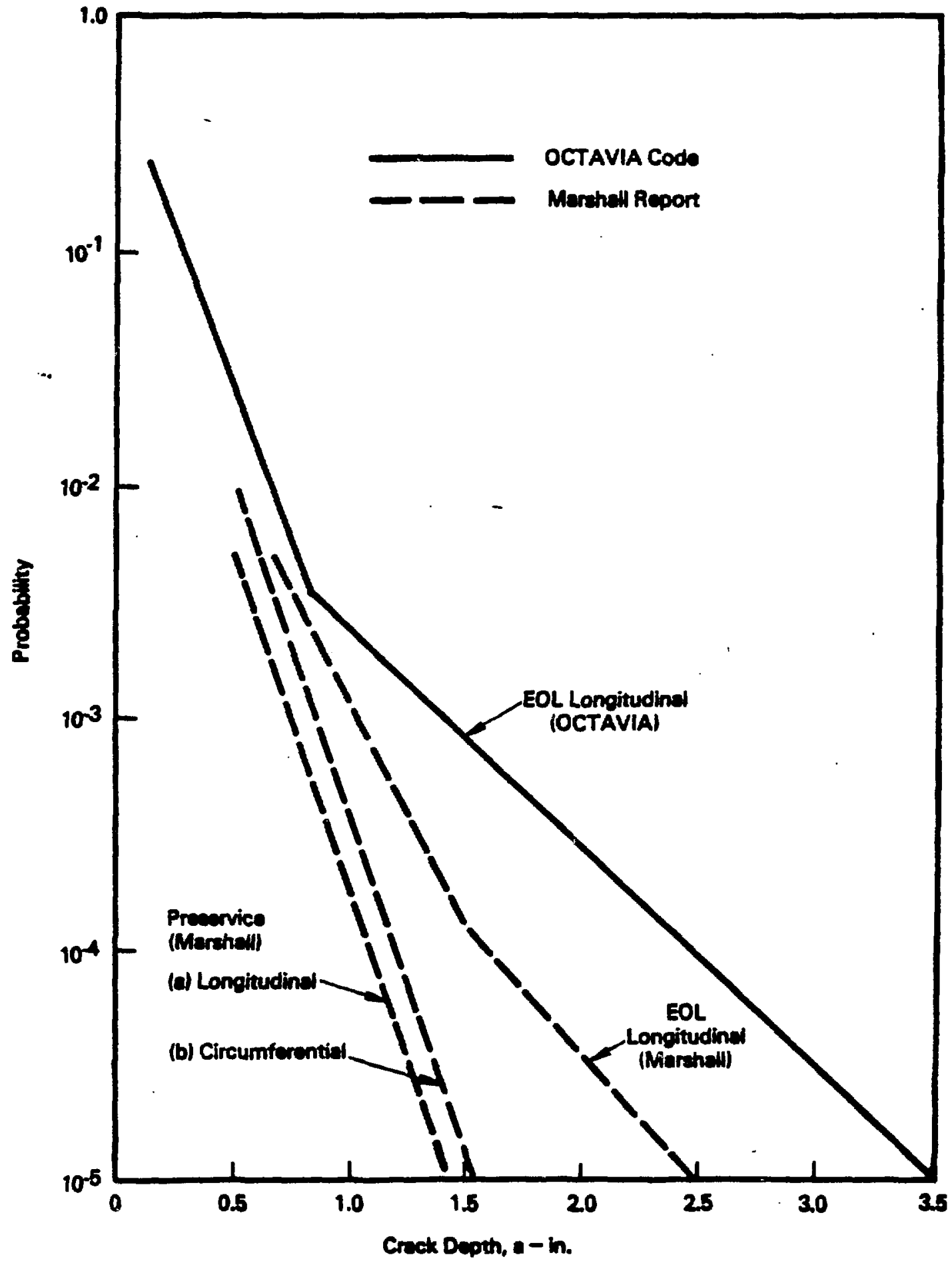

Figure D-5

Reactor beltine flaw distributions (fron NUREG-0778).

D- 10 


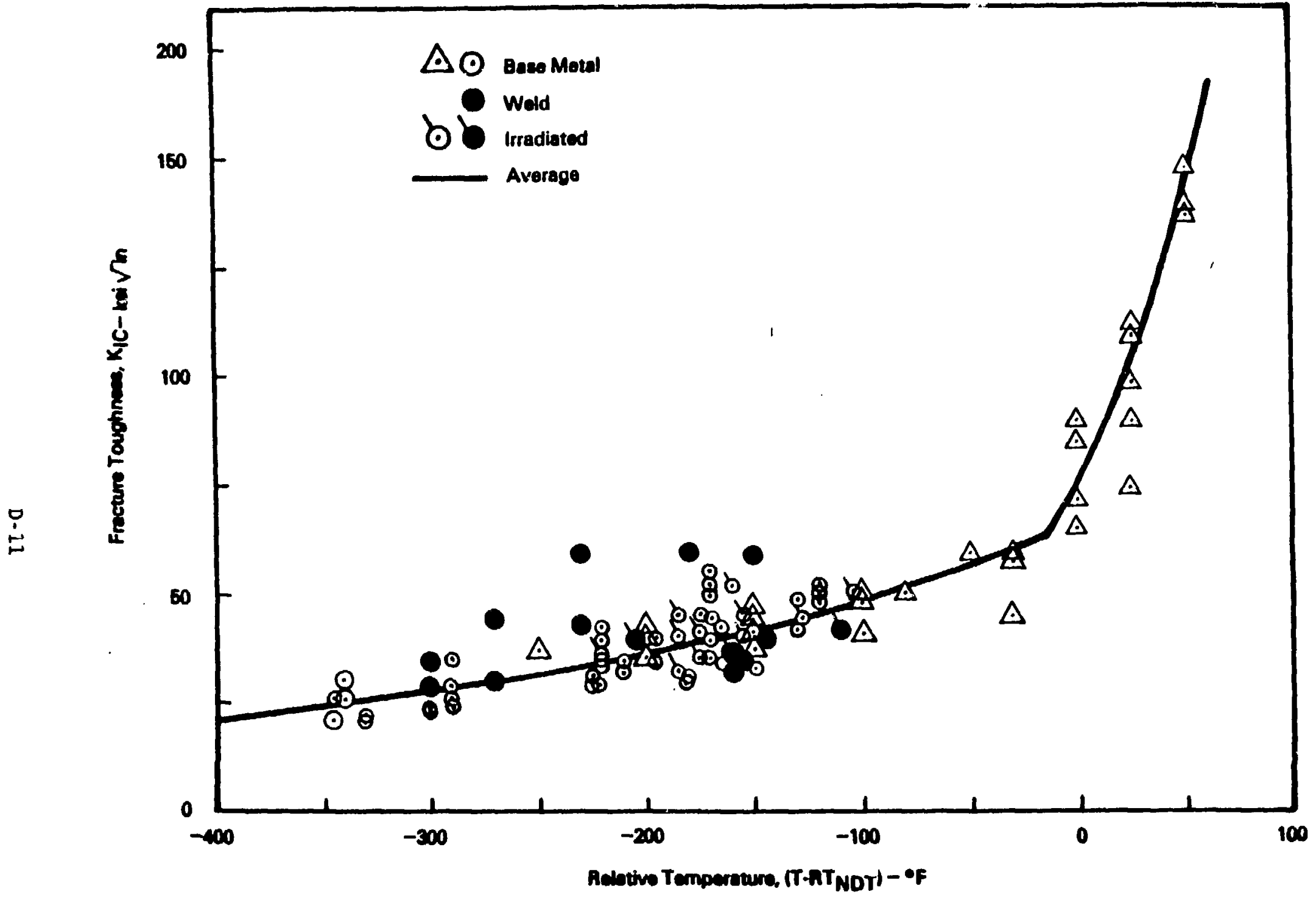

Figure D-6

Fracture toughness as measured in HSST and surveillance. 

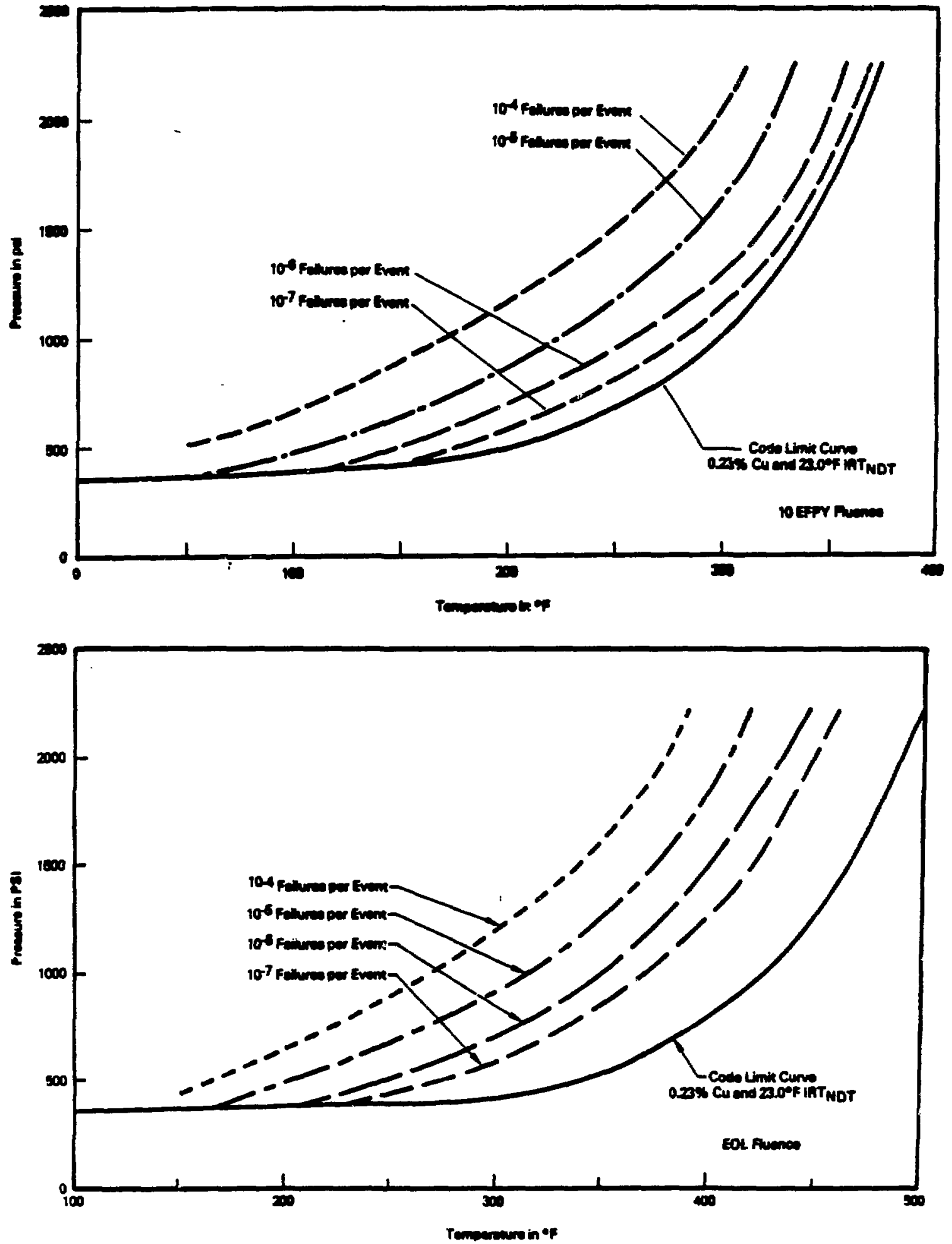

Figure D-7

Constant failure rate and code-allowable pressure temperature paths for reactor shutdown at 10 EFPY (upper figure) and at EOL (lower curve). 
The pressure transient frequency used in NUREG-0778 is that of OCTAVIA however NUREG-0778 performed some investigation of these data through simulation and sensitivity studies. The results of NUREG-0778 were validated to some extent by comparisons with the deterministic calculations of OCTAVIA.

\section{3 Relevance of Octavia and NUREG-0778 to ANS}

NUREG-0778 represents a refinement of the methods used in OCTAVIA but would require considerable adaptation for deternining pipe break probabilities for ANS. Like OCTAVIA it calculates the probability of beltine vessel fracture as a function of pressure, temperature, fluence and material composition subject to a pressure transient. Considerable work would be necessary to convert this to a piping analysis and if this were done, it would only provide analyze of this one cause (albeit a catastrophic type) of pipe failure. Comparisons should be made with Thomas (Appendix G) to estimate the completeness that would be afforded. It would not, for example, include stress corrosion cracking. Furthermore, neither of these codes contain algorithms for the growth of imperfections through stress cycles thus aging is only a function of Irradiation. 


\section{APPENDIX E}

\section{REVIEW OF OCA-P, THE ORNL DETERMINISTIC AND PROBABILISITIC}

FRACTURE-MECHANICS CODE FOR PRESSURE VESSELS

\section{E. 1 Qverview}

OCA-P (Cheverton, 1984) $)^{1}$ is a probabilistic fracture-mechanics code for evaluating the integrity of PWR vessels subject to overcooling accidents (pressurized thermal shock). It is based on linear-elastic fracture mechanics, has two dimensional and limited three-dimensional flaw modeling capability and can treat cladding as a discrete region. As a deterministic code, it can conduct a search for critical values of fluence and nil-ductility reference temperature corresponding to flaw initiation. As a probabilistic code, OCA-P uses Monte Carlo methods for calculating the probability of vessel failure as a function of: fluence, flaw depth, fracture toughness, nilductility reference temperature, copper, nickel and phosphorous. The code provides plots of critlcal crack depth diagrams for the deterministic analysis and histograms for the probabilistic analysis.

OCA-P accepts as input, the reactor primary system pressure and the reactor vessel downcomer coolant temperatures as functions of.time in the transient and it calculates the wall temperatures and stresses as a function of time and radial position in the vessel wall. The stress intensity factors are calculated as a function of crack depth and time.

In the deterministic mode, the values of the static crack initiation toughness $\left(\mathrm{K}_{\mathrm{Ic}}\right)$ and the crack arrest toughness $\left(\mathrm{K}_{\mathrm{Ie}}\right)$ are calculated and compared with $K_{\mathrm{r}}$ to provide an evaluation of flaw behavior. The deterministic aspect of OCA-P was developed in the code OCA-II (Bal1, 1984); the probabilistic aspect in the contribution of OCA-P.

In the probabilistic mode, OCA-P performs the same steps using Monte Carlo sampling from distributions of flaws, times, pressures, and positions. For each of the "vessels", a deterministic fracture mechanics analysis is performed as described above to determine if vessel fallure occurred for the sampled ensemble of parameters. The conditional fallure probability is the number of failures divided by the number of trials.

\section{E. 2 Deterministic Calculation}

Figure E.I summarizes the deterministic procedures performed in OCA-P. As shown in the figure, the primary system pressure and the reactor vessel downcomer coolant temperatures are input as a function of time. The coolant temperature is used with a fluid-film heat transfer coefficient in a onedimensional (1-D) thermal analysis to determine the wall temperatures.

1 Presumably the OCA part of the name stands for over-cooling accident and the $P$ stands for probabilistic. 
Conversely the wall temperatures, if known, may be input directly as well as radial varlations in the material properties. The wall temperatures allow a 1-D stress analysis of the un-flawed vessel to deternine the circumferential and longftudinal pressure and thermal stresses as a function of time and position in the vessel wall. If the stresses are known, the may be directly Input.

The stress intensity factors are calculated with a superposition technique described in Ball, 1984 that uses influence functions available in OCA-P for 2-D and 3-D flaws.

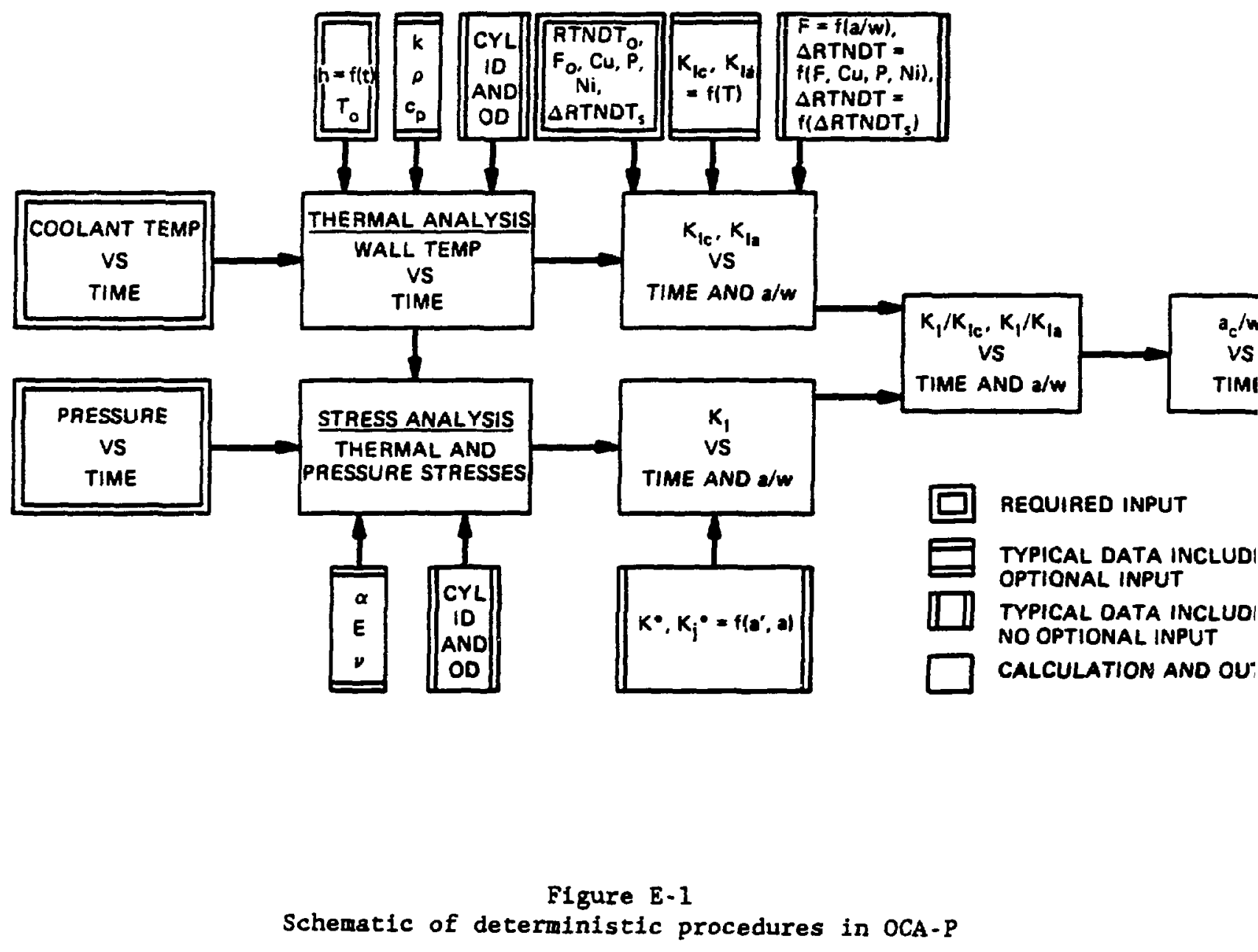


The calculation of $\mathrm{K}_{\mathrm{Ic}}$ and $\mathrm{K}_{\mathrm{I}_{*}}$ as functions of time and radial position uses relations of the type

$$
\begin{aligned}
& K_{I C}, K_{I_{e}}-f(T-R T N D T), \\
& T-f(a / w, t), \\
& \text { RTNDT }-\operatorname{RTNDT}_{0}+\Delta R T N D T, \\
& \Delta R T N D T=f(C u, N i, P, F), \\
& F-F(a / w)
\end{aligned}
$$

where

T - temperature at crack front, ' $C$;

a - crack depth or radial position in wall from inner surface, mm;

w - wall thickness, min;

$t$ - time in transient, $s$ or min;

RTNDT - nil-ductility reference temperature, ${ }^{\circ} \mathrm{C}$;

RTNDT $_{0}$ - initial (zero fluence) value of RTNDT, ${ }^{\circ} \mathrm{C}$;

$\triangle R T N D T$ - increase in RTNDT due to radiation damage, ${ }^{\circ} \mathrm{C}$;

$\mathrm{Cu}, \mathrm{Ni}, \mathrm{P}$ - copper, nickel, and phosphorous concentrations, wt 8 ;

$F$ - fast neutron fluence (neutron energy $>1 \mathrm{MeV}$ ), nuetrons $/ \mathrm{cm}^{2}$.

These are similar to the relations described in Appendices A, C and D and will not be repeated but reference should be made to Covington, 1984 .

OCA-P performs a correction for the fast flux attenuation as

$$
F=F_{0} e^{-m e n}
$$

where $m-0.0094 / \mathrm{mm}$ and performs an approximate correction of the neutron attenuation in the wall.

\section{E. 3 Probabilistic Analysis}

Probabilistic treatment is similar to that of NUREG-0778 and will only be briefly discussed. The parameters used in the deterministic calculation are sampled from normal distributions with parameters as indicated in Table E1 ; the program logic is presented in Figure E-2. It is seen that the calculation begins with the definition of transient in terms of the coolant temperature and pressure. Mean values for the fluence, nickel, copper and inicial $\mathrm{RT}_{\mathrm{NDI}}$ are provided. Values for the crack depth and $\mathrm{dRT}_{\mathrm{KDr}}$ are selected from their distributions as well as weld properties and a calculation of $\mathrm{RT}_{\mathrm{NDF}}$ is performed. A stop way be placed according to information that may be avail. able on the depth at which the crack growth is arrested. The error in $K_{I c}$ is calculated, time is advanced and $K_{I c}$ is recalculated for the new pressure and temperature at this later phase of the transient. $K_{I c}$ is recalculated and a test is performed to determine if $K_{I} / K_{I C}>1$. If it is not, then a test is performed to see if the transient is over and the trial stops. If $K_{I} / K_{I C}<1$ then the crack depth is increased and a test is performed to see if the 
calculation is in the range of plastic instability, if so failure is declared, If not, $\mathrm{RT}_{\mathrm{IDT}}$ and $\mathrm{K}_{\mathrm{I}}$ are calculated and the test $K_{1} / K_{I C}<1$ is performed which if true results in crack arrest and if not checks to see if all crack depth have been calculated. If enough trials have not been performed, the process is repeated and if they have, the probability of vessel failure is calculated as the ratio of failures to trials.

Table E-1

Parameters used in the OCA-P Monte Carlo Simulation

\begin{tabular}{lcc}
\hline Parameter & $\begin{array}{c}\text { Standard } \\
\text { Deviation } \\
(\sigma)\end{array}$ & Truncation \\
\hline Fluence & $0.3 \mu(F)$ & $F=0$ \\
Copper & 0.0258 & \\
Nickel & 0.0 & 2 \\
RTNDT. & $9^{\circ} \mathrm{C}^{2}$ & 2 \\
ARTNDT & $13^{\circ} \mathrm{C}^{2}$ & $\pm 3 \sigma$ \\
$K_{\text {Ic }}$ & $0.15 \mu\left(K_{I_{e}}\right)$ & $\pm 3 \sigma$ \\
$K_{\text {Ia }}$ & $0.10 \mu\left(K_{I_{a}}\right)$ &
\end{tabular}

${ }^{1}$ Normal distribution used for each parameter.

${ }^{2} \sigma(\mathrm{RTNDT})-\left[\sigma^{2}\left(\mathrm{RTNDT}_{0}\right)+\sigma^{2}(\mathrm{ARNNT})\right] 1 / 2$, truncated at $\pm 3 \sigma$.

The flaw-depth density function is taken from the Marshall report (Marshall, 1976).

$f(a)=0.16 c^{-0.16 n, m-1}$,

where

a - crack depth, mm

$f(a)$ - (fraction of cracks with depths in the range $a \rightarrow a+d a$ )/da.

The probability of non-detection is also taken from this report as

$B(a)=0.005+0.995 e^{-0.113 a}$

Both of these are plotted in Figure E-3.

Convergence of the Monte Carlo calculation may be accelerated by stratifled sampling (Rubinstein, 1981) which divides the sampling space into discrete intervals thereby forcing the sampling in low probability intervals. This produces $a$ blasing that must be corrected.

OCA-P also computes the uncertainties in the prediction of the probabil. ity of vessel failure by propagation of the varlances in quadrature. 


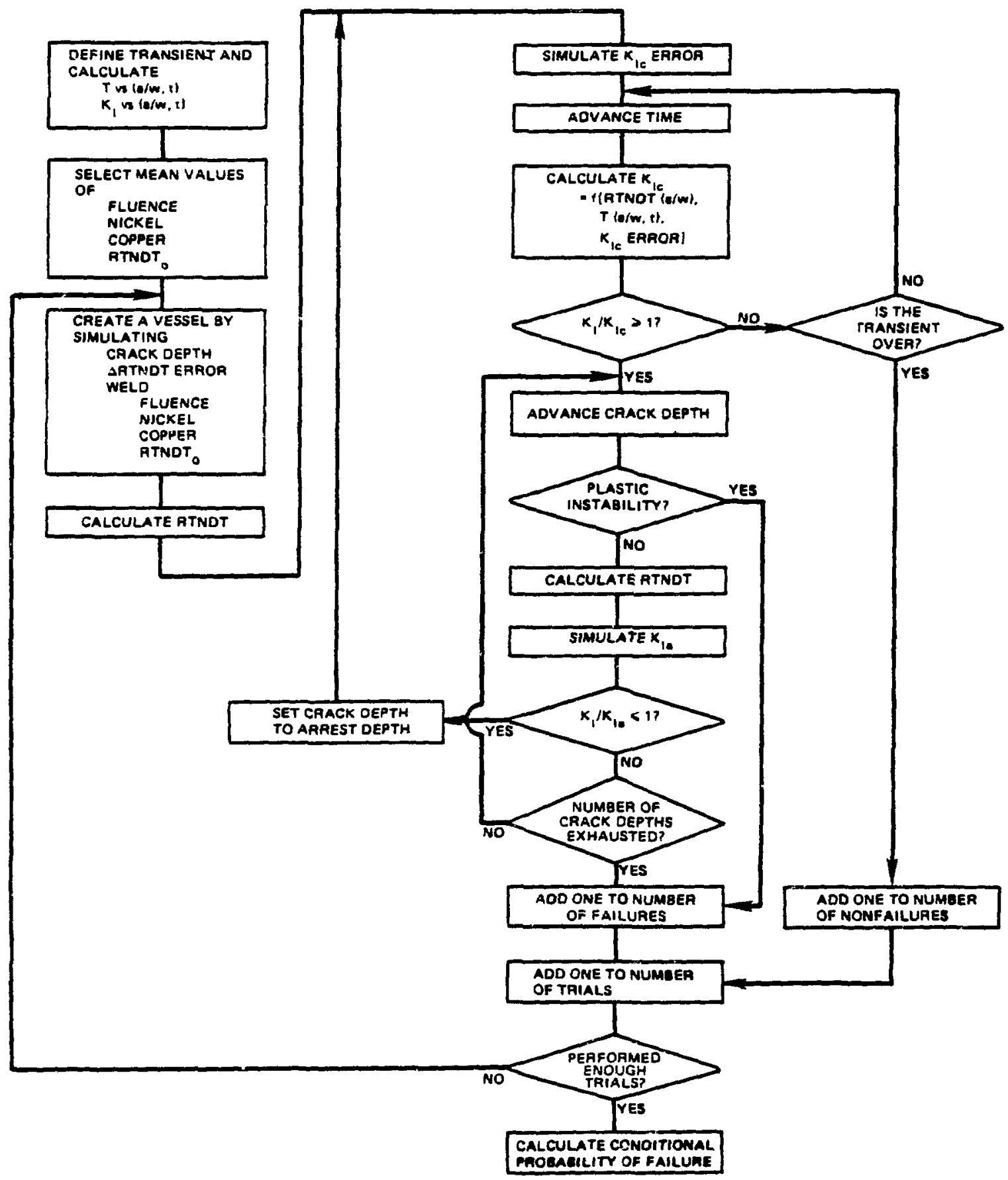

Figure E-2

Program logic used in the Monte Carlo simulation 


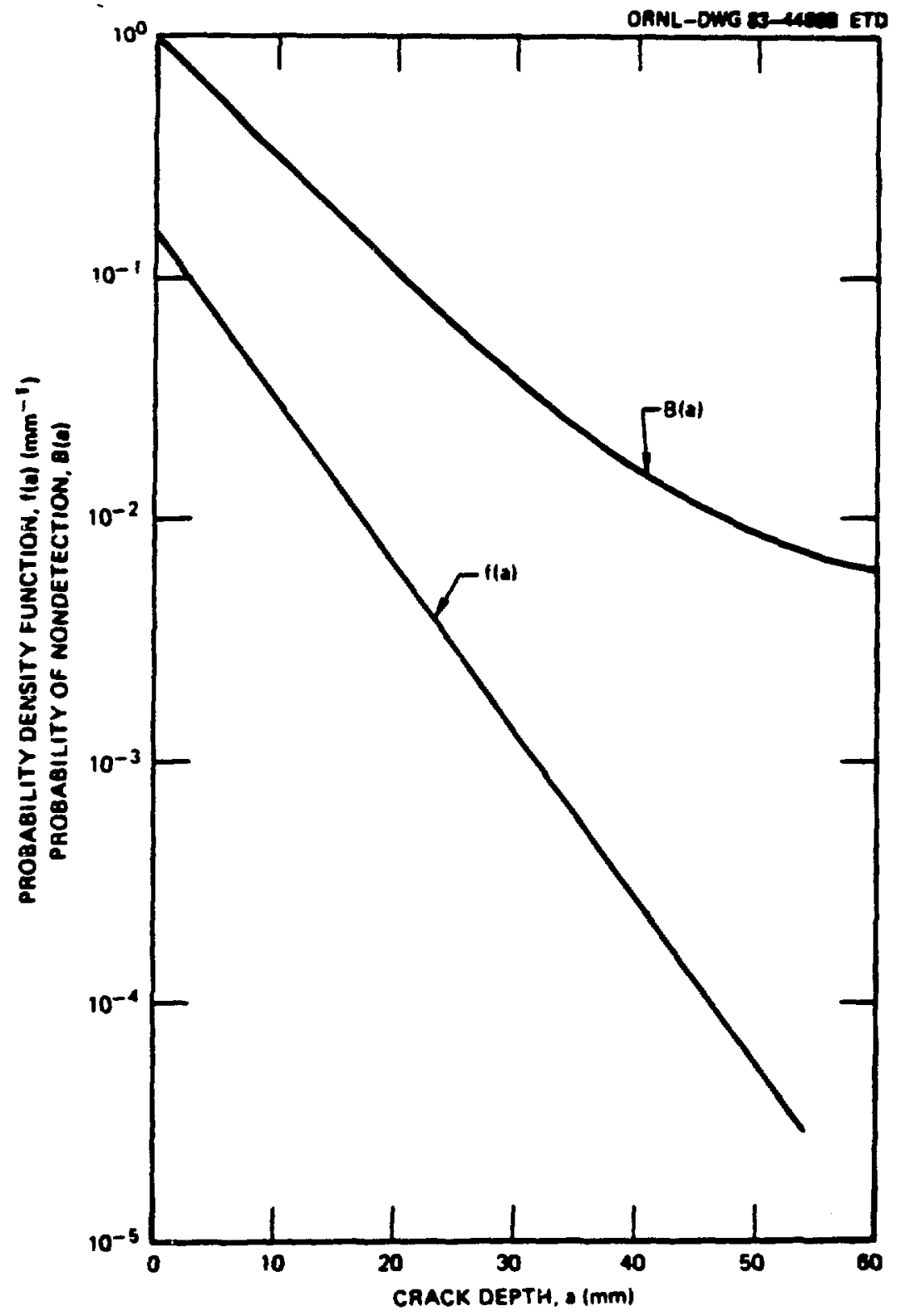

Figure E-3

Flaw-depth density and non-detection probability

(from Marshall, 1976)

\section{E-6}




\section{E. 4 Relevance of OCA-P to ANS}

OCA-P is similar to OCTAVIA and NUREG-0778 but has additional features. Like these, it is concerned with the calculation of the probability of centerline reactor vessel failure from a pressure transient or an overcooling accident. OCA-P has some desirable features such as the accelerated Monte Carlo convergence and the non-detection probability. In discussions with Cheverton, it appears that considerable work would be necessary to reconfigure the code for the analysis of pipe break. Residual stresses would need to be introduced for example but the end result would not represent all modes of pipe fallure so would not be the full probability. The ability of any code to predict the absolute probability may be asking too much. It may be better to depend on a model based on material propertles to predict the variation with parameters and to normalize the code to field observations. The appropriateness of the use of normal parameter distributions in OCA-P was not demonstrated in the report and even if they are suitable for vessel fracture, they may not be suitable for pipe fracture. 


\section{APPENDIX F \\ REVIEW OF VISA, THE PNL DETERMINISTIC AND PROBABILISTIC \\ FRACTURE-MECHANICS CODE FOR PRESSURE VESSELS}

\section{F.1 Overview}

The VISA code (Stevens, 1983) is the last member of the family of codes similar to the OCTAVIA to be discussed. It was developed primarily for the analysis of pressurized thermal shock and bears a striking resemblance to OCA$P$ in being a deterministic-probabilistic code.

\section{F.2 Deterministic Calculation}

VISA uses closed-form solutions for the heat transfer and stress calculations which are presented in the appendix of the report. The applied stress intensity factors are calculated in VISA using influence coefficients developed by Labbens, 1976 and Hellot, 1978.

VISA does not explicitly conslder vessel cladding so an effective heat transfer coefficient must be calculated and provided to the code.

$$
h_{\text {off }}=\left(1 / h_{t}+t h / k\right)^{-1}
$$

where $h_{k}$ is the fluid transfer coefficient, $k$ is the thermal conductivity of stainless steel clad and th is the thickness of the clad. VISA allows the use of temperature independent or dependent heat transfer characteristics. If temperature dependent properties are desired, a set of predefined curves for the thermal diffusivity are contained within the code. At the occurrence of a simulated transient, VISA allows the selection of a step temperature change or closed-form changes such as exponential or a fourth-order polynomial representation.

At each time step, thermal and other stresses are represented by a fourth-order power series in the ratio of position to wall thickness with the coefficients of the series being determined by curve fitting. In turn, this leads to representation of the stress intensity factor $K_{I}$, another fourthorder power series in the ratlo of crack depth to wall thickness in the product of the coefficients of the previous distribution and influence functions expressed as polynomial functions of the crack depth as calculated by Heliot, 1978 and Labbens, 1976. One of the restrictions of VISA is that the influence functions are calculated for a ratio of vessel wall thickness to vessel radius of $1: 10$. This is approximately correct for PWR vessels and variations from this are expected to cause little error.

\section{F. 3 Probabilistic Calculation}

Like OCA-P, VISA performs the probabilistic calculation by simply repeating the deterministic calculation for different parameter values selected from appropriate distributions. For each simulation, the initial $\mathrm{RT}_{\text {NDI }}$ fluence at the inner wall, flaw size and copper content are selected 
from their distributions. With these values fixed for the iteration, the code steps through the time history of the transient. For each time step, the applied stress intensity factor at the crack tip is taken from stored values from the deterministic calculation. This fluence is calculated as exponentially attenuated fron the value at the inner wall as was done in OCA-P. The shift in $\mathrm{RT}_{\mathrm{KDI}}$ is calculated according to the Regulatory Guide 1.99 prescription to obtain the adjusted $R_{\mathrm{NDI}}$. The value of the fracture toughness $\mathrm{K}_{\mathrm{Ic}}$ is sampled and compared with the stress intensity factor at the crack tip to determine crack initiation. VISA, at this point, allows for the option of warm prestress. If this is selected, crack growth is not initiated if the stress intensity factor is increasing, if not selected, crack growth is initiated if $K_{I c}$ is sampled and found to be greater than the stress intensity factor at the crack tip. If initiation does not occur VISA goes to the next step. If it does occur, the crack depth is extended 0.25 in. and a new value of $K_{I}$ is simulated. The process continues until the vessel fails or the transient is over.

VISA uses a modification of the OCTAVIA flaw size distribution. The OCTAVIA distribution is not normalized to 1 which is taken to suggest that much of the probability is in the small crack sizes. The flaw size distribution used in VISA is presented in Table F-1. It should be noted that if the small flaw sizes could be considered to be non-fallures, the fracture mechanics calculation would not have to be performed and the efficiency of the code would be improved - a feature that may be added to future VISA versions.

Table $F-1$

Flaw Size Distribution used in VISA

\begin{tabular}{ll}
\hline Flaw Size (in.) & Probability \\
\hline 0 & 0.918 \\
0.125 & 0.055 \\
0.25 & 0.022 \\
0.5 & 0.0042 \\
1.0 & 0.00036 \\
1.5 & 0.000071 \\
2.0 & 0.000017 \\
2.5 & 0.000005 \\
3.0 & 0.0000025 \\
3.5 & 0.00000083
\end{tabular}

The mean value functions of the fracture toughness for crack initiation ( $\left.K_{I c}\right)$ and arrest $\left(\mathrm{K}_{\mathrm{I}}\right)$ were obtained by non-linear regression to the data of Dircks, 1982:

$$
\begin{aligned}
& \mathrm{K}_{\mathrm{Ic}}-36.2+49.4 \mathrm{e}^{0.01049(\mathrm{t}-\mathrm{RTNDT})} \quad \text { if } \mathrm{T}-\mathrm{RT}_{\mathrm{KDT}}<-50 \\
& K_{I c}=55.1+28.0 e^{0.2014(t-R T M D I)} \quad \text { if } T-R_{\text {KDI }}>-50 \\
& \mathrm{~K}_{\mathrm{I}}=19.9+43.9 \mathrm{e}^{0.0000(\mathrm{t}-\mathrm{RTNDT})} \quad \text { if } \mathrm{T}-\mathrm{RT}_{\mathrm{NDT}}<-50 \\
& K_{\text {Ia }}-70.1+6.50 \mathrm{e}^{0.188(t-R T N D T} \text { if } T-R T_{\mathrm{RDT}}>-50
\end{aligned}
$$


F.4 Comments on the Relevance of UISA to ANS

It appears that VISA may be a bIt simpler that OCA-P and therefore easier to adapt to ANS pipe break analysis that OGA-P. Otherwise the comments of Appendix E.4 apply equally to VISA. 


\author{
APPENDIX G \\ REVIEW OF THE PHENOMENOLOGICAL METHOD OF THOMAS
}

\title{
G.1 Qverview
}

Appendix B presented some of the data on pipe and vessel leak and break probabilities. Thomas, 1980 uses the data to determine scaling parameters to gain insight into the effects of paraneter that affect the pipe break probability. This appendix reviews Thomas's paper and exemplifies Thomas's method by an applications to HFIR taken from Johnson, 1987.

It is generally believed and data demonstrate that a pipe or vessel is more likely to leak than to fracture. This may be understood by considering a large break to be at an extreme of the distribution of leaks sizes. Thomas's approach assumes:

$$
P_{c}=P_{1} \star P_{c} / P_{1}
$$

where $P_{c}$ is the probability of a catastrophic pipe break and $P_{1}$ is the probability of a leak. This equation takes advantage of the better statistical accuracy associated with leak probabilities for inferring pipe crack probabilities but requires knowledge of the ratio $P_{c} / P_{1}$. Thomas summarizes the attributes and objectives of the model as:

2. $P_{1}$ and $P_{c}$ are separately identified and the model applies to discrete parts and features of a plant.

2. It recognizes the relative importance of various factors involved in pipe and vessel failure. The input data are readily available and the calculations are readily performed.

3. The approach is based on observed statistics and recognizes a multiplicity of failure causes and modes.

4. Each modeled factor is scaled with a dimensionless ratio and each is amenable to statistical validation.

5. The approach is modular and may be improved by improvements in the separate modules thereby facilitating updating. bilities.

Table G-1 indicates factors that affect pipe and vessel failure proba- 
Table G-1

Factors Affecting Plpe Fallure Probability and

Range of Effect

Factor

Range of Effect on the Probability

size and shape

3.5

weld zone

1.5

age

quality

causes: fatigue, corrosion etc.

1

rupture on leakage

2

2.5

4

\section{G. 2 The Probability of Leak Nodel}

The leak probability $\left(P_{1}\right)$ is assuned to be governed by the following proportionality:

$$
P_{1}-P_{R} * Q_{a} * F
$$

where $P_{R}$ is a reference probability exhibited in the pipe break data after the equivalent quality factor $\left(Q_{0}\right)$ and aging (F) have been removed. The equivalent quality factor is

$$
Q_{.}=Q_{p}+50 * Q_{\text {w }}
$$

where $Q_{p}$ is the quality factor for the parent or base netal $p i p i n g$ and $Q_{w}$ is the quality factor for welding including a 50 times penalty for welding as observed in the nuclear power industry.

\section{G. 3 Quality Factor for the Parent Material}

The determination of $Q_{p}$ is concerned with how pipe break probability scales with pipe dimensions for a given class of $p i p e$. It is clear that $Q_{p}$ should scale with the surface area of the pipe hence proportional to area (A) or diameter (D) and the length. If it were proportional to the number of initial flaws then if would be propertional to the volune ( $t$ ); hence, proportional to DLt. This is not observed in the data for several possible reasons. One is that flaws may not contribute equally to fallure fron an arbitrary location in the metal, pipe thickness is related to internal pressure through the pipe schedules, QA may vary fron small to large piping, maximum flaw size varlations, crack growth rates and crack proportions to the wall thickness. For whatever reason. Thomas assumes a scaling law of the form and searches the data for a best fit to the free paraneter, $x$ as

$$
Q_{P}=A t^{X}
$$

where $A$ is the area of the pipe equal to the length times the outside diameter and $\tau$ is the wall thickness. 
Figure G-1 shows fits of equation G-4 to the data for various values of $x$. These conparisons used the dsta of Basin, 1977, WASH-1400, 1975 and Anderson, 1979. Computer optimization of the fit of $x$ to the data gives a value of -2.46 . at a statistical significance level of 99. Thomas performs other comparisons with BWR weld fallures using a relationship of weld area to pipe dianeter of $0.367 D^{2}$ based on a weld width of $1.75 t$. While the data still tend to favor a large negative exponent, Thonas believes there are enough uncertainties to justify a more physical value of $x=-2$ whish is done in the rest of the report.

Hence, $\quad Q_{p}-D * L / t^{2}$

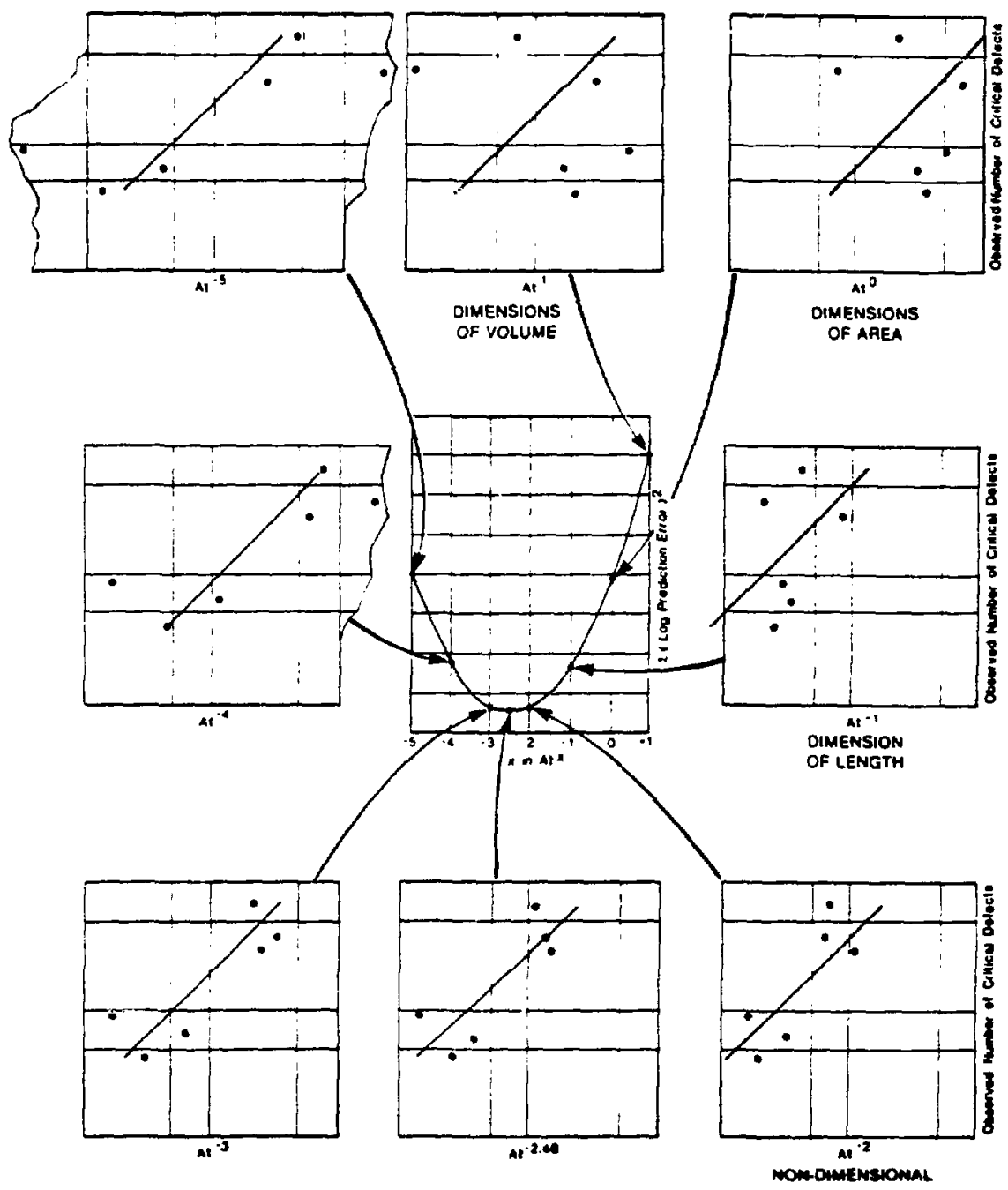

Figure G-1

Comparison of various functional forms of equation $G-4$ 


\section{G.4 Quality Factor for the Weld Matertal}

Using weld widths as being typically about 1.75 tines the thickness of the wall naterlal, in equation $G-4$, the weld naterial quality factor $Q_{m}$ is estinated as

$$
Q_{n}-1.75 * t * D / t^{2}-1.75 * D / t
$$

Working with data (in particular Basin and Burns, 1977) on the frequency of failure in parent material and in welds, Thonas determines that the ratio $Q_{w} / Q_{p}$ is about 50 (this is the factor of 50 used in equation $G-3$ ).

\section{G.5 Equivalent Ouality Factor}

Using the results of equations G-5 and G-6 in equation G-3, the following results

$$
\text { Q. }=L * D / t^{2}+87.5 * D * n / t
$$

where $n$ is the number of welds in this dianeter of piping.

\section{G.6 Reference Plpe Break Frequency}

Thomas calculates the $Q_{0}$ 's for 6 sources of pipe break data thereby correcting for the geometry and welds. By dividing the fallure frequency by the $Q_{\text {. factors, }} P_{R}$ for each of the data sources are determined. The geometric mean of his results is $2.0 \mathrm{E}-8$ and the arithnetic nean is 2.9E-8. The closeness of these types of averages is indicative of the swall dispersion in the values.

\section{G.7 Effects of Aring}

Thonas examines the cumulative probability of pipe, vessel and steam generator tube failure occurring before sone tine $T$ over 210 year range. While several data sources extended over a longer range of tine, this represented a conpronise between a significant tiue and including as much data as possible. The sources reported in Thomas, 1980 consisted of U.S., English, and German data for both nuclear and fossil plants. The arithnetic average of these distributions is shown in Flgure G-2. Figure G-3 is the differential of the aging $F$ curve. For a constant aging model, this would be a horizontal straight line however Figure G-3 shows this to be a nonotonically reducing curve. Thonas discusses this as being in the infant mortality region with the defects being identified and remove and possibly evidence of a learning curve.

This evidence of fallure rate reducing with age is in contradiction to many of the theoretical nodels. The theoretical nodels vary in detail but usually assume that fatigue is the failure node which doninates and fatigue crack growth is the doninant factor in relating failure probability with age. In pipe and failure statistics, fatigue crack growth is just one mode contributing perhaps <18 of the failures (Thonas, 1980, p. 121). 


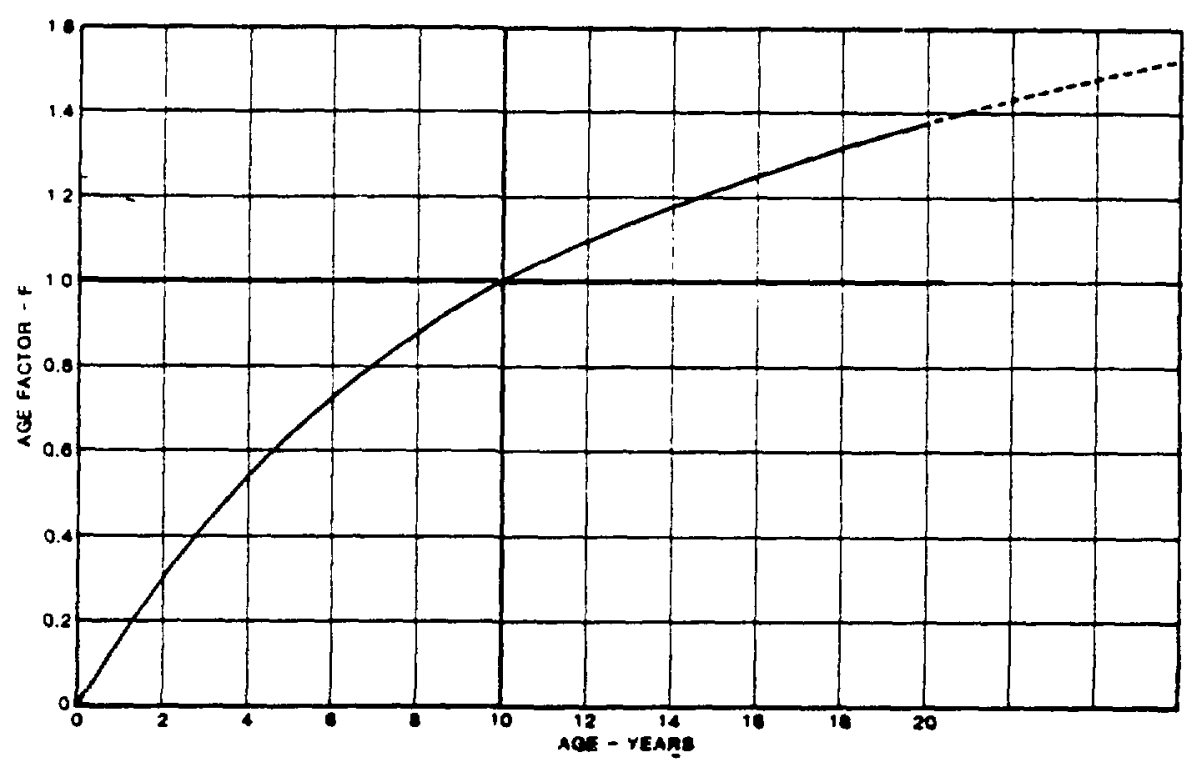

Figure G-2

Arlthmetic average age factor vs age

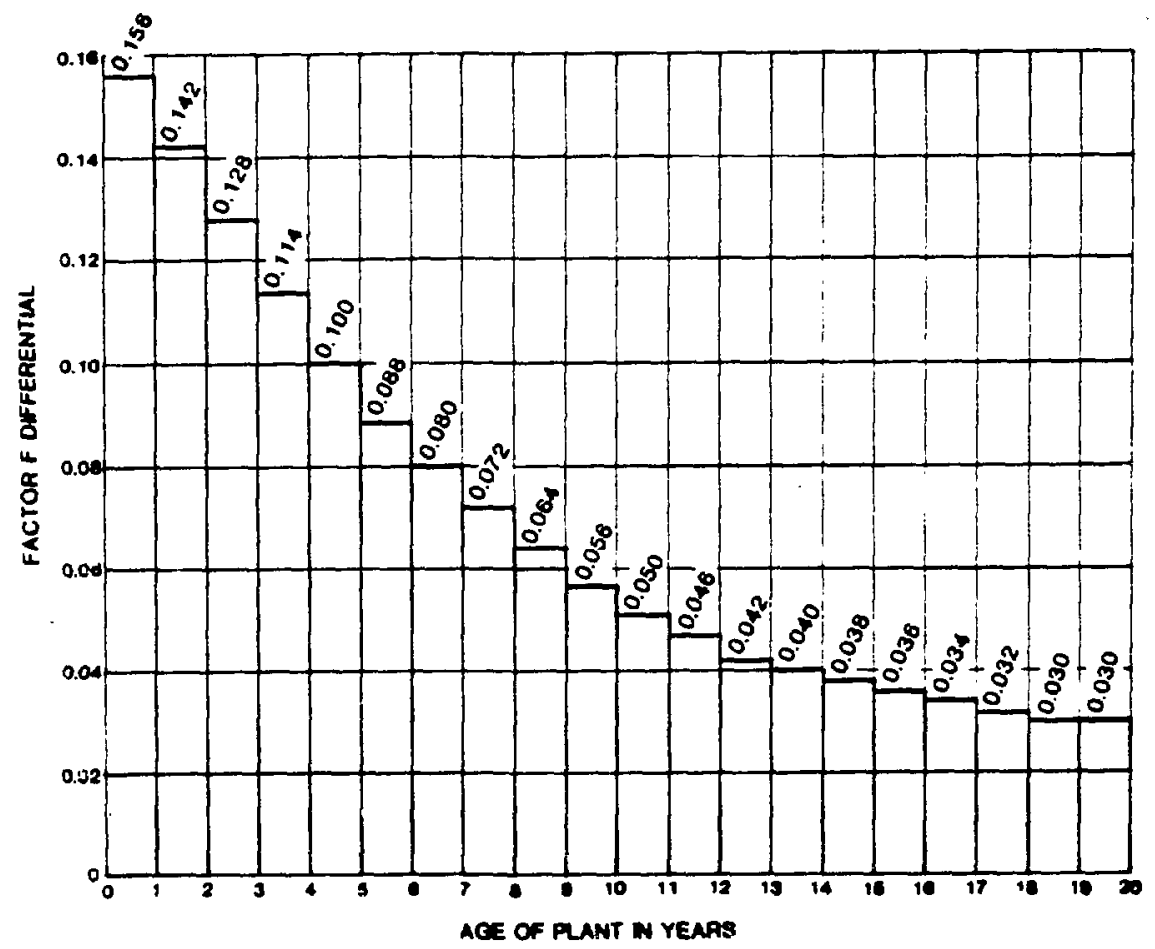

FIgure G-3

Aging rate histogram - differentlal of figure G-1

G-5 


\section{G.8 Ratio of Breaks to Leaks}

At this point, Information necessary to determine the leak probability has been obtained and the other factor in equs-ion G-1, the ratio of breaks to leaks is needed. Generally this ratio. $P_{c} / P_{1}$ is about 0.05 to 0.1 . This is a global estimate and better estimates for specific causes may be obtained from operating experience. Table G-1, fron Thomas, relates main causes for pipe leakage and breakage to their occurrence frequency.

Table G-1

Main Causes of Pipe Leakage and the Ratio $P_{c} / P_{1}$

\begin{tabular}{|c|c|c|c|c|}
\hline \multicolumn{2}{|c|}{ Main cause of failure } & \multirow{2}{*}{$\frac{1}{\% \text { Age of }}$} & \multirow{2}{*}{$\frac{2}{\mathbf{P}_{C} / \mathbf{P}_{\mathrm{L}}}$} & \multirow{2}{*}{ 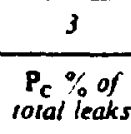 } \\
\hline & & & & \\
\hline $\begin{array}{l}\text { Manufacture } \\
\text { and fabrication }\end{array}$ & $\left\{\begin{array}{l}\text { Wrong and } \\
\text { defective } \\
\text { base } \\
\text { materials } \\
\text { Welding }\end{array}\right.$ & $\begin{array}{r}9.6 \\
11.8\end{array}$ & 0.08 & 1.74 \\
\hline \multicolumn{2}{|c|}{$\begin{array}{l}\text { Material selection } \\
\text { Fatigue } \quad\left\{\begin{array}{l}\text { Vibration } \\
\text { Low sycle }\end{array}\right.\end{array}$} & $\begin{array}{r}28 \cdot 8 \\
4 \cdot 3 \\
7.8 \\
2 \cdot 7\end{array}$ & $\begin{array}{l}0.03 \\
0.20 \\
0.03 \\
0.10\end{array}$ & $\begin{array}{l}0.80 \\
0.88 \\
0.23 \\
0.27\end{array}$ \\
\hline \multirow{2}{*}{\multicolumn{2}{|c|}{$\begin{array}{l}\text { Expansion and flexibility } \\
\text { Corrosion } \\
\text { Erosion } \\
\text { Maloperation } \\
\text { Thermal and mechanical shock } \\
\text { Miscellaneous } \\
\text { Total }\end{array}$}} & $24 \cdot 6$ & 0.02 & 0.47 \\
\hline & & $\begin{array}{r}2 \cdot 1 \\
1 \cdot 3 \\
7 \cdot 0 \\
100 \cdot 0\end{array}$ & $\begin{array}{l}0.45 \\
0.20 \\
0.04 \\
-\end{array}$ & $\begin{array}{r}0.93 \\
0.26 \\
0.27 \\
.5 .85\end{array}$ \\
\hline
\end{tabular}

This is a composite table from Thomas typifying the data found in Basin, 1977, Gibbons, 1964, Phillips, 1974 and Smith, 1974. It is believed to contain about 93 of the failures and highlights the main causes. The $P_{c} / P_{1}$ ratio is estimated from these sources. A further refinement to the ratio $P_{c} / P_{1}$ may be obtained by considering the stress in the walls. This has an effect in cases of highly stressed thick-walled vessels with low fracture toughness. The corrections for this effect, may be determined by the fracture mechanics model in Thonas, 1979.

\section{G.9 Application of the Thomas Method to HFIR}

Johnson, 1987, in their Appendix C provides a demonstration of the Thomas method, with some refinements of their own to estimating the probability of a pipe break.

The basic Thomas equation is G-1. Johnson, 1987 examines the data for the probability of leak $\left(P_{1}\right)$ before break $\left(P_{c}\right)$ and concludes that Thomas's recommendation of 0.05 to 0.1 appears too high; suggests that it is in the range of 0.01 to 0.2 , and provides a subjective probability distribution as shown in Table G-2. 
Table G-2

Subjective Probabilities for the Ratio of $P_{c} / P_{1}$

Used in HFIR Evaluation

$\mathrm{P}_{\mathrm{c}} \not \mathrm{P}_{1}$ Ratio
0.01
0.02
0.04
0.06
0.1
0.2

Probability of Ratio
0.15
0.25
0.25
0.2
0.1
0.05

It may be noted that this distribution is highly asymmetrical toward the low ratios and has a mean of 0.049 .

The formulation of the probability of leak is

$P_{1}-Q_{0}$ FBEGR

where

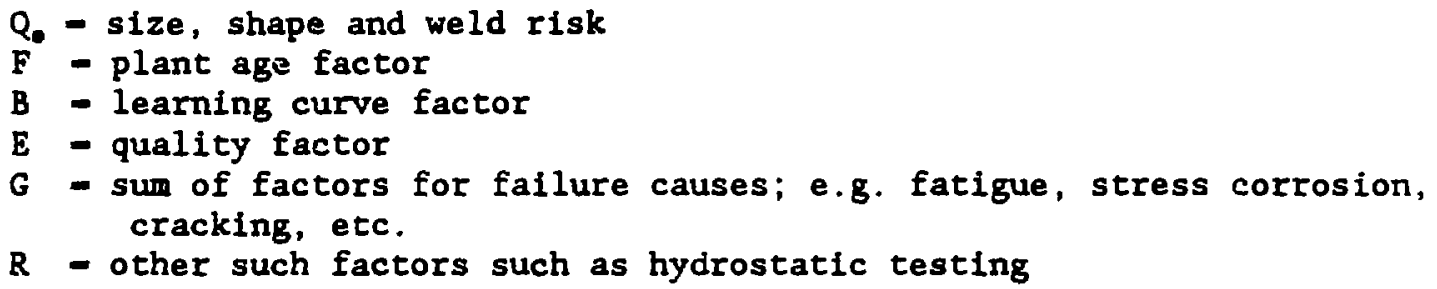

The $R$ factor was not in Thomas's formulation. The quality factor is broken into two terms:

$$
Q_{0}=Q_{p}+A Q_{w}
$$

where

$Q_{p}=$ size and shape factor for parent material

$Q_{\text {. }}$ - size and shape factor for weld material

A - weld penalty for weld zones prone to additional leakage

Johnson, 1987 state that for a plant of the age of HFIR, the product of $F$ and $B$ is approximately 1 and $P_{1}$ simplifies co

$$
P_{1}-C\left(Q_{p}+E A Q_{w}\right) R
$$

where $C$ is a constant of proportionality leading to an equation for a catastrophic break:

$$
P_{c}=\left(P_{c} / P_{1}\right) C\left(Q_{p}+E_{A Q}\right) R
$$


Thomas modifies the sccling relationship to be of following form for welds

$$
Q_{m}-\frac{{N D_{n}}_{L_{n}}}{t_{n}^{2}}
$$

where

$$
\begin{aligned}
& N \text { - number of welds } \\
& D_{w} \text { - diameter of weld } \\
& L_{w} \text { - length of weld } \\
& L_{w} \text { - thickness of weld }
\end{aligned}
$$

If the weld dlaneter is that of the pipe and the thickness of the weld is that of the pipe. Thomas observes that the width of the weld is about 1.75t. The $Q$ factor for circumferential welds is

$$
Q_{\text {we }}-1.75 \mathrm{ND} / \mathrm{t}
$$

Johnson, 1987 at this point departs fron Thonas by also calculating a $Q$ factor for the longitudinal welds in the pipe seans. ${ }^{1}$ An equivalent pipe size may be defined as:

$$
D_{0}-\frac{L_{p}}{\pi}
$$

where

$$
L_{p} \text { - length of longitudinal weld (pipe length) }
$$

Substituting this into equation G-13 to obtain a $Q$ factor for longitudinal welds as:

$$
Q_{m L}-\frac{1.75 L_{p}}{\pi t}
$$

To complete the evaluation, Johnson defines subjective distributions for the weld penalty factor $A$, the normalization $C$, the quality factor $E$ and the allowance for hydrostatic testing $R$ as presented in Tables G-3 through G-6.

Table G-7 summarizes $Q$ factors for various locations in HFIR. In comparing these, it should be borne in mind that welding is weighted by the $A E$ factor. The mean of the $A$ factor is 50 as was used by Thomas; the mean of $E$ is 0.29 and the product $A E$ is 14.5 which is provided in the table.

I In our opinion, the data have already included this fact in the scaling relationship based on the length of piping. Furtherwore, a distinction needs to be made between seamless, shop and field welded pipe. 
An examination of Table G-7 shows that heat exchanger piping is dominating the results by perhaps a factor of 5 and that the parent metal $Q$ is in the ratio of $2: 1$ to the weld $Q$. In some cases the dominance is even higher.

A summary of results provided by Johnson are that the probability of a large loss of coolant accident is $1.03 \mathrm{E}-5 / \mathrm{yr}$. The major contributor is pipe rupture at $9.5 E-6 / y r$ (938) followed by valve/pump body rupture at $7.43 E-7 / y r$ (78). Plpe rupture inside the reactor pool has a frequency of $1.3 E-6$ (138/yr of LOCA frequency).

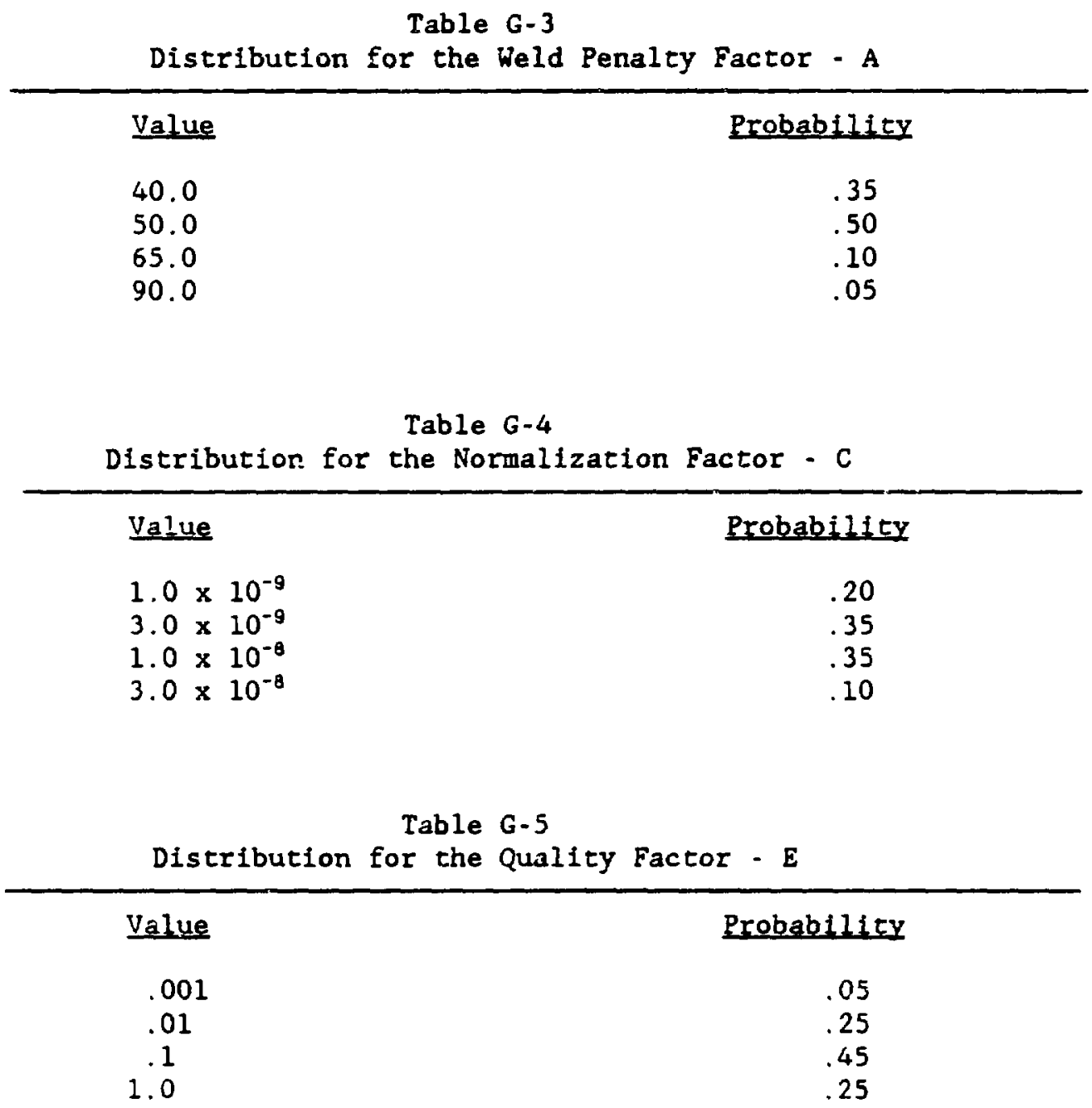


Table G-6

Distribution for the Hydrostatic Testing and Other Factors - $\mathbf{R}$

\section{- Value}

.001

.01

.05

1
Probability

.10

.20

.50

.20

Table G-7

Quality Factors as Calculated by Johnson, 1987

\begin{tabular}{|c|c|c|c|}
\hline Location & o Desionation & Q Factors & $14.5 *$ Weld 5 \\
\hline $\begin{array}{l}\text { Core Outlet Header } \\
\text { inside the pool } \\
\text { Core Outlet Header } \\
\text { outside the pool } \\
\text { Core Inlet Header } \\
\text { inside the pool } \\
\text { Core Inlet Header } \\
\text { inside the pool } \\
\text { Heat Exchanger Inlet } \\
\text { and Outlet Pipes } \\
\text { Pressurizer Pump } \\
\text { Discharge Ptping } \\
\text { Relief Valve Piping } \\
\text { inside the pool }\end{array}$ & $\begin{array}{l}Q_{P 1 I} \\
? \cdot x+1 I \\
Q_{W L 1 I} \\
Q_{P 10} \\
Q_{H C 101} \\
Q_{W L 10} \\
Q_{P 2 I} \\
Q_{W C 2 I} \\
Q_{W L 2 I} \\
Q_{P 20} \\
Q_{W C 20} \\
Q_{W L 20} \\
Q_{P 30} \\
Q_{W C 30} \\
Q_{W L 30} \\
Q_{P 40} \\
Q_{W C 40} \\
Q_{W I 40} \\
Q_{P 50} \\
Q_{W C 50} \\
Q_{W L 50}\end{array}$ & $\begin{array}{l}19800 \\
280 \\
345 \\
43800 \\
168 \\
761 \\
25200 \\
859 \\
429 \\
45000 \\
411 \\
830 \\
199000 \\
500 \\
4000 \\
4000 \\
140 \\
229 \\
8500 \\
187 \\
397\end{array}$ & $\begin{array}{l}18700 \\
18000 \\
109000\end{array}$ \\
\hline
\end{tabular}




\section{G.10 Applicability of the Thomas Method to ANS}

Thomas's method rests on fleld data and the analysis thereof to determine the scaling. . The disadvantage is that it reflects an average over many types of piping in varlous environments prepared by varying skills and prepared according to the regulatory guidance provided by the NRC for commercial power plants. By itself, it is not useful for design selection among e.g. types of steel, inspection techniques and other factors that may be used in ANS to improve over the past. Nevertheless, it provides a reference for ANS to excel. Scaling as the inverse square of the wall thickness is a valuable characteristic as well as emphasizing the truism that the least amount of piping is the most reliable - all other factors being the same. 


\section{APPENDIX H}

\section{METHOD OF OVERLAPPING STRESS-STRENGTH DISTRIBUTION}

\section{H. 1 The Method}

Lehner, 1986, used the method of overlapping stress and strength distributions to determine the probability of a pipe break for Generic Issue 61. This issue addresses the question of the safety significance of a transient initiation of a rupture of one of the high pressure steam lines that pass through the wet-well airspace in a BWR thereby pressurizing the containment. Three systems with components whose rupture could do this are: the Main Steam Relief Valves and discharge lines, High Pressure Coolant Injection turbine exhaust, and the steam condensing relief valves in the Residual Heat Removal system.

This method assumes that both the strength of the material involved and the stress imposed on them are distributed random varlables. In the region of overlap (FIgure $\mathrm{H}-1$ ), stress is greater then the strength of the material so failure occurs. The probability that stress will exceed strength is just the area of the overlap. If stress and strength are assumed to be normally distributed, the calculation of the overlapping area is simply performed by a varlable transformation and is itself, normal (Haugen, 1980). With this change, the probability of pipe break is:

$$
p_{s}=\int_{z}^{\infty} f(z) d z
$$

where

$$
z=|\bar{s} \cdot \bar{s}| / \sqrt{\sigma_{s}^{2}+\sigma_{s}^{2}}
$$

Lehner, 1986, estimates the mean strength $(\overline{\mathbf{S}})$ as

$$
\bar{s} \text { - (ultimate stress + yield stress) } / 2
$$

and the standard deviation of the strength $\left(\sigma_{2}\right)$ as

$$
\sigma_{\mathrm{S}}-\sqrt{\sigma_{\mathrm{yt \ell ld}}{ }^{2}+\sigma_{\mathrm{ultimate}}^{2}}
$$

From 9 incidents with nuclear power plants, the mean stress is estimated to be 23,700 psi with a standard deviation of 2560 . If data on Al06 Grade B steel consisting of 59,200 and 4290 psi for the mean and standard deviation strengths are respectively used, equation $\mathrm{H}-1$ may be evaluated from a standard table for a cumulative normal distribution to give a probability of $7.0 \mathrm{E}-13$ per transient of the type under consideration. These results may also be presented using the ratio $\sigma / \bar{S}$ as the independent variable as shown in Figure $\mathrm{H}-2$. 


\section{H. 2 Relevance to ANS}

This method as applied to estinating the probability of pipe break under transient conditions. The transient conditions for ANS remain to be defined but current concerns are the frequency of pipe break as a spontaneous event not as the result of some initiating incident. To use the method, it would be necessary to deternine the appropriate stresses and strengths for ANS but additionally, how the strengths vary with cracks, irradiation, temperature, water chemistiy and periodic inspection. Conceptually the method is attractive but extensions would be required for the immediate ANS purposes.

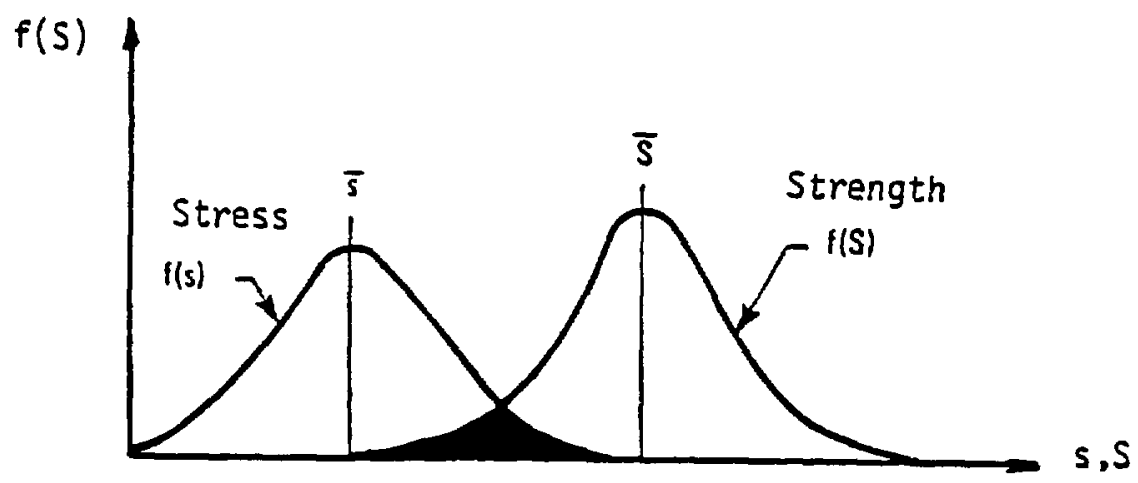

Figure $\mathrm{H}-1$

Illustrative stress and strength distributions. 


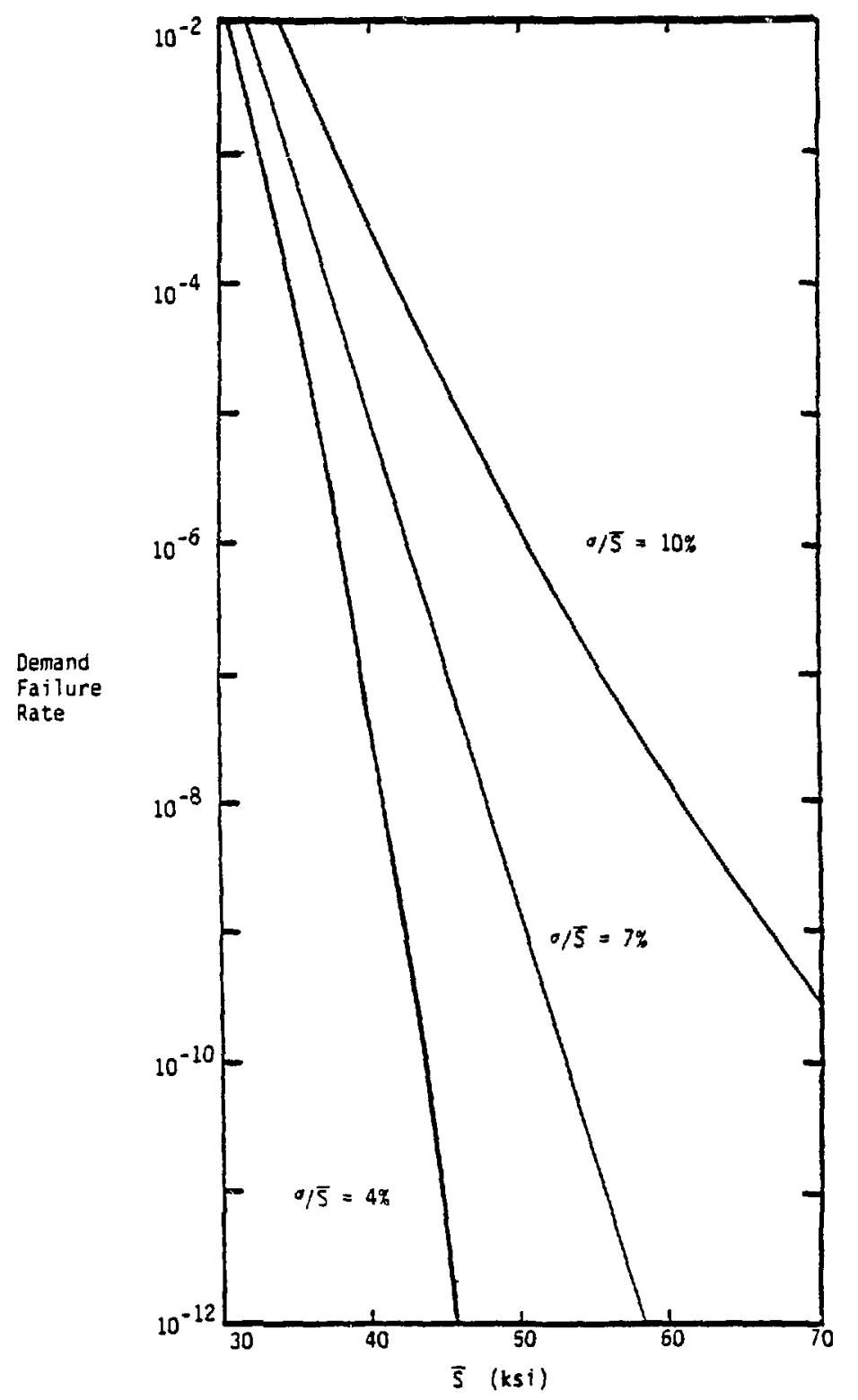

Figure $\mathrm{H}-2$

Pipe Failure Rates Estimated by the Stress Strength Overlap Method

H- 3 